FINAL TECHNICAL REPORT

\title{
COMMERCIALIZATION DEMONSTRATION OF MID-SIZED SUPERCONDUCTING MAGNETIC ENERGY STORAGE TECHNOLOGY FOR ELECTRIC UTILITY APPLICATIONS
}

\author{
Submitted in Completion of: \\ DEPARTMENT OF ENERGY \\ COOPERATIVE AGREEMENT NUMBER \\ DE-FC36-94GO10011
}

\begin{abstract}
Performed and Submitted by:
BWX TECHNOLOGIES, INC.

LYNCHBURG, VIRGINIA
\end{abstract}

\author{
Principle Investigator and Author: \\ CHARLES M. WEBER
}

JUNE 27, 2008

DISTRIBUTION NOTICE

- NO RESTRICTIONS - 


\section{TABLE OF CONTENTS}

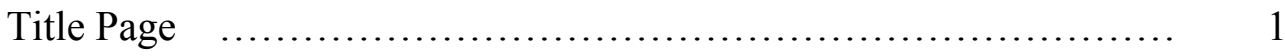

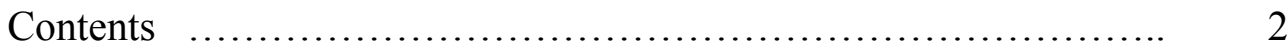

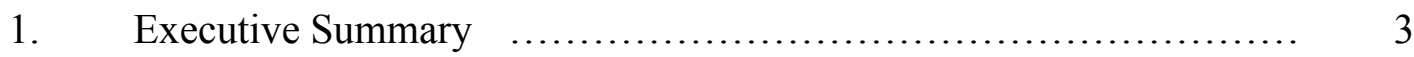

2. Summary of Accomplishments versus Project Goals $\quad \ldots \ldots \ldots \ldots \ldots \ldots . . . \ldots$

3. Summary of Project Activity and Results $\ldots \ldots \ldots \ldots \ldots \ldots \ldots \ldots \ldots \ldots$

3.1 Anchorage Municipal Light and Power and The Spinning Reserve Period ..................................... 7

3.1.1 Program \& Administrative Overview ............... 7

3.1.2 Design Description \& Key Technical Accomplishments 10

3.2 American Electric Power and The Transmission Line

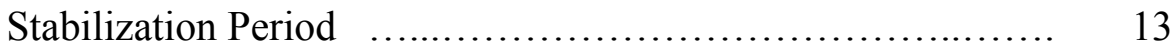

3.2.1 Program \& Administrative Overview $\ldots . . . \ldots \ldots \ldots \ldots . . . . .13$

3.2.2 Design Description \& Key Technical Accomplishments 17

3.2.2.1 Product Design Summary .................... 17

3.2.2.2 Product Description Summary ............... 20

3.2.2.3 Manufacturing Methods Overview ........... 29

3.2.2.4 Key Test Results Summary $\ldots . \ldots \ldots \ldots \ldots \ldots . . \quad 33$

3.3 Center for Advanced Power Systems and the Demonstration

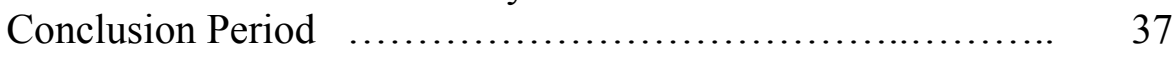

3.3.1 Program \& Administrative Overview ............... 37

3.3.2 Key Technical Accomplishments \& Conclusion ...... 39

4. Products Developed and Technology Transfer Activities $\quad \ldots \ldots \ldots \ldots \ldots . . . . . \quad 40$

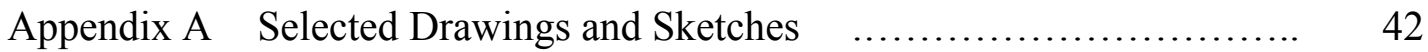

Appendix B Miscellaneous Photographs and Illustrations $\ldots . \ldots \ldots \ldots \ldots \ldots . . . .68$ 


\subsection{Executive Summary}

As an outgrowth of the Technology Reinvestment Program of the 1990's, an Agreement was formed between BWXT and the DOE to promote the commercialization of Superconducting Magnetic Energy Storage (SMES) technology. While awaiting activation, a superconducting magnet can store large quantities of instantly available electrical energy due to the properties of its superconducting materials, which conduct electricity with no (zero) resistive losses. Business and marketing studies showed that the performance of electric transmission lines could be improved with this SMES technology by stabilizing the line thereby allowing the reserved stability margin to be used. The parties hoped to realize a number of benefits of this technology which would be acquired in addition to improving the stability, reliability and availability of the transmission lines of the nation's electrical grid system. One main benefit sought was to double the capacity and the amount of energy flow on an existing transmission line by enabling the use of the reserved stability margin, thereby doubling revenue. Also, electrical disturbances, power swings, oscillations, cascading disturbances and brown/black-outs could be mitigated and rendered innocuous; thereby improving power quality and reliability. Additionally, construction of new transmission lines needed for increased capacity could be delayed or perhaps avoided (with significant savings) by enabling the use of the reserved stability margin of the existing lines. By providing an instantly available source of real electric power, the SMES can stabilize the transmission system and provide control to both inject, and absorb power, in the opposite direction or polarity of the disturbance, thereby mitigating, stabilizing or neutralizing the disturbance and avoiding the large power swings and excursions for which line capacity is reserved. Utility and industry support for this application was apparent, real and documented. To accomplish this novel application of a new technology, a demonstration of a SMES system was needed to prove the adequacy of the concept and the performance of the technology. Two crucial technical aspects were required; first, a large, powerful, dynamic, economic and reliable superconducting magnet, capable of oscillating power flow was needed; and second, an electrical power interface and control to a transmission line for testing, demonstrating and verifying the benefits and features of the SMES system was needed. BWXT, with cooperation from several utilities and the DOE, began the development and deployment of such a system. A project was formed with the goals of commercializing the technology by demonstrating SMES technology for utility applications and to establish a domestic capability for manufacturing large superconducting magnets for both commercial and defense applications.

This project was redirected several times to account for changes in political, economic and business conditions. BWXT successfully established a design that incorporated unique technical features for this technology application. The magnet had very low AC losses to support the dynamic and oscillating nature of the stabilizing power flow. Moreover, to economically interface to the transmission line, the magnet had the largest operating voltage, which required a robust, reliable and unwavering insulation system. The final design was qualified by testing to full life and stress conditions and this design exceeded expectations by over a factor of 8 . The manufacturing of that design was 
achieved by establishing a factory with newly designed and acquired equipment, tooling, methods and skilled personnel. The factory was efficiently operated and the required large superconducting coils were produced. The final magnet system was modular in design, allowing for convenient future power changes without tooling changes. It was transportable to support various application locations, and it was low cost from the design and manufacturing innovations incorporated. The final magnet system measured 14 feet in diameter, 10 feet in height, and weighed about 35 tons. The superconducting magnet and design technology was successfully implemented and demonstrated.

The project was not successfully concluded however; as the critical planned final demonstration was not achieved. Additional investment was required from the stakeholders, particularly from industry, to finish the construction and testing. To justify the added investment, future business needs and the resulting markets needed to be defined, understood and sufficient. The utilities could not understand or clarify their future business needs and the regulatory requirements, because of the deregulation policies and practices of the country. Much uncertainty existed which prevented utilities from defining business plans, including asset allocation and cost recovery. Utility ownership, rate structures and competitor access regulations were changing, uncertain and unknown. The utilities were unwilling to invest in a new technology and application without assurances of future benefits. Consequently, the manufacturing industry was unwilling to commit additional funds to support the investment. Despite the technical successes and achievements, the commercial development could not be implemented and achieved. Thus, the demonstration of this enhancement to the utility's transmission system and to the reliability of the nation's electrical grid was not achieved. The factory was ultimately discontinued and the technology, equipment and product were placed in storage.

\subsection{Summary of Accomplishments versus Project Goals}

The high-level goals and objectives of the SMES Technology Demonstration Project as stated in the Agreement are:

1. Commercialize mid-size SMES technology for utility applications including transmission stabilization.

2. Establish design and manufacturing approaches that can produce reliable, low cost mid-sized SMES systems for commercial and defense applications.

3. Install the first commercial mid-size SMES with sufficient stored energy and capable of operating at the multi-megawatt power level.

Project activities were performed over nearly a decade of time aimed at achieving these goals. At the conclusion, only goal \# 2, the only goal for which there was internal control of events and activities, was achieved. That accomplishment is highly valued by the contributing team of dedicated and skilled personnel who achieved that goal. External regulatory, business and market forces impeded the progress to achieve the other two goals: \# 1 and \# 3. A summary of the status of accomplishment for each of these goals follows: 


\section{Goal \#1 - Commercialize mid-sized SMES technology for utility applications including transmission stabilization. $\quad$ STATUS - Not Achieved.}

The SMES technology provides an instantly available source of a very large quantity of both electrical energy and power. The energy is efficiently stored in the superconducting magnet without electric resistance (ohmic) losses. An important outcome of this project was the marketing survey results for application of this technology. It was learned that SMES technology used for energy storage application for utilities was not economically attractive due to the high cost of the magnet, which increased with increased energy storage size. But, studies and electric industry experts confirmed that SMES technology when applied to transmission line stabilization did provide value. In particular, a dynamic SMES with real power injection and exchange would improve transmission line and system stability and reliability, avoid brown/black-out conditions and permit a twofold increase in reliable power flow and capacity of existing transmission lines (perhaps delaying or mitigating new transmission line construction at enormous costs). This project produced a system design that included the properly sized superconducting magnet and the design of the electrical interface and control with a utility's transmission system. Three separate utilities and the electric industry consortium of the Electric Power Research Institute (EPRI), along with several Government agencies, including the DoD and the DOE, actively participated, guided and encouraged the success of this project. Three separate utility applications were studied and active during the life of the project. However, in the end, commercialization of the SMES technology was not achieved, despite these great efforts. During the performance period of this project, deregulation of the US utility industry was promoted. The US electric utilities were unsure of the future regulatory policies and their business environment. Utilities were being re-organized into generation, transmission and distribution organizations and combined or sold. Asset ownership and allowable rates were uncertain. In short, each utility did not have clear understanding of the business, of regulatory policy and future restrictions, or of their competitors, assets or rate structure. With this enormous uncertainty created by the deregulation of the US utilities, the utilities were unable to commit to investment in the commercial development of this technology. The future business opportunities were thus vague and industry providers, such as BWXT, could not sufficiently identify and realize the market. The commercialization of this technology required a successful demonstration of this first-of-a-kind technology and it required business investment to achieve follow-on sales. This project developed the SMES technology and identified a viable utility application, transmission line stabilization, but it did not achieve commercialization of the technology as the project activities ended before the demonstration was completed and the uncertainties of the environment stopped continued investment.

\section{Goal \#2 - Establish design and manufacturing approaches that can produce reliable, low cost mid-sized SMES systems for commercial and defense applications. STATUS - Achieved.}

Much of the balance of this report is devoted to documenting the design and production accomplishments of this project. Within the US, there is no industrial capability for production of large superconducting magnets. Establishment of such a capability and facility would aid producing other large magnets for both commercial and defense applications. The utility application selected for demonstration required two key design features for successful, economic implementation. To achieve a dynamic magnet system capable of \pm power exchange required a conductor that has very low AC losses.

Excessive AC losses could cause quenching and system instability thereby reducing 
reliability and performance. This SMES design introduced a new, low loss, cable-inconduit conductor that was tested and qualified in large, cyclic representative magnetic fields and performed 3 times better than the design requirement. The other key was the very high operating voltage for this magnet - the largest ever made. This required robust insulation design and manufacturing methods. The insulation system was tested and qualified following full life, maximum stress testing, and achieved nearly an order-ofmagnitude of excess voltage withstand capability compared to the operating requirements. To convert this design into product required that major manufacturing processes, equipment and tooling be developed and efficiently implemented and that a skilled and trained workforce be acquired. A large manufacturing facility was established to produce this magnet system. The completed magnet was nearly 14 feet in diameter and weighed 35 tons and was modular and transportable. It was designed to have 1,600 turns of superconducting conductor imbedded as a composite of an insulating epoxy. The major equipment and process developments included production of 1,600 foot lengths of splice-free CIC conductor, coil winding of 12 foot diameter precision, 2ton coil modules, and epoxy potting the components into a monolithic structure. All the equipment and tooling was designed, built and qualified on development hardware. All aspects of large magnet production operations were efficiently established and operated. Much discussion and photographic evidence is included in the remainder of this report as documentation. Clearly, BWXT successfully established a domestic manufacturing capability for large magnet production for commercial and defense applications.

\section{Goal \#3 - Install the first commercial mid-size SMES with sufficient stored energy and capable of operating at the multi-megawatt power level. STATUS - Not Achieved.}

The SMES system designed and partially built during this project had capacity for 96 Megawatts (MW) of instantly available power and 100 Megajoules (MJ) of stored energy. The system was designed to be transportable and was modular in design allowing for easy future size alterations. The system was designed to exchange power with a transmission line at $\pm 50 \mathrm{MW}$ at about $1-2 \mathrm{~Hz}$ or provide power bursts of up to 96 MW. The SMES system was a very large, dynamic superconducting solenoid magnet with very low internal $\mathrm{AC}$ losses to achieve the dynamic operating feature. It was designed to be the largest operating voltage magnet ever created and was robustly insulated to achieve $24 \mathrm{kV}$ terminal-to-terminal operating voltage at 4,000 amperes DC operation. The magnet's coil was fabricated, but the project ended before the construction of the entire system was completed. Consequently, it was not installed or tested. It clearly was of sufficient size for the first commercial demonstration, but because it was not completed and installed, this goal was not achieved.

\subsection{Summary of Project Activity and Results}

A summary of the project activities has been prepared to provide an overview of all the activities over the duration of this project. It has been broken into sections with descriptions covering the development thrust for three distinct periods of the life of the project. The initial period deals with the Anchorage Municipal Light and Power application of the SMES technology; the second period focuses on the SMES transmission line stabilization application with American Electric Power; and the ending period covers the revised demonstration and transition to the Center for Advanced Power Systems. For each period, the description is divided into two sections. The first section covers project administration activities, which provides programmatic and business 
information about the approach used and the objectives sought. The second section of each period provides technical descriptions, design features and specific technical accomplishments. This arrangement provides a comprehensive overview of both the administrative and technical aspects of this multi-faceted development endeavor covering the three periods of its life.

\subsection{Anchorage Municipal Light and Power and the Spinning Reserve Period}

\subsubsection{Program \& Administrative Overview}

Superconducting Magnetic Energy Storage (SMES) is a concept that efficiently stores energy in a magnetic field where the coil conductors are made from a superconducting material. Superconductivity is a phenomenon where, at very low temperatures below a critical value, certain materials will conduct electricity with no electrical resistance. Without any electrical resistance, coils can be made that can carry huge electrical currents that produce huge magnetic fields in which energy is contained and stored. One can store the energy, roughly proportional to the square of the size of the coil, with no electrical resistive losses - and this feature represents very high potential efficiency.

Superconducting materials are generally expensive and the cost of a storage coil will vary in proportion to the size of the coil, among other factors. Discharging the energy from a large magnetic coil can provide energy and very high power to power electrical systems or pulsed energy systems for weapons. The stored energy is electrical in nature and is instantly available, without conversion to energize these electrical systems. For devices where the additional energy is desired only for occasional or infrequent use, an efficient storage method is advantageous. A superconducting magnet offers the potential benefits of energy storage without energy losses, since there is no electrical resistance, and the energy is instantly available when needed in an electrical form.

In the mid-90's, a DoD agency was interested in developing a US manufacturing base for large superconducting magnets, initially for supporting pulsed weapons applications, but later for homeland security to improve the reliability of the nation's electrical grid. Also, at about that time, Congress passed legislation directed at supporting US industries after the collapse of the Superconducting Supercollider. This Technology Reinvestment Program (TRP) solicited ideas advancing the commercial use of superconducting technology. A proposal was prepared and submitted by BWXT for the dual benefits that the potential superconducting applications could satisfy the needs of both the TRP objectives and the DoD agency's goals. The key parameters of this program were to 1) reduce risk and promote commercial development of business aligned with superconducting technology, 2) provide incentive and risk reduction to industry by providing cost-sharing and ownership of the intellectual property rights, and the developed equipment/tooling/material/product and 3) establish a domestic, US business to provide an industrial manufacturing base for large superconducting magnets for further commercialization and potential defense needs. This proposal was accepted and a government/industry partnership emerged where it was agreed that a demonstration of a mid-sized superconducting magnetic energy storage system and the underlying technology, for an electric utility application, would provide industry the development and commercialization boost needed to achieve the benefits of all the parties. Ultimately, 
an Agreement with the DOE was structured and thus began the work which is the subject of this report. A Cooperative Agreement entered into between BWXT and the DOE, entitled "Commercialization Demonstration of Mid-Sized Superconducting Magnetic Energy Storage Technology for Electric Utility Application,” provided a vehicle for achieving the goals and benefits given above and was signed.

An influential Senator from Alaska was very supportive of this TRP program effort and provided political support to focus this phase on Alaska for the first demonstration. As it turns out, a unique and fortuitous arrangement exists with an Alaskan utility where a mutually beneficial opportunity arose. The City of Anchorage is unique as it is connected to the Intertie Network Grid serving Anchorage to Fairbanks, but is otherwise isolated and not connected to the mainland's electric grid. The utility servicing the area is Anchorage Municipal Light and Power (AML\&P) and the City of Anchorage provides ownership, direction and rate control authority. Electrical power quality and reliability problems plague Anchorage and its residents due to the environmental and configuration conditions. The Intertie connects power generation to users, including the Trans-Alaska Pipeline with its large pumping stations and other large loads. Another challenge is government regulation of utilities with requirements for power quality parameters, reserve capacity, and what is known as spinning reserve (this is reserve power that is to be imminently ready for supply). Whenever the pipeline's large pumps started, the power demand was so large that it often overloaded the system, degrading power quality. Roving brown/blackouts were implemented to temporarily reduce loads and restore system stability. Consequently, the City implemented rotating power outage schedules so that the problem was equally shared (rotating black-outs) around all of Anchorage.

Anchorage has a reserve hydro-electric capability at near-by Bradley Lake. It takes about 2 minutes to open the valves initiating water flow to spin-up the turbines to drive the generators to provide electrical power. Anchorage's electric power could be restored from one of these blackouts in about 2 minutes using the hydroelectric power from Bradley Lake. The SMES solution was to station nearby a SMES of sufficient size to store and deliver 2 minutes worth of electricity to the city of Anchorage for the 2 minutes while Bradley Lake came on-line. The SMES offered a solution to meet the spinning reserve requirements that Bradley Lake was unable to meet and provide the extra power for the sudden increased loads. This TRP program could be used for this application where BWXT would design, build and install the SMES; AML\&P would support connection to their Intertie grid and financially support the industry cost-share in the TRP agreement plus provide additional financial support due to the large size and scope of the effort. With this arrangement, all the goals and objectives of the Agreement could be satisfied and a useful demonstration of the SMES technology achieved.

To provide the spinning reserve needed by AML\&P for the utility application of the SMES, studies were made of the energy and power needed. The amount of energy needed for the 2 minutes of power supply was estimated to be 1,800 MJ (about $0.5 \mathrm{MW}$ hr) (a very large magnet). Initial magnet designs were developed to supply that energy, resulted in a very large solenoid magnet design. Transportation capacity due to the size of the magnet soon became the limiting factor. Eventually, an on-site fabrication scheme was developed to reduce cost and eliminate the transport barrier. As the design matured, 
it became apparent that the system cost would greatly exceed the initial estimate. The developing design called for a cryo-stable, aluminum stabilized superconductor in a large solenoid coil with axis horizontal with power conversion electronics for connecting to Anchorage Municipal Light and Power's (AML\&P) Intertie transmission line. The magnet diameter was limited by transportation restrictions (the railroad bridge along BWXT's plant at Mt Athos road in Virginia was the most limiting condition) which caused the length to increase beyond that which could be transported and thus, reduced stored energy. Project engineers became increasingly concerned that project budgets could not be met with the scope of the magnet system being designed. The design on hand was formally estimated and a sizeable funding shortfall was identified. A project review and new cost-to-complete estimate was ultimately made.

Due to the estimated cost and budget conditions, it was decided to re-design and reengineer the magnet system to remove as much cost as possible and try to comply with the budgetary restrictions. The magnet system was re-designed with many improvements, such as the following: 1) in-situ coil winding was proposed for fabricating the coil/magnet at AMP\&L's site which greatly lowered transportation costs and enabled a larger diameter coil (a more efficient energy storage configuration which, in-turn, lowered the superconductor material costs, 2) a simplified winding machine/approach was developed by placing the magnet's axis in the vertical position which also enabled a large increase in the diameter, and 3) a copper stabilized conductor was used which eliminated troubling cold work and cryo-stability issues associated with the aluminum stabilized conductor and also lowered conductor size and costs; and, 4) a simplified insulation system was designed, which further lowered costs. The new design approach was formally re-estimated for cost and schedule impact. A design review was held with all the project stakeholders and outside experts to further confirm the project design and plan. The design review was successfully concluded.

Because financial support from the utility was needed for this demonstration and because the City of Anchorage maintained rate control authority of AML\&P, AML\&P had to obtain approval for their capital expenditure from the Anchorage City Council. All the affected parties had the newly developed plan information with both cost and benefit estimates. This latest proposal was submitted and was being reviewed for approval and adoption. AML\&P had agreed to move forward with the project if Anchorage City Council approved (and provided the financial resources). The issue was no longer technical, but rather, financial. The issue was placed on the agenda for Anchorage City Council debate and vote. As the voting date neared, and unbeknownst to BWXT, the City of Anchorage was given the rights to a near-by natural gas field by another donor. An internal assessment was made where it was determined that the City could procure gas turbines and generate electric power to satisfy their power, power quality and spinning reserve needs at much less cost (and technical risk). In other words, the City of Anchorage was given free natural gas supply and consequently, all other power generation projects became seriously uncompetitive. With that, Anchorage City Council dismissed the BWXT SMES revised proposal and would not authorize funding. They proceeded to develop and deploy the gas reserves at great savings. 
The SMES project no longer had the funding resources for the industry cost share portion of the Agreement. As the AML\&P demonstration collapsed, meetings were held with the project stakeholders to decide the future direction. On-going BWXT utility applications and business studies were indicating that energy storage for emergency use or spinning reserve were not economically viable. Rather, economic viability was indicated for transmission line stabilization. Here, less energy is needed (which is the primary cost driver due to the size of the magnet and subsequent cost of the superconductor) while higher real power is most beneficial. The higher power could be more economically achieved with increased voltage rather than current, again reducing cost. With these revelations, a new demonstration of the SMES technology for transmission line stabilization was developed. A proposal to redirect the project was prepared, submitted and ultimately accepted. The new proposed demonstration was designed to meet and exceed the original objectives and expectations. Thus began an entirely new project period with new design and fabrication efforts to support a new demonstration.

\subsubsection{Design Description \& Key Technical Accomplishments}

The engineering effort during the initial phase of this project was directed at developing a magnet system design and manufacturing capability. The magnet system was intended to provide active real power as well as to provide reactive power for VAR (Volt-Ampere Reactive) compensation. A specification was developed and agreed to with AML\&P, which defined the system and main interfaces. AML\&P agreed to provide the following:

- The site for the SMES installation including buildings, foundations, fencing etc.;

- An interface transformer and connections between the $115 \mathrm{kV}$ line, $12 \mathrm{kV}$ auxiliary power line, and the SMES terminals;

- Circuit breakers and step-down transformers to SMES auxiliary power connections;

- Potential and current transformers on all three phases of the $115 \mathrm{kV}, 12 \mathrm{kV}$ and SMES ac lines with connections to the Power Conversion System (PCS) console;

- A Remote Terminal Unit connecting the Supervisory Control with the SMES monitoring and control room.

BWXT agreed to build, deliver, install and test the SMES system at the AML\&P site. The SMES system consisted of the Superconducting Magnet Subsystem, a Power Conversion Subsystem (PCS), including an ac breaker and dc switchgear, and a Helium Refrigeration System. Installation also included liquid helium and nitrogen for cooling the magnet and charging, cool-down and check-out of the system and acceptance testing. The SMES system would provide both active and reactive power with the following maximums:

$\begin{array}{ll}\text { Variable VAR } & 30 \mathrm{MVAR} \\ \text { Combined Operation } & 10 \mathrm{MW} \text { and 28MVAR }\end{array}$

The following are the main system ratings:

$$
\begin{aligned}
& \text { Rated Energy: 1,800 MJ at full charge } \\
& \text { Rated Power (four-quadrant forced commutation): }
\end{aligned}
$$

Active power: $\quad 31.5 \mathrm{MW}$




$\begin{array}{lll} & \text { Capacitive power: } & \text { 31.5 MVAR } \\ & \text { Inductive power: } & 31.5 \mathrm{MVAR} \\ & \text { Combined: } & 31.5 \mathrm{MVAR} \\ \text { Line Frequency: } & 60 \mathrm{~Hz} \pm 2 \mathrm{~Hz} \\ & \text { Operate if rate of change is } 3 \mathrm{~Hz} / \mathrm{sec} \text { or less } \\ & \text { Disconnect if frequency exceeds rated limits } \\ & 115 \mathrm{kV}, 3 \text {-phase } \\ \text { Line Voltage: } & \text { Operating range: } \pm 10 \%,-20 \% \\ & \text { Phase unbalance: less than } 3 \% \\ \text { Magnet Current: } & 10.8 \mathrm{kAmpere} \text { DC maximum } \\ \text { Magnet Voltage: } & 3.375 \mathrm{kV} \text { DC maximum, charging or discharging }\end{array}$

The magnet design and engineering effort began to define a system capable of meeting the above system requirements. Various arrangements where considered but it was quickly learned that the most efficient and cost effective configuration for energy storage was a solenoid (which minimized the amount of conductor and hence cost). It was determined that the limiting factor in transporting the magnet coils from Virginia to Anchorage was the diameter to allow passage under certain bridges. A maximum diameter was selected based on the transportation restrictions. The coil length was then estimated to provide the energy storage capacity. 1,800 MJ of stored energy (about 500 $\mathrm{kw}-\mathrm{hr}$ ) is a very large magnet.

The winding insulation design was developed to minimize cost. Here, G-10 pickets were devised (these were bonded to a tape for easy feeding during winding) which would provide a minimum stand-off between winding turns. A favorable condition existed due to the discharge characteristics of liquid/gaseous helium where it was observed that more than enough voltage withstand capacity existed for the spacing envisioned. (A Kapton wrap was considered but the degraded conductor cooling was judged to detract from the benefit of the added insulation). So the coil insulation system designed for this magnet consisted only of maintaining sufficient spacing by using G-10 picket spacers and relying on the helium discharge characteristics to withstand the very low turn-to-turn voltage without discharge or leakage.

The next design feature established was to use pool boiling helium to cool the conductor and to design a cryo-stable conductor. A cryo-stable conductor is one where sufficient cooling exists by the superconductor to dissipate heat and prevent quenching even with a disturbance to the superconductor. This was initially developed by designing a very high RRR (residual resistivity ratio) aluminum stabilizer surrounding the superconducting strands with sufficient mass and conductivity to remove any quench-causing excess heat. A RRR of 700 minimum was selected for very high purity aluminum. But because of this very high RRR requirement, only a very small amount of cold work could be imparted during manufacturing. An added strengthening agent was needed to withstand the Lorentz forces. Toward that end, a high strength aluminum alloy sheath was devised to cover 3 sides of the stabilizing pure aluminum leaving one side open for direct exposure to the cooling helium. This conductor design concept was eventually patented 
as US Patent 5,718,034 "Aluminum Stabilized Superconductor Supported by Aluminum Alloy Sheath." The following is an illustration of that conductor design:

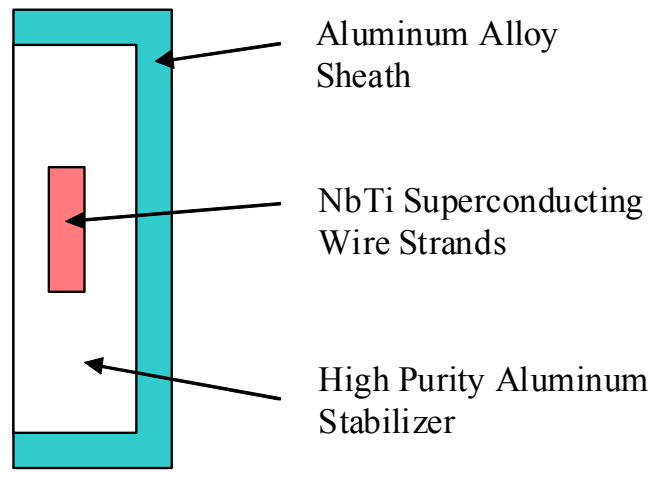

Later, a revised conductor design emerged. Because of the size of the pure aluminum needed for cryo-stability, the length of the conductor was excessive to achieve the stored energy. Also, the magnet winding operations were imparting cold work, which potentially could exceed the RRR requirements that would threaten the cryo-stable performance. It was decided to redesign the conductor using copper as the stabilizer. Because pure copper has better conductivity and strength compared to aluminum; the cryo-stability could be preserved while making the conductor and magnet smaller. So a grooved pure copper conductor was envisioned where the superconducting cable was brazed into the groove (allowing direct contact between the SC and the pool boiling helium. Here, stability analysis confirmed that a cryo-stable conductor was achieved. The copper stabilized conductor also facilitated field or in-situ coil winding which was a major benefit.

As the conductor and magnet design developed, cost estimates emerged which exceeded budgetary requirements due to the expense and size of this large magnet. Trade studies were performed to develop cost reductions. The key results of these studies were:

- Performing the coil winding in-situ at the site would result in significant cost reductions due to the following:

o Removing the diameter limitation from the shipping constraint which reduced transportation costs.

0 The larger diameter was more efficient at energy storage (varies by the diameter squared) thereby reducing the amount of expensive conductor needed.

o The larger diameter could be more easily wound with the axis vertical which reduced winding machine expense costs and winding time. Previously the axis was horizontal for factory and shipping constraints.

- The conductor design was changed to copper stabilized and was successfully analyzed for cryo-stability.

o The new conductor was less expensive with lower RRR and higher strength

o The design was more compact and efficient requiring less conductor to achieve the stored energy.

o The insulation design combined with the vertical axis enabled pool boiling coil cooling with natural circulation which lowered refrigeration costs 
The design and engineering effort was now finalizing the details of the new, lower-cost conceptual design. Manufacturing trials were engaged to fabricate conductor and perform confirmatory tests. Equipment and tooling designs were initiated for the new design. As the administrative requirements developed, the overall project goal was changed and the AML\&P SMES design was abandoned as described in section 3.1.1.

\subsection{American Electric Power and the Transmission Line Stabilization Period}

\subsubsection{Program \& Administrative Overview}

Aware of the growing project challenges, BWXT conducted studies of other markets and applications. It became apparent that with the high cost of superconducting materials and associated equipment (e.g. power electronics, vacuum and cryogenic systems), very large energy storage magnets for spinning reserve were not economically viable or marketable. Other energy storage devices, such as batteries and flywheels were more economical and available (albeit with different challenges). In the course of researching the electric utility industry, a new application, vision and product began to emerge; one that did offer good benefits, value, economic justification and cost savings to utilities with potential to grow into a bona-fide business.

BWXT personnel met with DOE and other stakeholders on several occasions to determine the future direction and activity of the project. SMES as just an energy storage device was seen to be very limited and costly for the benefits obtained, making market potential not viable. However, BWXT marketing studies had shown that SMES technology could be reconfigured and applied to transmission line stabilization as a viable business. Transmission line stabilization devices require very high power and much less energy and were, accordingly, much smaller and less expensive magnets. With a new vision, this SMES stabilization device could provide multiple benefits to utilities, including reliability improvement, improved power flow and increased revenue from utilizing the reserved stability margin, stability and power quality improvements, blackout prevention and perhaps avoidance of new transmission line construction. For the manufacturer, sales of multiple units were apparent and attractive as an ongoing business. From these initiatives, American Electric Power (AEP) was approached for interest in supporting and developing this technology for transmission line application and stabilization. AEP, one of the largest electric utilities in the U.S. and a leader in transmission line technology and application, became quite interested and offered their support. A new demonstration objective was established and was supported by industry, BWXT and AEP. DOE was contacted for their support and guidance. All stakeholders were in agreement that the new demonstration was extremely significant and so a new project demonstration goal was created. A proposal reflecting these changes was made to DOE and ultimately adopted with a modification to the Agreement.

The new market and system envisioned a much smaller (and hence, less costly), mid-size SMES as a cyclic, very high power, instantly available, energy storage/injection system to counteract reactive power excursions (both + and -) on transmission lines to create a net zero effect in counteracting these power oscillations. The new SMES could be used 
as a stabilizing device for transmission lines by appropriately injecting or absorbing power, 180 degrees out of phase with the electrical power transient; so when combined with the transient, the transient would be cancelled or zeroed out, thereby stabilizing the network and system. Such a system could also provide corrections for variations in reactive power, which would improve reliability and power flow and costs. The amount of power that can be transmitted on a transmission line is limited by several factors there is a physical limit due to the wire size, a thermal limit for protection from resistive overheating, and a real or reactive power excursion limit (stability limit) for uncontrolled power oscillations due to power oscillations from failures, large surges, lightening strikes, cascading effects, etc. The stabilization limit is about half the transmission line capacity to allow for and safely accommodate those unplanned power swings. If a device could be added that would safely and reliably limit the power oscillations and stabilize the line, then higher reliability and fewer outages would be obtained. The capacity of power transmission could be increased (up to about $2 \mathrm{X}$ or twice the present rating) on the line to nearly double the revenue. This could also result in postponement or elimination of construction costs for new transmission lines (at a cost of about $\$ 1 \mathrm{M} / \mathrm{mile}$ ) while providing more power. About $100 \%$ more power could be transmitted on the same line to increase revenues twofold. The key to this technology is to have a dynamic system which can quickly and controllably, both inject and absorb, at frequencies of about 1-2 Hertz, large amounts of real power but with modest amounts of energy. A superconducting magnet could be an ideal solution as the energy is stored in the magnetic field with instant availability and with no electrical losses and a more economical design with higher power and lower energy could be used. The magnet size (the key cost driver) could be optimized to achieve high power by lowering the current (the size of the conductors and thus cost) and increasing the voltage (higher insulation costs/risks) to increase the power. Also, improving the reliability of the transmission lines to eliminate brown/black-outs and otherwise improve power quality and system reliability and availability was of major interest to the utilities and the government. The market study identified this product as a viable one with very good business potential and electric utility interest.

American Electric Power (AEP) was contacted for their interest in such a device. AEP was immediately interested and was very encouraging. AEP saw an opportunity to acquire the benefit of government financial support to lower their development cost, maintain a leading position in transmission line operation and stabilization, and improve system reliability (a key internal goal). Most fortuitously, AEP had just installed the largest solid state power converter/inverter in the US at Inez, KY. These twin $160 \mathrm{MW}$ inverters (320 MW total) were stabilizing and optimizing power flow at a node of 6 transmission lines serving 4 states. The system used a $24 \mathrm{kV}$ DC bus with high power solid state electronics to adjust reactive power and flow in their transmission lines with their 320MW converter/inverter system. Our DC magnet could be added to their $24 \mathrm{kV}$ DC bus to provide real power injection and absorption at the appropriate phase angle, with minimal energy to stabilize the AEP transmission system. AEP was very interested and further desired and recommended a portable device so that it could be moved to another trouble spot if needed. AEP was also very concerned about the risks of connecting an unproven device to their elaborate system and was concerned over the 
potential for damage to their large inverter system. Clearly a demonstration of the technology was required to reduce risks for this application and for future sales.

Thus began the redefinition of the original TRP project. A new proposal based on this new SMES concept was developed and submitted to DOE. This proposal for the demonstration of a mid-sized SMES, with AEP's Inez, KY, station as the host site, for transmission line stabilization and demonstration was submitted, reviewed and approved. An Agreement modification was issued to change the demonstration site, schedule, scope of work and budgets. The connection electronics to the transmission line was largely in place from AEP's prior investment and these investments were essential for the demonstration and were recognized as industry contribution, support and cost share. A new magnet conceptual design was developed - one that featured a high voltage $(24 \mathrm{kV})$ interface for providing maximum power exchange of $96 \mathrm{MW}$ and reversing power exchange at + and $-( \pm) 50 \mathrm{MW}$ at $0.2-2$ Hertz. A system rated at $96 \mathrm{MW}$ total power and $100 \mathrm{MJ}$ total stored energy, (considerably less than the 1,800 MJ planned for AML\&P), was conceived and proposed with an accompanying plan and estimate. AEP benefited with a lower cost stabilization device and improved power reliability; and BWXT benefited by developing the technology, design, and experience, manufacturing capability and market entry; and the Government benefited as BWXT established the domestic large magnet fabrication capability, improved the reliability of the nation's electrical grid, completed the TRP with a major demonstration and with excess cost share and recovery of past project expenses.

Work began again to redesign the magnet system and develop the interface between the magnet and the $24 \mathrm{kV} \mathrm{DC}$ bus of the power inverters. An Nb/Ti, copper stabilized superconductor cable design emerged with a Cable-in-Conduit configuration as the preferred approach. A modularized coil section approach was developed so that future magnet capacity changes could be easily made without design or hard tooling cost impact. It was desired that the system be transportable so that other applications could be supported. A new and unique insulation system was designed to provide the reliable high voltage operation. Coil modules consisting of 20 turns per layer with 8 layers or 160 turns per module emerged. A total of 10, 12 foot diameter modules were needed for the 100 MJ SMES system. A factory was established and operated to produce the SMES magnet system.

Project work was underway and actively progressing. System design activities were proceeding, manufacturing equipment and tooling designs were developing and AEP integration and support was progressing. A Preliminary Design Review of the AEP demonstration system was held (12/96) at BWXT with DOE, DARPA, AEP and BWXT attendees. A re-baselined project plan and estimate was developed as the design matured.

With the project goals, technical and integration requirements established for the new system demonstration; engineering design and manufacturing planning progressed in earnest. A low cost, cryogenically stable, high voltage, robust magnet coil design was developed with drawings and specifications. The manufacturing approach with special designed equipment and tooling was developed, specified and procured. A 
manufacturing facility was established and made operational and personnel were trained and procedures developed and written. Procedure development with test trials and mockup activities were performed and successfully completed. Key sub-system tests were successfully completed. Major subcontractors were selected and purchase orders placed. Project management and administration activities were performed as the overall project progressed well. This progress was continually reported to the stakeholders.

Design and manufacturing work progressed well in the ensuing years; however, continuing cost-to-complete estimates revealed a potential funding shortfall. Now, the primary component that was underestimated was the electronic power conversion hardware (not the superconducting coil) - the solid state electronics that interfaced between the DC magnet and AEP's DC bus in the inverter (UPFC) system. This device is known as a DC-DC chopper and was a unique, custom design.

Electric power reliability was rapidly becoming a national priority and both AEP and BWXT were potentially offering an industry solution. Power reliability was rising to the top of DOE national energy priority and EPRI (Electric Power Research Institute consortium of US utilities) was initiating major power quality and reliability programs. SMES was uniquely situated as an upcoming solution. All that remained was to demonstrate the technology - the exact purpose of the TRP Agreement. Meanwhile, deregulation issues were changing rapidly and AEP was very unsure of their future business - who would own such a device and how would they get cost recovery (especially from their competitors if forced to use it). AEP was evaluating breaking its business into three segments (generation, transmission and distribution) and was planning to divest itself of its transmission business to a new consortium. How would cost recovery and rates be adjusted, and who would own and/or operate or maintain the units? All these issues and questions were unsettled and unknown. Ultimately, AEP management was willing to allow the test connection at Inez but was unwilling to provide any additional financial support due to the uncertainties and risks.

Because of the national reliability interest, The Electric Power Research Institute (EPRI) was contacted for project interest and support. AEP is one of the largest financial contributors to EPRI and has membership on key advisory committees at EPRI. EPRI would acquire other co-sponsors and coordinate their joint support. After management review, EPRI wanted an independent market evaluation and member survey before funding. This study was ultimately favorably completed. EPRI finally developed the position that they would provide funding to support the project as one of their joint cosponsored development projects contingent upon BWXT providing additional comatching funds.

EPRI organized a co-sponsored project for the support of this technology. The market study they conducted concluded that future applications were real and very probable and other utility sponsors were encouraged by and supportive of the technology and its applications. This additional funding was ultimately not acquired, as BWXT management was unwilling to commit any additional resources due to the confusion and uncertainty from deregulation which caused confusion and uncertainty in the future 
business projections. The marketing forecasts became extremely volatile and unreliable and could not be used to justify any additional investments. With uncertainty from the utility customers, driven by the deregulation uncertainties, the future SMES sales were nonexistent and forecasts could not be reliably made. BWXT could therefore not accept the additional funding from the EPRI joint co-sponsored group. EPRI and the other utilities dropped their support and their co-sponsored project.

The deregulation policies, practices and uncertainties were the overwhelming obstacle that all the project stakeholders could not overcome. The technical objectives and accomplishments were highly regarded and supported by all the stakeholders, but the commercial and regulatory forecasts could not be agreed upon or supported. The project was forecasting a budget shortfall. These combined conditions, in the current political and economic environment, were placing the successful, planned completion of the project in jeopardy.

\subsubsection{Design Description \& Key Technical Accomplishments}

\subsubsection{Product Design Summary}

American Electric Power's Transmission Division was contacted and interested in strengthening the robustness and improving the reliability of their power transmission systems. They recognized that an instantaneous available energy and power source could be used in conjunction with their existing equipment to dampen damaging power swings and oscillations on the transmission lines typically caused by lightening strikes and thereby avoid shut-downs or power limitations. AEP had previously taken action to strengthen their transmission system by installing a state-of-the-art Unified Power Flow Controller (UPFC) at their station in Inez, KY. At this station, six transmission lines (up to $765 \mathrm{kV}$ ) come together and the power can be routed and controlled to serve their system and customers in 4 states. The UPFC employed 2 -160 MW converters/inverters operating with a common $24 \mathrm{kV}$ DC bus. Reactive power and power flow could be adjusted to improve power flow and provide some dampening to power surges and variations. Lightening strikes are a frequent occurrence and can result in huge power surges and oscillations. Load variations contribute to stability issues also. It was recognized that a superconducting magnet could provide an instantaneous source of very high power (discharge of the stored magnetic energy) over a short time period and it could also absorb large power (similar to charging a magnet). The magnet also operated as a DC system and could potentially be connected to the UPFC's DC bus to both inject and absorb real power into the UPFC. This cyclic, DC power source (SMES) could then be used to counteract transmission line power variations (surges, swings, oscillations etc.). AEP engaged their staff in an electrical system study to assess power profiles that would add stability to their system. Two basic profiles were identified as potentially beneficial in adding increased stability to the transmission system: 1) short high power pulses on demand and 2) low frequency, high power, injection and absorption, timedecayed oscillation to act essentially 180 degrees out of phase with the disturbance (observed mostly from lightening strikes). By absorbing or injecting power $180 \mathrm{deg}$ out of phase with the line oscillation the SMES would effectively dampen and remove the disturbance/oscillation thereby providing the stabilization and enhanced reliability. 
A demonstration project was initiated with AEP as a co-sponsor to demonstrate a SMES for utility (transmission line stabilization) application. AEP would provide the site (Inez, KY station) and access to their UPFC and provide technical support and system test integration and support. BWXT would design, build, install, test and demonstrate the SMES system. The demonstration objectives of the SMES system installation were to demonstrate the capabilities of the system, working in conjunction with the UPFC, to improve network reliability and power quality. SMES system availability and operating costs would also be determined. The system design would permit dismantling to major transportable units and relocation to another site if required. The SMES system consisted of the following major subsystems: liquid helium cooled superconducting coil, a cryostat; DC leads; DC bus, switchgear and energy dump; refrigeration system; magnet monitoring and protection system; supervisory control and data acquisition system; and a Energy Flow Controller (EFC) - a bi-directional DC current-to-voltage sourced converter that modulates the flow of power between the SMES magnet and the DC bus of the UPFC. The following are the major SMES System Ratings that were agreed to and formed the primary system design basis:

\section{SMES SYSTEM RATINGS}

Rated Energy: $\quad$ Net rated energy capacity shall be $100 \mathrm{MJ}$

Rated Voltage: $\quad$ Rated voltage on DC bus at magnet terminals shall be $24 \mathrm{kV}$ Rated voltage on bus between EFC and UPFC is $24 \mathrm{kV} \pm 15 \%$

Rated Current: $\quad$ Rated current shall be $4 \mathrm{kA}$

Power Profiles: $\quad$ A) Pulsed power discharges up to rated current and voltage. System shall support up to 3 pulses at rated voltage, each pulse being up to 0.1 second in duration and at intervals of 40 to 60 seconds. The system shall support discharge profiles within rated energy capacity, voltage and current, including discharge at power up to $50 \mathrm{MW}$ for a duration up to 1 second.

B) The SMES system shall support cyclic discharge and charge with an approximate sinusoidal power profile in the frequency range 0.2 to $2.0 \mathrm{~Hz}$, and with amplitude up to $50 \mathrm{MW}$. The power amplitude will decay exponentially with a time constant not greater than 5 seconds, and a maximum duration of 15 seconds. At frequencies below $0.3 \mathrm{~Hz}$, the power amplitude will be limited by the rated energy capacity.

To effectively provide stabilization to the transmission line requires the magnet to operate in a cyclic manner at very high power levels. The low frequency, $\pm 50 \mathrm{MW}$ requirement became the critical design basis feature. Typically, large superconducting magnets operate statically with dc currents flowing in the magnet that are not changing. Typically, these magnets are used to provide a steady, non-varying magnetic field. But 
this application required cyclic operation, which means that AC Losses within the system must be minimized, and also, heat generation and refrigeration costs must be minimized. This design requirement controlled the superconductor design to be a low AC loss design. The second major design feature was the large DC terminal voltage; which required a rigorous and robust insulation design. This was the largest rated voltage magnet design ever made. So, the two design driving issues of this SC SMES magnet system were:

- Very low AC losses in the conductor to reliably achieve the charge and discharge power exchange of $\pm 50 \mathrm{MW}$; at low cost

- Very high insulation design and integrity to achieve $24 \mathrm{kV}$ terminal-to-terminal voltage

A system design was produced to meet these requirements and objectives. The design adequacy was proven both by analysis and testing. Each of the major components was tested to confirm and validate the design and manufacturing processes. The resulting system was a unique, First-Of-A-Kind, cyclic magnet, the largest superconducting cyclic magnet ever designed and built, and the highest rated voltage magnet ever built. The low AC loss conductor, splices (both internal and external), and helium isolators were unique. The EFC, a DC-DC chopper, was a unique specialty electronic power transfer equipment design. The insulation system and fabrication methods were robust, efficient and of high quality and reliability. It is not possible to provide the entire design and validated basis in this summary technical report. A synopsis of the highlights of the major elements with photo documentation is provided for your information in the following sections and pages.

The resulting SMES design is summarized with the following data listing:

Table 3.2.2.1 - 1 Summary of Key BWXT SMES Characteristics/Parameters:

\begin{tabular}{|l|l|l|}
\hline \multicolumn{1}{|c|}{ Parameter } & \multicolumn{1}{c|}{ Unit } & \multicolumn{1}{c|}{ Value } \\
\hline Coil Configuration & & Solenoid \\
\hline Rated Current & Ampere & 4,000 \\
\hline Rated Voltage (terminal-to-terminal) & Volts & 24,000 \\
\hline Peak Power & MW & 96 \\
\hline Stored Energy @ Rated Current - 4,000 A & MJ & 86 \\
\hline Stored Energy @ 4,300 Amperes & MJ & 100 \\
\hline $\begin{array}{l}\text { Max. Power Exchange, power oscillation } \\
\text { frequency of 0.2-3 Hz, 15 sec. maximum power } \\
\text { exchange with exponential decay at 5 sec time } \\
\text { constant }\end{array}$ & MW & \pm 50 \\
\hline Winding Type & & Pancake \\
\hline No. Pancakes & No. & 88 \\
\hline No. Double Pancakes & No. & 44 \\
\hline Winding turns per layer (pancake) & No. & 20 \\
\hline Total No. Turns & No. & 1,760 \\
\hline Maximum NI & $\begin{array}{l}\text { MAmpere- } \\
\text { Turns }\end{array}$ & 7.04 \\
\hline
\end{tabular}


Final Report - DOE Agreement No. DE-FC36-94G010011

Commercialization Demonstration of Mid-Sized Superconducting Magnetic Energy Storage Technology for Electric Utility Applications

\begin{tabular}{|l|l|l|}
\hline Inductance & Henry & 10.8 \\
\hline Bmax, @ Rated Current & Tesla & 4.03 \\
\hline Coil Inner Diameter (w/o ground wall) & $\mathrm{m}$ & 3.14 \\
\hline Coil Outer Diameter (w/o ground wall) & $\mathrm{m}$ & 3.63 \\
\hline Coil Height (w/o ground wall) & $\mathrm{m}$ & 1.42 \\
\hline Conductor - Cable-In-Conduit, Nb-Ti & & CICC \\
\hline Cu/SC Ratio & & 2.9 \\
\hline Cu RRR, minimum & & 70 \\
\hline No. SC strands per cable & No. & 180 \\
\hline No. Cu strands per cable & No. & 30 \\
\hline Total No. strands per cable & No. & 210 \\
\hline Strand Diameter & $\mathrm{mm}$ & 0.48 \\
\hline Cabling pattern & & $(6+1) \times 5 \times 6$ \\
\hline Strand Critical Current, nominal at 4.2K, 5T & Ampere & 129 \\
\hline Strand Critical Current Density & $\mathrm{A} / \mathrm{mm}{ }^{2}$ & 2750 \\
\hline Operating Current/Critical Current & $\%$ & 17 \\
\hline CICC Jacket Material - 316 LN & & $316 \mathrm{LN}$ \\
\hline Conduit Outer dimensions & $\mathrm{mm}$ & $14.7 \times 10.9$ \\
& & $\left(0.579{ }^{\prime \prime} \mathrm{x} 0.4299^{\prime \prime}\right)$ \\
\hline Conduit Inner dimensions & $\mathrm{mm}$ & $11.4 \times 7.6$ \\
\hline Nominal Void Fraction, f & & 0.53 \\
\hline Refrigeration - Supercritical Helium & & \\
\hline Helium Inlet Temperature at 5 bar, maximum & $\mathrm{K}$ & 4.6 \\
\hline Helium flow capacity & $\mathrm{g} / \mathrm{sec}$ & 15 \\
\hline
\end{tabular}

\subsubsection{Product Description Summary}

In the following pages, a brief description will be given for each of the major components of the SMES magnet assembly. The important features will be identified along with drawings and photos (given in Appendices A and B) to aid with the description. The progression will start with the smallest component, the superconducting strands, and end with the magnet assembly. A Cable-In-Conduit Conductor (CICC) design was developed to minimize AC losses and minimize helium cooling inventory and refrigeration costs. The design basis and critical features were given above and permeated the design and build process to assure that a fully compliant, quality, reliable and robust SMES was produced.

Superconducting Strand - The superconducting wire was designed to provide low ac losses by using very fine superconducting filaments with a tight twist within the strand. The strands were coated with a very thin layer of nickel to provide much higher inter-strand contact resistance to reduce eddy current flow and avoid inter-strand sintering and bonding. The wire was produced to specification SS-02-1003 C which contained the following highlights:

NbTi superconductor with $\mathrm{Nb} 47 \pm 1$ wt $\%$ balance Ti, high homogeneity grade Maximum filament size not to exceed $10 \mu \mathrm{m}$, twisted filaments Filaments surrounded by $\mathrm{Nb}$ diffusion layer 
Oxygen free Copper area not less than $0.132 \mathrm{~mm}^{2}$

Wire electroplated with 1-2 $\mu \mathrm{m}$ thick $\mathrm{Ni}$

Strand critical current of 121 Ampere (minimum) at 4.22K with 5.0 Tesla applied perpendicular

RRR at final size of more than 70

Wire diameter of $0.484 \pm 0.003 \mathrm{~mm}$

Wire twist will be right hand with twist pitch between 6.0 and $7.5 \mathrm{~mm}$

Wire free of surface defects and no splices in at least $450 \mathrm{~m}$ per spool

This specification was intended to provide quench protection, cryo-stability, and minimal $\mathrm{AC}$ losses by minimizing the coupling area and providing inter-strand resistance. A sufficient quantity of the superconducting wire was successfully produced and tested for the SMES product and all the testing effort. Dummy strand made of copper was used for manufacturing trials and mockups to conserve expenses.

Superconducting Cable - The superconducting wire was fabricated into a cable with added features to reduce $\mathrm{AC}$ losses and provide quench and cryo-stability control. The cable was produced to specification SS-02-1002 B. The cable was made in 3 stages. The first stage involved cabling 6 superconducting strands around 1 pure copper strand of the same diameter. The design diameter considered the geometric arrangement for compactness and the added copper strand increased stability, quench protection and mechanical stability and achieved the final $\mathrm{Cu} / \mathrm{SC}$ ratio. Five of the first stage cables were then cabled to form the next subcable. A $0.025 \mathrm{~mm}$ thick x $6.25 \mathrm{~mm}$ wide $(0.001$ " $\mathrm{x}$ 0.25 ") 304 stainless steel foil was then wrapped over the subcable with a 1.3 -2.6 mm gap between adjacent helical wraps. The final cable was made by cabling 6 of the above subcables and wrapping with the stainless steel foil. The resulting cable was referred to as 6 around 1 by 5 by 6 or a pattern of $(6+1) \times 5 \times 6$. This produced a superconducting cable of 180 strands of superconducting wire and 30 strands of copper wire for a total of 210 strands. The following are some additional key parameters:

\begin{tabular}{|c|c|c|}
\hline Stage & Twist Pitch $(\mathrm{mm})$ & Diameter $(\mathrm{mm})$ \\
\hline $\mathbf{1}(6+1)$ & $12-15$ & 1.45 \\
\hline $\mathbf{2} 5 \times(6+1)$ & $38-42$ & 3.80 \\
\hline $36 \times 5 \times(6+1)$ & $110-120$ & 11.5 \\
\hline
\end{tabular}

All twists are right handed

All stainless steel wraps are left handed lay

No splices in completed cable length

$440 \mathrm{~m}$ minimum cable length

Conduit Tubing - A special specification was developed for the conduit tubing that provided for restrictive chemistry control. The material was $316 \mathrm{LN}$ stainless steel and was acquired at nominal $11 / 16$ " OD by 0.065 " minimum wall thickness. The tubing was acquired in straight lengths, free of defects in 100 foot minimum lengths. Special shipping arrangements were developed for this length of tubing, which was selected to minimize the number of tube butt welds required and hence costs. 
Cable-In-Conduit Conductor (CICC) - It was decided to employ a cable-inconduit conductor design to achieve the performance requirements and to minimize the helium refrigeration system costs associated with operating the magnet. The void fraction of the formed conduit interior was a critical parameter to ensure adequate cooling and cryo-stability. A void fraction value of 0.52 was selected and numerous analyses performed to confirm the expected performance. This value was critical in developing the forming methods for producing the CICC. Also critical was the integrity of the conduit as it had to be helium leak tight and of sufficient strength to withstand the Lorentz forces and more significantly, the potential quench pressure excursion. Helium leakage would damage the vacuum integrity and overall temperature control. The quench analysis indicated that a potential pressure of 1150 bar might occur. The CICC was suitably designed for that withstand. All produced CICC was pressure and helium leak tested by placing the spooled conductor into a vacuum chamber and pressurizing with $\mathrm{He}$ to 1150 bar. This acceptance test was performed prior to insulation and coil winding to assure that an acceptable conductor was being installed.

The fabrication of the CICC required considerable expertise and innovation. Essentially, a 1,600 foot length of continuous SC cable had to be inserted into 1,600 feet of high integrity, non-magnetic tubing and then tube reduced to final dimensions and this conduit had to a of extremely high integrity and helium leak tight. A patented process was developed to meet these needs. A folded fabrication line was developed so that this operation could be performed indoors. The manufacturing building was 450 feet long by 55 feet wide. A long table measuring about 300 feet long was used to support the assembly. Three, 100 lengths of tubing were orbital TIG butt welded together to form a 300 foot length. A pressurized plug blowing system was used to feed a fishing line and then a cable thru one end. The SC cable was pulled thru the 300 foot length. On each end of the table were large diameter drums for stringing the cable back and forth down the table length so that the SC cable feeding could be done from the same direction. Another 300 foot length of welded tubing was positioned and cable feed from the drums. This feeding continued until the entire length was provided. The tube rolling and forming mill was activated and the first 300 foot length was reduced, formed and spooled. During the tube roll forming, a tensioning system was used to apply tension to the cable to avoid kinking and enable the growth of the stainless steel tube over the superconducting cable as the dimensions of the tube were reduced; the tubing would "grow" about 15 feet over the cable in a 300 foot run. A loop of the cable was removed from the drum and the tube slid over the excess cable to make a butt joint with the first length. The joint was orbital TIG welded (with special provisions to prevent damage to the superconducting cable) and helium leak inspected. Then the next 300 foot length was formed. The process continued until the 1,600 foot continuous length was produced. The resulting product was high integrity, formed CICC on a spool of sufficient length to form one double pancake winding. Two photographs of the CICC manufacturing facility and the 300 foot table are given in Appendix B - 1 and B - 2. These pictures were taken from the middle of the table looking toward each end of the CICC fabrication table.

The final size and shape of the conductor was selected from several additional considerations. A rectangular shape was selected and the final dimensions and approach 
were determined empirically. Mechanical stability of the formed conductor to facilitate winding was one key. Here, bending during winding was to be done about the major axis (easier bend load) and for stability, the major axis should be larger than the minor axis. A 3:2 ratio of the major/minor axes was selected to attempt to minimize any damage to the conductor cable and to minimize compaction which could lead to sintering and potentially degraded performance. Since the cable had 6 major subcables, these naturally could be squeezed into a 3 by 2 array. Only at the twist pitch locations were there much deformation; otherwise a $3 \times 2$ rectangular shape was a natural fit. The final size was set to achieve the mechanical strength, the He void fraction and the dimensions were slightly adjusted from the 3:2 ratio. The starting tube size was set to the largest inner diameter to facilitate stringing the cable that could be tube reduced and rolled to the final conduit dimensions. An 18-stand tube reducing and rolling mill was used for tube reduction and a dual Turks head roller was used to impart the $\sim 3: 2$ rectangular final shape. Critical to this operation was the selection of parameters to uniformly produce the shape without any twisting of the CICC. No twist was essential during coil winding to achieve the coil dimensions to fit into the VPI mold. Any twist would result in an excessive layer build dimension and threaten final dimensional control and assembly into the mold. Included in the Appendix A as Figure A- 1 is a drawing of the formed SMES CICC conduit. Also, given below is a sketch illustrating the integration of the wires into CICC and the coil assembly.

Figure 3.2.2.2-1 Illustration of BWXT, Low AC Loss, Cable-In-Conduit Conductor
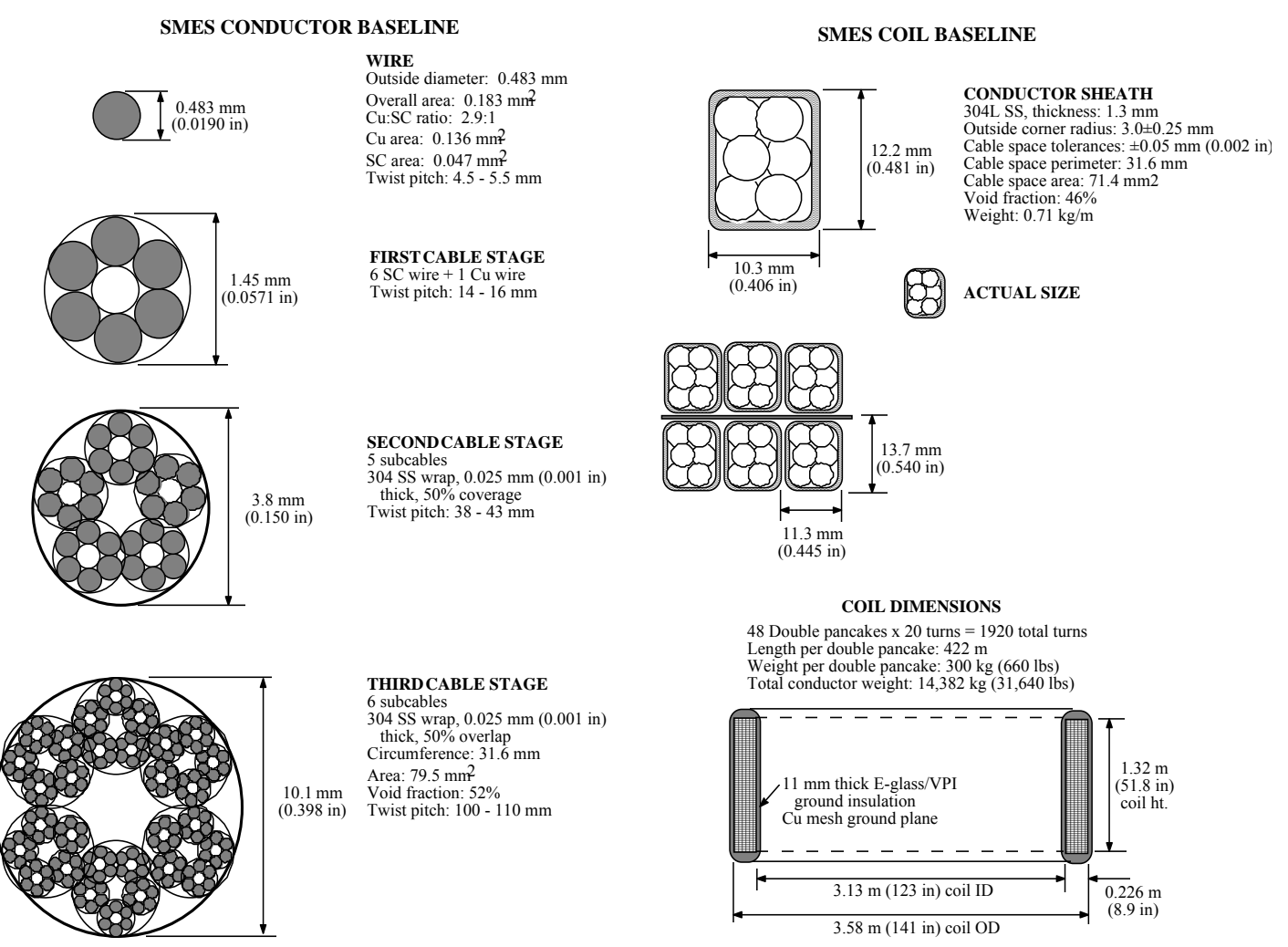
Insulation - Because of the high voltage connection to the transmission line's power electronics $(24 \mathrm{kV})$, the insulation design and integrity were of paramount importance. Because the SMES system was to connect to high voltage, a $24 \mathrm{kV}$ DC bus, and because reliability of insulation systems is the most common failure mode; these conditions required dedicated expertise and attention to assure a successful SMES demonstration. Other issues were considered in the design also such as cooldown stress from cryogenic operation, loads from Lorentz forces, crack propagation from high stress regions, elimination of chips, debris and other foreign particles during fabrication, redundancy etc. The final coil insulation design was defined as illustrated in the following illustration:

Figure 3.3.3.2-2 SMES Coil Electrical Insulation System

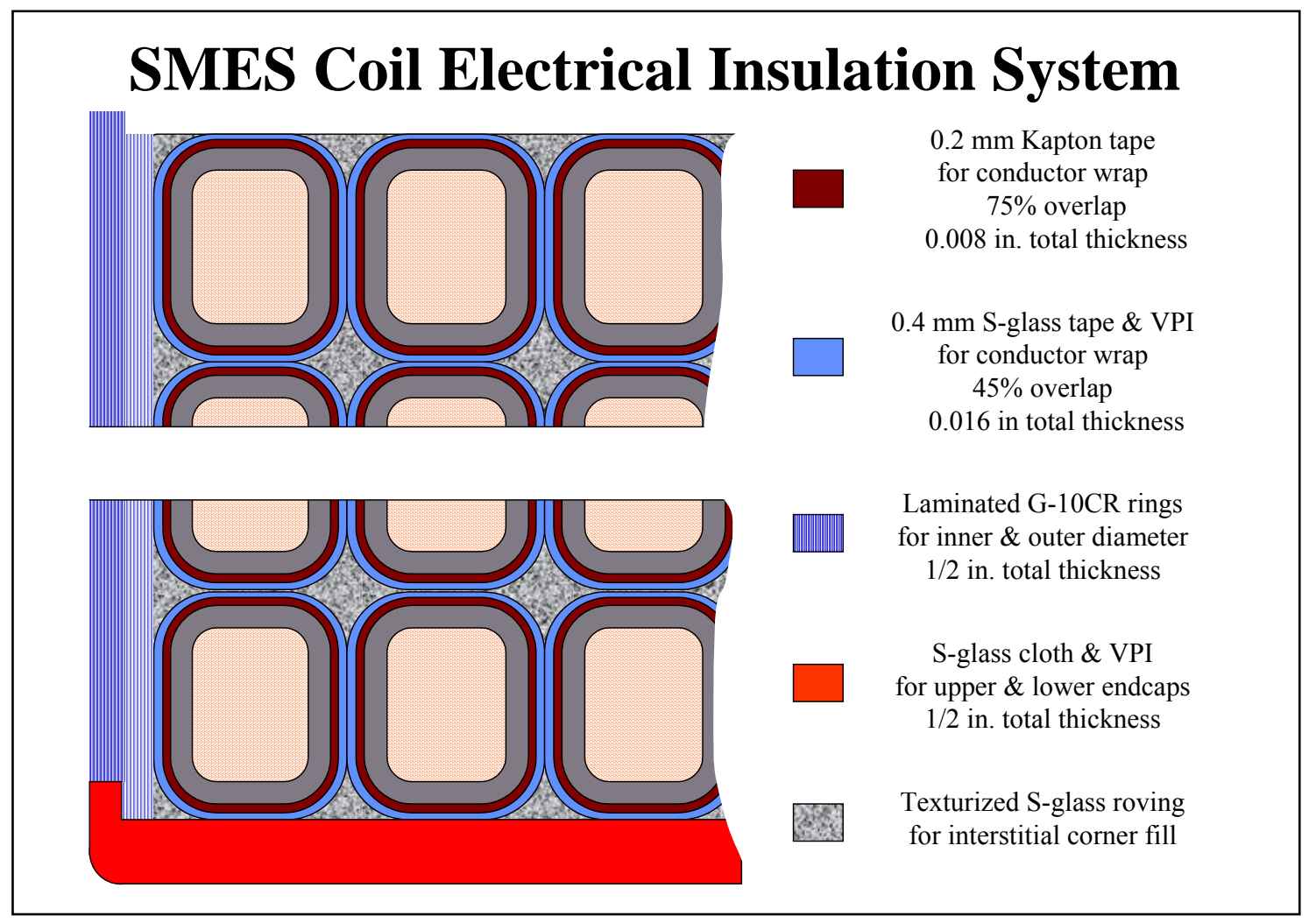

The primary insulation was provided by the redundant Kapton tape wraps, which have a dielectric strength of about $256 \mathrm{kV} / \mathrm{mm}$. The Kapton tape was not bonded using adhesive to the conduit to allow some minor slip and reduce the potential for cracking. To reduce the mechanical stress on the insulation, the glass cloth tape was woven to contain through thickness fibers to provide the needed strength. Also, 3-dimensional corner roving was used to provide adequate 3D strength. The epoxy chosen for this application was CTD$101 \mathrm{~K}$ and it was selected due to availability of mechanical properties at cryogenic temperatures and proven successful application in other magnet systems. These features provided the coil turn-to-turn insulation. For, coil to ground insulation, a special 0.5 " thick G-10CR composite with a lap joint was used. This material provided a dielectric 
strength of about $34 \mathrm{kV} / \mathrm{mm}$. All this resulted in a very robust insulation which was thoroughly tested with system mockups. A photograph of an insulation test mockup illustrating the insulation system is given in the Testing section of the report.

The following is the insulation design and test requirements developed, (along with the convention used to arrive at some of the test values), and applied during the project:

\begin{tabular}{|l|l|}
\hline Rated Terminal to Ground Voltage & $12 \mathrm{kV}$ \\
\hline Maximum Temporary Terminal to Ground Voltage & $14 \mathrm{kV}(12 \mathrm{kV}+15 \%)$ \\
\hline Test Voltage (terminal to ground) & $30 \mathrm{kV}(\sim 2 \mathrm{X}+1 \mathrm{kV})$ \\
\hline Test Voltage (terminal to terminal) & $36 \mathrm{kV}$ \\
\hline MOV Clamping Voltage (terminal to ground) & $24 \mathrm{kV}$ \\
\hline Design Voltage (terminal to ground) & $45 \mathrm{kV}(1.5 \mathrm{X})$ \\
\hline
\end{tabular}

Splices - Splices of the superconducting cable were a critical design and performance issue which were successfully developed and verified. First of all, the splices will possess some electrical resistance as opposed to the superconductor which has none. Therefore, they are a source of heat generation and as such a possible quench initiation site. About half of the heat load to the refrigeration system was attributed to the splices and to control costs, minimal resistance splices were needed. Two types of splices were required, one type for the High Voltage Current Leads to the internal bus and the other for connecting all CICC connections - pancake to pancake and pancake to internal bus. A total of 80 double pancake splices were needed for the assembly. A design was developed that had an organizational clamp and then each sub-subcable (the $(6+1)$ cable was a twisted pair and silver soldered over a 4" length and secured into another clamp that provided He cooling to the soldered joints. A photograph of a splice joint without the surrounding helium vessel is given in Figure B -3 . Here the organizing and clamping are seen as the cables emerge from the welded CICC vessel end plate. Drawings of the splice joint assemblies are given in Figures A - 2, 3, and 4 in the Appendix A.

Splice Box - The splice box was a region along the OD of the coil where all the inter-pancake splices were located along with the helium feed-throughs and instrumentation. Each double pancake was connected to its neighbor for electrical continuity. Also, each double pancake was supplied with liquid helium on one end and the helium was removed from the other end. The helium was connected to a supply and return manifold and each splice was connected to a voltage isolator. Each helium isolator was designed to withstand full operating and quench pressure and to withstand $20 \mathrm{kV}$. The isolator, connecting tubing and splice assembly were potted into a box arrangement which provided ground plane insulation. A drawing of the splice and isolator assembly is given in Figure A - 5.

Internal Busses - Two busses were designed for the cold mass for connecting each end of the coil to the High Voltage Current Leads. The HVCL in turn, connected the magnet through the cryostat to the external DC bus power and utility's connection. There was an upper bus, connecting the upper coil pancake splice to HVCL, and a lower 
bus, connecting the lower coil pancake splice to the HVCL. The lower bus was routed radially inward to near the center of the coil then ascended vertically up to the HVCL. The upper bus was routed vertically down along the outer diameter of the coil, and then radially inward to near the center of the coil then ascended vertically up to the HVCL. The vertical routings were selected to be aligned with the magnetic field so as to minimize Lorentz forces applied to the busses. Both busses were made by bending CICC to conform to drawing requirements. The insulation was special and included Kapton tape layer wrappings and about 1 inch layer of wet layup glass cloth wrap and air curing epoxy covered with a fine conductive screen and painted with a conductive paint. Figure A-6 provides a drawing of the upper bus assembly showing the size and complexity of the bus with its HVCL splice.

High Voltage Current Leads - The HVCL provided the electric power feedthrough from the external power terminals, through the cryostat to the internal bus and superconducting coil. It was designed to minimize heat loss while operating at high current and very high voltage. Liquid nitrogen and liquid helium provided staged cooling of the leads with boiling of liquid helium providing the final cooling to maintain the $4 \mathrm{~K}$ temperature and assure superconducting performance. The HVCL was designed and built by STC Sentez and a drawing of the HVCL assembly is given as Figure A - 7 .

Coil Module - A modular construction concept was developed so that future magnet systems could utilize the same tooling yet expand or contract in power and energy capacity by changing the total number of modules. The magnet diameter was selected to be the largest for allowing transportation; the length could then be as needed based on the total number of stackable modules. A coil module consisted of 4-double pancakes with lead clamps and CICC for splicing. Figures $\mathrm{A}-8$ and $\mathrm{A}-9$ provide a drawing of the coil module assembly. A coil module was 12 feet in diameter and about 5 inches thick. All modules were identical except the top module which had a different ground plane insulation lap joint design. Each module had 160 turns of potted CICC and weighed a little less than 2 tons. A unique feature consisted of the ground plane insulation combined with the VPI processing method. It was decided to fabricate the inner and outer ground plane insulation from a laminated build-up of G-10CR strips. These ground plane rings were epoxy bonded 5 layers of strips with lap joints for all the strips. The winding was performed on the inner ground ring and then the outer ground ring was placed around the winding pack and lap joints were epoxy bonded. These ground rings formed an integral part of the VPI tooling and mold. O-ring seals were used to seal the upper and lower VPI tooling plates to the ground rings to form a leak tight mold for the pressurized VPI potting of the assembly. An alternative could have been to wrap the winding pack in glass cloth and pot the entire assembly in a 4-sided mold. With our design, the integrity of the ground plane insulation was assured (and not dependant on the VPI processing and with the risks of holidays or holes) and it reduced the tooling costs. Figure B -3 is an illustration of a coil module in the VPI tooling assembly with the ground plane insulation. Figure $\mathrm{B}-4$ is a CAD illustration of a coil module assembly and Figure B - 19 gives a photo of a completed potted module. The CICC leads are clamped in the clamp block and prepared for splicing. The turn-to-turn insulation was applied and described above. The entire assembly was potted and bonded together to 
provide the structural integrity for handling and more importantly, operational loading. Also, each module was high-pot tested at $5 \mathrm{kV}$ to verify the insulation quality prior to stacking.

Cold Mass Assembly - The cold mass assembly consisted of a vertical stack of the coil modules with CICC busses and with the splices vertically aligned in the splice box and the top and bottom ground plane insulation plated. The coil modules were epoxy bonded together to form a rigid structure with the desired insulation capacity for the high voltage operation. CTD 528 epoxy was selected for this bonding which is an air cured epoxy. Figures A - 10 and A - 11 are drawings of the cold mass assembly showing the stacking arrangement of the coil modules. Figure A - 12 gives an isometric view of the coil with the leads. The completed assembly consisted of 10 coil modules to store up to $100 \mathrm{MJ}$ and provide for low ac loss design for this dynamic magnet system. Again, the magnet was designed for $96 \mathrm{MW}$ at $100 \mathrm{MJ}$ capacity with power exchange of $\pm 50 \mathrm{MW}$ at $0.2-2.0 \mathrm{~Hz}$ and $24 \mathrm{kV}$ terminal-to-terminal voltage. The coil was modular in design so that succeeding designs could be readily fashioned by changing the number of coil modules. The unit was portable (although heavy) so that it could be moved or transported to various sites if needed as the diameter was sized to accommodate shipping. The unit was factory assembled and tested. It was designed to provide low AC losses, low operating costs and operate dynamically. This system was clearly a First-Of-A-Kind magnet device with the largest operating voltage ever built. It was a very large magnet but not a large as some special detector magnets. Figure $\mathrm{B}-6$ provide an additional CAD illustration of the cold mass assembly showing the coil leads and splice zone.

Cryostat - The cryostat was specially engineered to support the coil assembly and provide minimum heat loss. Special support posts made of the composite Ultem 2300 were designed to support the coil weight and qualified for the SSC. Previous tests showed very low thermal conductivity and heat conduction to the stainless support base plate. A liquid nitrogen, LN2, thermal shield was designed using copper sheets and connected with copper braided straps. The MLI consisted of 10 layers with polyester spacers. The vacuum vessel was designed from 304L stainless steel and had access ports for the HVCL, the splice box, instrumentation ports and a man-way for final splicing of the coil leads to the HVCL. System vacuum was maintained with an on-demand vacuum pump and getters were incorporated.

The final completed magnet assembly which included the $10 \mathrm{SC}$ coil modules in the cryostat with the HVCLs was transportable so that it could be shipped to the site and later moved to another site if needed. The final dimensions for the completed assembly were 10 feet high by 14 feet in diameter. The estimated final weight was 35 tons. Figure B -7 provides an exploded CAD view of the final assembly illustrating the final arrangement of the coil on the support base with the vacuum vessel hovering above the unit. Figure B -8 provides a CAD illustration of the closed magnet vacuum vessel.

Other Features - The DC bus and switchgear also provided energy dump resistors for quench energy dissipation and safety and disconnect switches. Specifications were developed for several other key subsystems: 
- Helium Refrigerator System

- Magnet Monitoring and Protection Subsystem (MMPS)

- DC Switchgear and Magnet Protection Subsystem

- Energy Flow Controller (EFC)

To lower costs, the helium refrigerator was a small standard helium refrigerator. The MMPS provided for magnet system control and an interface to AEP's UPFC site control. System status, including magnet status, could be monitored at AEP's main control facility in Roanoke, VA. A block diagram of the MMPS is given in Figure A-13. Figure A 14 provides the Process \& Instrumentation Diagram (P\&ID) for the SMES. Together, these two diagrams illustrate the magnet control system. The DC bus and switchgear and magnet protection system provides the connection and protection to connect the magnet system to the Energy Flow Controller (EFC). The physical arrangement of the SMES equipment at the site building is given in Figure $\mathrm{A}-15$. Given below as Figure 3.2.2.2-3 is an illustration of the electrical connection of the SMES system to the transmission lines Unified Power Flow Controller (UPFC).

Figure 3.2.2.2-3 Sketch of DC Bus and Switchgear and Connection to UPFC

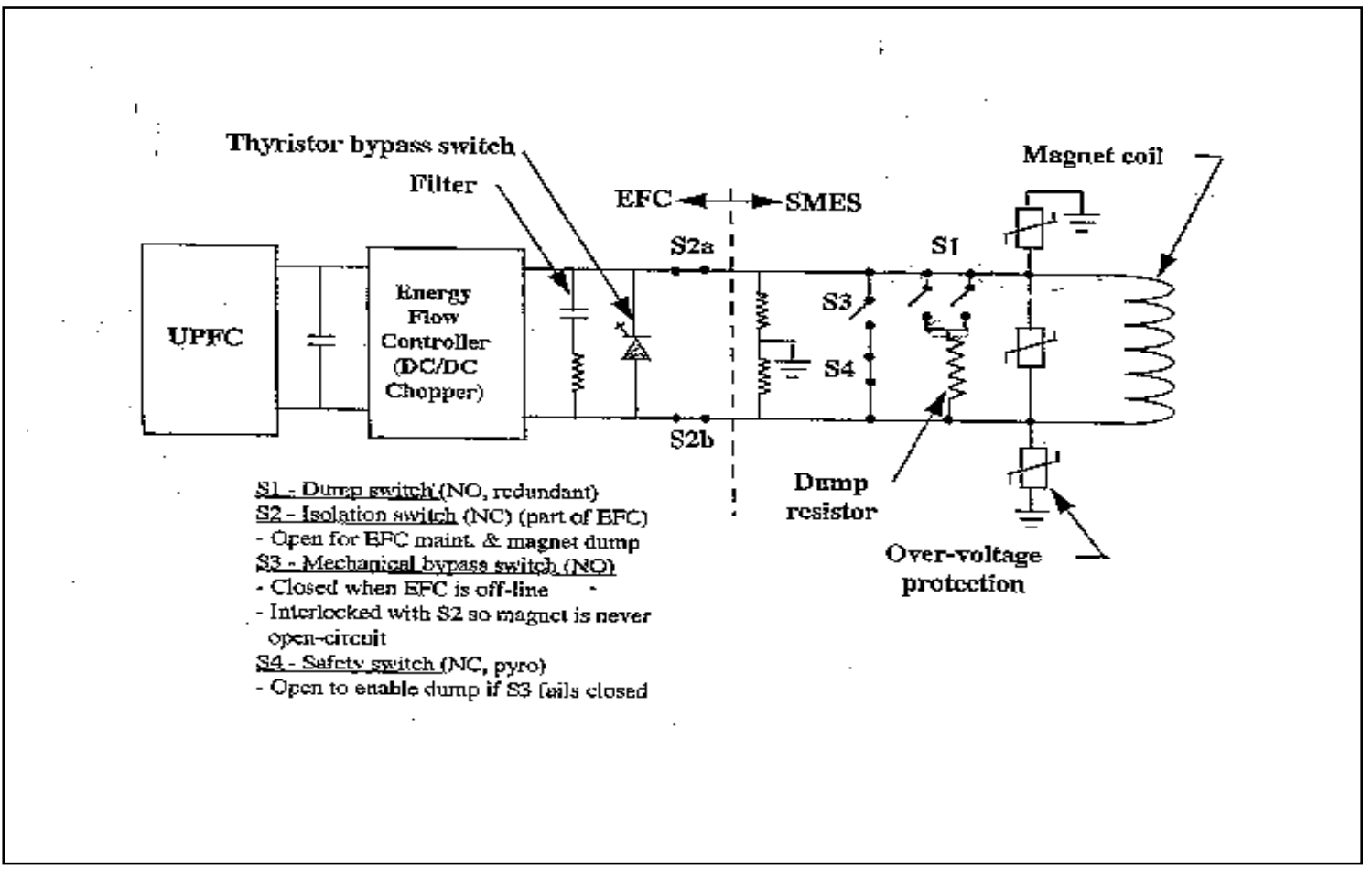

And lastly, a specification and a preliminary design were developed for the EFC. This was a solid state electronic device that served as a DC/DC chopper and interfaced the magnet dc power to the UPFC and the transmission lines. This interface and connection was a major concern to the utility and accordingly, the UPFC manufacturer was instrumental in the design and integration of the EFC. 


\subsubsection{Manufacturing Methods Overview}

The above material provided a summary of the SMES system and product from a design perspective. Integral with the product design was the ability to develop and establish methods, tooling and equipment to manufacture the design. Very high integrity and quality was essential to achieve the demanding performance requirements. Particular attention was paid to cleanliness as particles represented a threat to the insulation integrity. The following tabulation gives the major sequential steps in fabricating the magnet:

\section{BASIC MAGNET FABRICATION OPERATIONS}

- Pull SC cable through $300 \mathrm{ft}$ conduit tubing

- Reduce/Form $300 \mathrm{ft}$, coil on spool

- Weld/Inspect (helium leak) next length

- Complete 1 spool ( 1600 ft)

- In vacuum vessel, Helium Leak Test conductor

- Winding - apply Kapton and glass insulation, wind double pancake (4 dbl pancakes/module) bends, clamps, machining

- Complete mold assembly

- VPI-Epoxy Impregnate coil/mold

- Stack modules, inter-module bond

- Weld conductor/Helium vessel plate

- Splice conductors

- Weld Helium isolators

- Splice lead busses

- Weld helium vessel, helium leak test

- Assemble/epoxy splice box ground insulation

- VPI fill splice box

- Install thermal shield, MLI, Vacuum Vessel

- Attach leads to HV current leads, apply insulation, VPI

The basic, key fabrication operations were splice-free CICC fabrication, coil winding, and coil module potting. For each of these basic operations, a brief discussion, illustrated with photographs will be given. A host of other important operations were developed such as conduit machining for stripping conduit without touching the conductor, conduit bending, conduit welding, conduit-to-splice plate welding, splicing/soldering, wet insulation layups for bus insulation, ground plane insulation bonding, splice box epoxy filling, high voltage feedthrough connections, electrostatic shield application, and helium leak testing.

\section{CICC Fabrication -}

The basic CICC process involved inserting a long superconducting cable into a long, butt welded and inspected tube; progressively tube reducing and roll-forming the tube to smaller diameter using a rolling mill; forming and inspecting the final conduit 
configuration using a 2-stand Turks Head roll former; coiling the conductor onto pay-out spools; and performing final helium leak inspection on the completed CICC. An amount sufficient to wind 1 double pancake was produced for each run. The factory was sized to coordinate the major operations and tooling such that 1 coil module was produced each month; i.e. 1 coil module per month and therefore 1 CICC spool per week. Storage space for many large, round objects was optimized with factory operations. The magnet manufacturing facility was a clean, tile floored, environmentally-controlled building measuring 450 feet long by 55 feet wide and was serviced by two overhead cranes with 5-ton and 25-ton capacity.

A 1,600 foot length of continuous SC cable had to be inserted into 1600 feet of tubing and tube-reduced to final dimensions and this conduit had to be of very high integrity and helium leak tight. A patented process was developed to meet these needs. A folded fabrication line was developed so that this operation could be performed indoors in an incremental fashion. A long table measuring about 300 feet long was used to support the assembly. Three, 100 lengths of tubing were orbital TIG butt welded together to form a 300 foot length; less than 6 of these lengths were produced for each batch. A pressurized plug blowing system was used to feed a fishing line and then a cable through one end. The SC cable was pulled thru the 300 foot length. On each end of the table were large diameter drums for stringing the cable back and forth down the table length so that the SC cable feeding could be done from the same direction. Another 300 foot length of welded tubing was positioned and cable fed from the drums. This feeding continued until the entire length was provided. The tube rolling and forming mill was activated and the first 300 foot length was reduced and spooled. During the tube roll forming, a tensioning system was used to apply tension to the cable to avoid kinking and enable the growth of the stainless steel tube over the copper cable as the dimensions of the tube were reduced. The tubing would "grow" about 15 feet over the cable in a 300 foot run. A loop of the cable was removed from the drum and the tube slid over the excess cable to make a butt joint with the first length. The joint was orbital TIG welded (with special provisions to prevent damage to the superconductor) and helium leak inspected. Then the next 300 foot length was formed. The process continued until the 1,600 foot continuous length was produced. The resulting product was high integrity, formed CICC, on a spool of sufficient length to form one double pancake winding. Two photographs of the CICC manufacturing facility and the 300 foot table are given in Appendix B as Figures B -1 \& 2. These pictures were taken from the middle of the table looking toward each end of the table. Another perspective of the CICC fabrication line is given in Figure B -9 which is a view overlooking the tube rolling mill and down the entire manufacturing bay. The 300 foot long CICC table is seen in the middle of the bay. Production of a helium leak tight CICC made to tight tolerances without any twist (which could jeopardize winding dimension control and VPI mold tooling fit) was critical and a huge, successful achievement. During production, there were no yield losses or failures of the CICC.

\section{Winding -}

The winding operations involved several important steps. The basic sequence is as follows: The winding was done as a double pancake winding starting at the middle of the 
CICC length with the second half of the winding spooled and stored on the winding machine. Figure A - 16 provides a sketch of the winding fixture with a take-up spool. This fixture was attached to a hydraulic scissor table that provided rotation with winding tension control. As the process began, a CICC spool was thread through the orbital tapping head and the layers of Kapton insulation and glass cloth were applied. The orbital rotation was synchronized with the linear feed. The insulated CICC was wound onto a spool on the rotating winding table. At the mid-length of the CICC, the CICC was bent to conform to a G-10 layer transition piece and winding onto the lower mold plate and ID ground plane insulation ring was begun. CICC continuously fed from the supply spool, through the tapping head and was wound into the winding pack. Hydraulic clamps held the winding tight and secure and were automatically actuated to accept the next layer as the table rotated. As the first layer was completed, the excess CICC was cut. The second layer insulated CICC spool was transferred from the winding table onto the payout station. Winding of the second layer proceeded until completion of the double pancake and until a total of 4 double pancakes were wound. After the coil was wound, G-10 lead clamp plates were installed. The CICC was bent to conform to the contour of the clamp plate grooves. The CICC ends were machined to remove the conduit and prepare for splicing. The outer ground plane insulation ring was installed and bonded to the nose block. Constant dimensional checks were performed and continual attention to cleanliness was maintained. After winding, thin bands were wrapped around the winding pack as a safety securing device. The entire assembly was transported to the VPI station. Here, the upper VPI mold plate was lowered into position covering the winding pack. The safety bands were removed and the upper plate lowered into final position. Mold release agents were previously applied to all VPI plates for ease in subsequent removal.

Figures $\mathrm{B}-10$ through $\mathrm{B}-15$ show various views and arrangements during the winding operation. The winding table is seen with the hydraulically actuated clamps. Several views show insulated CICC being stored on the winding table fixture for use in the second layer. The payout station can be seen with both first layer CICC and the glass wrapped $2^{\text {nd }}$ layer CICC. A view showing the first layer winding onto the lower VPI plate and the orbital taping head applying the layer insulation system is also given. Several views of the lead clamp plates and the winding pack are also included. The tooling for hydraulic bending and machining of the CICC is not shown. Operating experience was acquired and the production rate goal of 1 coil module per month was achieved with 1 shift operation and about 2 days of overtime. The complex winding, potting preparation, and CICC lead preparation activities were successfully performed without any yield loss or manufacturing deviations.

\section{Coil Potting -}

The coil module was potted into a monolithic structure to provide structural adequacy and integrity and to complete the insulation system. This was accomplished by preparing and degassing the epoxy, injecting the heated epoxy into an evacuated, instrumented mold, by pressurizing the epoxy to reduce any residual bubble formation, and by resistance cartridge heating the assembly according to a prescribed thermal and pressure cycle to cure the epoxy and providing a controlled cool-down to room temperature. 
Figure $\mathrm{B}-16$ provides a cross-section view of the coil module in the mold tooling showing the arrangement for this potting operation. This was a high risk operation that, once started, must be successfully completed. Precise and uniform temperature control was needed as the epoxy curing is an exothermic chemical reaction which can prematurely block the flow of epoxy if encountered. Epoxy preparation and slow flow rate (injection rate) are crucial. CTD $101 \mathrm{~K}$ was the selected epoxy for which cryogenic mechanical property test results were known and acceptable. The epoxy was degassed and heated in a vacuum system with redundant processing chambers. The epoxy was metered and pumped with a special electric motor/pump, but an auxiliary inert gas pumping feature was provided in the event of an electrical failure.

The mold and tooling was prepared for the epoxy operation. Initially, mold release agent was applied to all surfaces contacting the epoxy. Provisions were incorporated into the tooling for injection access ports and hydraulic jacking ports for removal. The steel tooling plates covered the top and bottom of the module while the G-10CR ground plane insulation rings covered the sides. Tooling provisions for covering the CICC leads which extended through the mold tooling were made. "O" ring seals were used to seal the mold. Numerous bolted clamps were used to clamp the mold assembly. After mold completion, a helium leak test was performed on the mold to assure it to be leak-tight and adequate to prevent epoxy leakage and to provide epoxy pressurization to 5 bars. A drawing of the potting mold clamp fixture is given in Figure A - 17 which illustrates the clamping arrangement. Drawings of the lower and upper VPI tooling plates are given in Figures A -18 \& 19. Thermocouples and pressure gages were attached. Numerous $1.5 \mathrm{~kW}$ electric cartridge heaters were installed into receptacle plates and attached to the tooling plates. Clear Tygon tubing was used to connect all of the epoxy inlet and outlet ports. Insulating blankets were wrapped completely around the mold assembly to reduce heat loss and clear plastic drapes were installed to reduce convection heat losses. The mold assembly was evacuated using a portable vacuum pump system and leak rate tested. The mold was resistively heating to the starting temperature of $90 \mathrm{~F}$ and the mold was again helium leak tested. The heated and degassed epoxy was slowly injected into the mold. It took almost 24 hours to fill the mold assembly. Once filled, the mold was pressurized to collapse any remaining bubbles and the curing cycle was initiated. The heat-up, 2 hold levels, and cool-down required about 1 week to complete. Figures B -17 and B -18 are photographs showing the insulated mold assembly in preparation for the epoxy injection and curing operations. Emergency backup power was available. Once the VPI process was initiated, 24-hour supervision was required. All potting operations were successfully completed and no yield losses were experienced. Again, the mold preparation, potting and removal required about 1 month to complete. To conclude, it should also be mentioned that each coil module was voltage withstand tested to $5 \mathrm{kV}$ terminal-toterminal. (This was considered the maximum safe test voltage level to assure adequacy (2 $\mathrm{kV}$ is the operational value) while assuring that the test itself did not damage the module. The tested insulation system demonstrated $30 \mathrm{kV}$ after full life cycle.)

Figure B - 19 provides a photograph of a completed, potted coil module being handled. Handling procedures were developed to assure that the insulation was not damaged in the final product. The size of the completed coil module is apparent from the personnel 
performing the operation. Each coil module was about 5" thick, $12 \mathrm{ft}$. in diameter and weighed just less than 2 tons. The coil modules were stacked, one on top another, to build and complete the magnet's cold mass assembly. Each module was to be bonded to the next using an air cured epoxy for the final assembly.

\section{Other Operations -}

Numerous other manufacturing operations were developed and implemented to achieve the SMES manufacturing capability. Operations like inventory control, inspections, audits, quality control, handling, helium leak testing, high voltage testing etc. etc. were implemented. CICC splicing was the other key skill operation developed and successfully implemented. The cable twisting, organizing, and soldering operations were developed, implemented and ultimately qualified by testing. A discussion of these details is not provided in this summary report. It suffices just to say that an industrial capability was established, qualified and operated to successfully and efficiently manufacture the large SMES superconducting coils and magnet system.

\subsubsection{Key Test Results Summary}

Several key tests were performed on mockups or product to assess the quality of the design and/or the manufacturing processing. A summary of the key tests and the major results are given below. Detailed data and descriptions will not be given - only the major summary. All test results demonstrated a system design, with margin, that exceeded all specification requirements.

- Superconducting Wire - The specification for each spool of superconducting wire required in magnetic field critical current testing and minimum acceptable values. A minimum of 121 Amperes was required at $4 \mathrm{~K}$ and 5Tesla perpendicular magnetic field. All SC wire produced and tested conformed to and exceeded the critical current test requirement. The minimum tested critical current for the entire production was 128 Amperes, well exceeding the specification minimum and assuring exceptional superconducting performance.

- 4x5 Stressed, Full Life Cycled Insulation Test - Because of the criticality of the insulation integrity, a special mockup was fabricated and tested. Here an array of 4 layers of 5 CICC conduit tubes were insulated with the production methods and spacers added as needed to fill the cavity. The 0.5 " thick G-10CR ground plane insulation was fabricated and 2 typical lap joints epoxy bonded, were made. Grounded conductive electrical shield was applied to the exterior along with voltage stress relief rings on the ends. Figure $A-20$ gives a drawing of the $4 \times 5$ mockup and Figure B -20 provides and cross-sectioned view of the tested mockup. After preparation of the mockup the testing sequence involved full life thermal and cyclic mechanical stressing applied to the assembly and then voltage withstand testing to failure. Five temperature excursions were made to LN2 temperatures to represent the thermal stress and full life thermal cycling expectations. Cyclic, 3-point bending was applied for 5 times the design life at the maximum design operating stress. This cyclic, fatigue load was applied along 
with the thermal cycling to verify that insulation cracking and growth would not degrade the magnet or the insulation. DC voltage was applied between the conduits and ground and between several conduits. In other words, the turn-toturn breakdown voltage was measured and the turn-to-ground breakdown voltage was measured. For reference, and from other tests, dry wrapped (i.e. Kapton + glass tape but without epoxy) conductor to conductor tests showed a withstand voltage of $68 \mathrm{kV}$ ! - This value is compared to a maximum turn-to-turn operating voltage of 14 volts! The insulation was clearly robust but the withstand magnitudes also show the criticality of the turn to ground insulation. The mockup test and results confirmed the adequacy of the design and application and easily exceeded the design requirements. The following are the results after maximum stress, full life cycle testing:

1. Minimum Turn-To-Turn Withstand Voltage at failure: $\quad 30 \mathrm{kV}$ The turn-to-turn design requirement was $5 \mathrm{kV}$

2. Minimum Turn-To-Ground Withstand Voltage at failure: $96 \mathrm{kV}$ The turn-to-ground design requirement was $45 \mathrm{kV}$

Again, these insulation test results demonstrate a vigorous design with margin that greatly exceeds design requirements.

- Splice Box and HVCL Ground Plane Insulation Mockups - Mockups of both of these assemblies were made to develop the manufacturing process and provide evidence that the process met the stringent voltage withstand requirements. Here, G-10CR pieces were fabricated in a variety of shapes and the lap joint design, previously tested was used to bond the ground plane insulation pieces together. The splice box contained the splice joint and vessel, the helium isolators and penetrations for voltage taps and thermocouple leads; the box was filled with air curing epoxy and the lap joints epoxy bonded. The HVCL had various tubular shapes and high voltage gas isolators for liquid N2 and helium. Drawings showing the insulation configuration for both these mockups is given in Figures A -21 and $A-22$. Both these mockups were assembled and voltage withstand tested. A photograph of the HVCL mockup in the test stand is given in Figure B -21 . The results were inconclusive as both assemblies were tested to $100 \mathrm{kV}$ and no failures were obtained. The voltage withstand capability for this design exceeds $100 \mathrm{kV}$.

- HVCL Voltage Withstand and Heat Loss Test - The HVCLs were critical components providing the main DC electrical connection between the superconducting magnet and the exterior, ambient environment. The operating heat loss was very important as the junction from the copper bus to the superconductor had to be maintained at $4 \mathrm{~K}$ for stability of the superconductor and the heat loss magnitude determined the size, and cost, of the helium refrigerator. Tests were performed on the HVCL to demonstrate conformance to the specification. The voltage withstand was tested to the specification requirement and the HVCL met the requirement. Additionally, the unit was operated at $4 \mathrm{~K}$ and 4,000 amperes and the heat leak measured. At these conditions, with 0.46 
$\mathrm{gm} / \mathrm{sec}$ He flow, the heat flux measured was 8.34 watt; below the specification requirement of 10 watt heat flux at full operating current. The HVCL were performance tested and the unit met and exceeded the specification requirements.

- CICC Conductor and Splices AC Loss and Stability Tests - Perhaps the most crucial testing consisted of performance testing the CICC and the two splices at temperature, full current, in a perpendicular magnetic field at high ramp rates or rates of magnetic field change. These tests were designed to assess the acceptability of the superconducting system for stability and quench avoidance in a rapidly changing magnet field and to assess the design for low AC loss characteristics. This SMES magnet was a dynamic magnet design for large, alternating power exchange in the $1-2 \mathrm{~Hz}$ range. AC losses were the critical design feature of the $\mathrm{SC}$ cable and compact twisting and interstrand resistance were key design features. These tests were conducted to verify the adequacy of the design for $\mathrm{AC}$ losses in high ramp rates and stability in high ramp rates. A 1meter long assembly was fabricated using the construction methods and materials. There were 2 lengths of CICC. One end connected the 2 CIC conductors using a CICC splice joint assembly. Each of the other 2 ends contained a HVCL bus to CICC splice joint. So, this test article contained all the SC splice joints and 2, 1 meter lengths of production CICC and was tested for stability and AC losses at high magnetic fields and high ramp rates. Figure $\mathrm{A}-3$ and $\mathrm{A}-4$ are drawings of the test article. Figure B -22 is a photograph of the completed test assembly.

The results of these tests were separately reported and are complex. Tests were preformed at full current $(4 \mathrm{kA})$ in perpendicular magnetic fields with strengths of up to 4 Tesla with ramp rates up to 2 Tesla per second using triangular wave forms. All the conductors and the splices were stable and no quenching was observed. The stability of the system's superconducting design was confirmed by this test. Some of the test results are given in Figures B - 23 and B - 24 .

Additionally, the $\mathrm{AC}$ losses were low and were less than $1 / 3$ of the design value. An AC loss exponent, $\mathrm{n} \tau$, of $50 \mathrm{~ms}$ was the conductor design target value and a test result achieved was $12 \mathrm{~ms}$ (some of these results are given in Figure B - 24). The actual measured ac losses for this design exceeded the design goal (by $3 \mathrm{X}$ ) and were proven sufficiently low to meet the performance goals. Measurements of the interstrand resistances were made and high values were achieved indicating minimal interstrand bonding and minimal interstrand current transfer. All of these measurements showed an acceptable low loss conductor design. The SMES conductor and splices were performance tested in an AC magnetic field environment and the test results exceeded the design requirements by a factor of 3 , proving the stability and adequacy of this design.

- 8x20 (Full Section) VPI Process Development Mockup - It was necessary to develop and verify the tooling and methods for successfully fabricating the coil modules. A crucial element was the VPI tooling and VPI potting procedure. To acceptably demonstrate our methods, a mockup representing a full size crosssection of a coil module, but with smaller length to reduce costs was established. 
This mockup served to qualify the processing and tooling prior to VPI potting the production coils. A representative assembly was established and this mockup contained 8 layers with 20 rows per layer of insulated CICC. This is the exact arrangement of an actual module. Real CICC was used as the mockup was instrumented and the thermal response was determined, so the identical mass and conductivity was used by using actual conductor. The mockup served to confirm the VPI process, tooling adequacy, end fitting for CICC feedthrough, lead clamp plate bonding, epoxy flow, fill and uniformity, presence of bubbles, and mold integrity. This mockup was known as the $8 \times 20$ mockup. The mockup was fabricated and the tooling and procedures were used to successfully vacuum pressure inject the epoxy and cure the epoxy. Voltage withstand tests were performed after completion. The completed mockup was sectioned and examined for epoxy quality. Complete and uniform epoxy fill, without bubbles, was achieved. The adequacy of the approach was verified.

Figure $\mathrm{A}-23$ and $\mathrm{A}-24$ provide drawings of the $8 \times 20$ mockup and provide the sectioning plan. A photograph of the completed mockup with a cut out section is given in Figure $\mathrm{B}-25$. The overall quality of the potting is readily evident.

- Proof Test - A final test of the SMES electrical configuration was conceived and named the Proof Test. It was designed to provide the final proof of the adequacy of the insulation system design. For this test, all the components and their configuration (except for the coil) that was exposed to the high voltage terminals was to be voltage-withstand-tested, in vacuum, after 3 LN2 temperature excursions from room temperature. The cyclic stresses resulting from these thermal cycles were to stress the electrical insulation in a realistic fashion. All of the components with an electrical connection to the magnetic coil were included in the test configuration, including the instrumentation. The test included the insulated High Voltage Current Lead, the insulated lead bus, with splices, connecting the HVCL to the splice box and coil, the splice box, the helium isolators, the voltage tap wires and feedthroughs, the high voltage isolators/feedthroughs through the vacuum system, and the system ground screen. Ground screen conductive epoxy was applied to all components except the instrumentation wires. Figure $\mathrm{A}-25$ provides a drawing of the test configuration showing the major components. The HVCL and test assembly was connected to a liquid nitrogen supply. The entire test was assembled inside the vacuum vessel so that vacuum could be applied. Figure B - 26 is a photograph showing the vacuum vessel and some of the test components. The system was evacuated and the liquid nitrogen was used to cool the assembly to LN2 temperatures ( $\sim 80 \mathrm{~K})$, then room temperature nitrogen was used to warm the assembly back to room temperature. Three thermal cycles were applied to simulate the actual thermal stresses and to stress the insulation system. After the third thermal cycle and while at LN2 temperature, voltage was slowly applied from terminal to ground (vacuum vessel was grounded) and the leakage current was monitored. 
Because of the system's circuit design, the maximum voltage designed from terminal to ground was limited to $14 \mathrm{kV}$. The design value was $45 \mathrm{kV}$ for margin enhancement reasons but the actual operating maximum voltage terminal to ground was $14 \mathrm{kV}$ (and $24 \mathrm{kV}$ terminal-to-terminal).

The system test result was as follows: The applied voltage was increased until a failure or leakage current was obtained. The test recorded a failure at $25 \mathrm{kV}$. This value greatly exceeded the maximum operating point but was well below expectations. Since the test result greatly exceeded the operating maximum, the test was declared successful and proved the adequacy to the insulation system and the SMES design.

A failure analysis was performed to determine the cause of failure so that the design could be strengthened for future use. The failure point was finally located and it was a failure of the voltage tap instrumentation wire located about 10 feet from the flange feedthrough. The wire insulation failed which permitted current leakage and eventual arcing. The test could not be continued by removing the wire due to technical and financial limitations. A review of the voltage tap wire showed that the wire specification was for $35 \mathrm{kV}$ voltage withstand. The failure was reviewed with the supplier where it was learned that a mix-up had occurred and that a $20 \mathrm{kV}$ type insulated wire had been mistakenly supplied.

Much was learned from this test. In the final review, the proof test was successfully concluded and the adequacy and robustness of the SMES system's insulation design was proven. The test results verified the acceptability of the design. So, for the two critical design features, the stable, low loss conductor design for the dynamic, cyclic high power magnet, and the insulation integrity for the very high operating voltage; confirmation of the successful design and construction was achieved and verified.

\subsection{Center for Advanced Power Systems and Demonstration Conclusion Period}

\subsubsection{Program \& Administrative Overview}

As discussed in Section 3.2.1, completion of the AEP demonstration was in jeopardy. The uncertainties created by the deregulation policies, practices and environment at the time produced future business uncertainties which thwarted investment and needed additional financial support. A budget shortfall was developing as projected project expenses were forecast to exceed funding. With the expenses exceeding the budget and with no additional sponsors or sources of financial support, the AEP demonstration had to be reconfigured and an alternative project arrangement found.

All the project stakeholders were solidly behind the project and well pleased with the technical progress, the system design and the planned demonstration. A search was undertaken to find an alternate approach or an additional sponsor. The project was encouraged to find a less ambitious application and demonstration so that a SMES demonstration could be completed and the technology gains achieved to date proven 
useful and the technology made available for future application when the business and deregulation conditions stabilized and improved. A new host, offering a new solution, was identified. Florida State University is the host of two unique organizations which contribute to making FSU a very good and qualified site for continuing the demonstration(s). The first one is the National High Magnetics Field Laboratory which is fully staffed with superconducting magnet technical experts and which operates major magnet test facilities, including large infrastructure in test facilities, engineering design and analysis, high power electrical grid connection, and cryogenic facilities. During test operations, huge power demands for short durations are made as the large magnet systems are tested. The effects on Tallahassee Electric's transmission line is destabilizing with power quality concerns and provided a prime factor in NHMFL's utility expenses, (due to the demand surcharge). A SMES could be connected and tested as a power source providing peak power shaving and the power quality impact to the Tallahassee Electric's Ring bus could be assessed and minimized. This existing SMES unit was of sufficient size and capacity to met or exceed the application needs to be useful. Also as mentioned, this facility was fully equipped and staffed with expertise that could assist with magnet implementation and test operations. The second unique organization is a newly created $\mathrm{R} \& \mathrm{D}$ organization that was developed in response to dwindling national resources in electrical engineering and Navy research and development needs. The Center for Advanced Power Systems (CAPS) was established as a consortium of 4 southern universities (led by Florida State University at Tallahassee which also included the University of South Carolina, the University of Texas at Austin and Mississippi State University) and was located on the campus of Florida State University, adjacent to the NHMFL. Resource sharing was an asset and the technology was a boost to the primary objective of advanced education and training in electrical engineering. Co-sponsored R\&D projects were directed to CAPS. The CAPS facility could become an ideal testing location offering a variety of test configurations and applications, including transmission line stabilization application and testing. Included in Figure B -27 is a schematic illustration of a proposed test configuration at CAPS. Test operations would support the education objectives and the technology supported the interests of sponsors such as the Office of Naval Research.

Contacts were made with CAPS personnel and a mutually beneficial program began to emerge. Further discussions culminated in developing a "Collaborative Research Agreement" between BWXT and FSU (representing CAPS). The SMES demonstration site would be relocated to the CAPS facility and the demonstrations were expanded in scope to include additional testing. BWXT would finish the cold mass fabrication, relocate the fabrication equipment and inventory to CAPS, and provide engineering documentation and training. CAPS would complete the magnet assembly, install all the ancillary equipment such helium refrigerator, monitor and control system, quench protection, interface power electronics and complete the SMES system integration and demonstration testing.

This approach for completing the SMES demonstration project was discussed and reviewed with all the project stakeholders, including the DOE. It was decided that this was an acceptable and worthwhile approach. Although there were risks of schedule 
delay, postponement or even incompletion, it was judged a more desirable approach (i.e. continuing) and risk than stopping in place having little hope of completing any demonstration. In other words the potential benefit of a successful demonstration was judged more worthwhile than the certain loss of just stopping and not completing the demonstration objective. With all parties in agreement with this go forward approach, a revised proposal for the workscope and demonstration was prepared by BWXT and submitted to DOE for approval. This proposal was accepted and the Cooperative Agreement between BWXT and DOE was amended in December, 2001, to incorporate the BWXT proposal to change the SMES demonstration host site to CAPS/FSU and accordingly revised the scope of work.

With this new working arrangement, BWXT continued the fabrication of the coil modules comprising the cold mass. To reduce costs, it was decided to complete the fabrication of the magnet and SMES system at CAPS. The industrial facility established for large magnet fabrication would be reconfigured at CAPS and retained as a domestic facility with the capability to be used to support other national, CAPS or NHMFL fabrication needs. To aid in the transition, a technology transfer was undertaken where, on several occasions, CAPS technicians visited the Lynchburg facility and were trained on all on-going operations for use of equipment and operating procedures and methods. All the inventory of materials and fabricated product was to be transferred. With the completion of 7 coil modules and 2 double pancakes of CICC, production operations at Lynchburg were suspended and terminated. All the product, inventory, equipment and tooling for production of the SMES magnet were prepared for shipment. In June, 2003, a truck convoy transported these items to the CAPS facility.

CAPS personnel began the indoctrination of the technology and the reassembly of the production equipment. However, sponsors of CAPS' operations soon changed their testing priorities from the SMES to a newly-produced superconducting generator and a superconducting motor. CAPS resources were redirected to support these new priorities. Without financial support from their sponsors and the continued technical focus on these other technical advancements, the SMES efforts were delayed, and eventually abandoned. The SMES demonstration project ended, due to lack of support, with no further advancement. The SMES project's demonstration goals and objectives were not completed; leaving stranded the unique and special magnet hardware and facilities from the SMES commercialization endeavor.

\subsubsection{Key Technical Accomplishments and Conclusion}

Few technical accomplishments were made by BWXT during the final period of the project as planned. By agreement with CAPS, BWXT's responsibilities were primarily to complete the fabrication of the superconducting coil modules, provide technology transfer of the SMES design and manufacturing methods, train CAPS technicians in manufacturing procedures and methods and equipment/tooling operations, ship all magnet system product to CAPS, ship all manufacturing equipment and tooling and provide on-going technical assistance as needed to support future CAPS' operations. CAPS was responsible for completing the fabrication and assembly of the magnet, 
completing the assembly of the SMES system (cryostat, helium refrigerator, instrumentation and control, EFC, protection system, and interface), system acceptance testing, connection to the Tallahassee Electric Ring Transmission Line and local facilities/equipment, and documentation and demonstration of the SMES system operation and reporting. The CAPS facility was an excellent site for completing the demonstration of the SMES technology. In addition to the technical resources of the adjacent National High Magnetic Field Laboratory (NHMFL), the testing opportunities were abundant. The SMES system could be connected to test a variety of configurations and applications. The transmission line stabilization demonstration could be preserved and performed with a connection to Tallahassee Electric's transmission line, known as the $115 \mathrm{kV}$ Ring Bus which serviced the Tallahassee area and the FSU, NHMFL and CAPS. The ongoing NHMFL magnet testing operations were notorious for power sags and disturbances on the Ring Bus due to the sudden large loads and often pulsed loading. The Tallahassee transmission line was much smaller and of less capacity than the AEP system but the testing capabilities and variety were much greater. As a system demonstration and test site, more flexibility was available than with the higher reliability demands of the AEP site with less risk. A schematic of a proposed arrangement for the SMES demonstration and testing is given in Figure $\mathrm{B}-27$.

BWXT successfully completed all the agreed upon activities. The fabrication of the coil modules was completed and each coil module was in a stable, protected condition. Two (2) spools (sufficient for 2 double pancakes) of completed CICC were produced and ready for winding. Several technical exchange meetings were held with the technical representatives of the BWXT and CAPS organizations. Here, the technical approach and plans were discussed and technical information exchanged. Copies of specifications, design drawings and various analytical calculations were provided. Copies of tooling and equipment drawings were provided along with copies of processing procedures. On several occasions, technicians from CAPS visited our production facilities while we were in full operation and these technicians examined, and were instructed in, the details of the fabrication procedures and the use of tooling and equipment. A technology transfer of the technical design and the manufacturing methods and equipment was successfully completed. With CAPS personnel skill and the training and specific knowledge acquired from our operating facility, CAPS personnel were well equipped to re-establish operations at their site.

All the manufacturing equipment and tooling was prepared for transport to CAPS. Also, all of the completed product ( 7 completed modules plus all fabricated items) and the entire inventory were prepared for shipment. On June 23, 2003, a convoy of 8 trucks left the Lynchburg facility for transport of all the material to CAPS. This successfully completed the transfer to CAPS for the completion of the SMES demonstration project.

\subsection{Products Developed and Technology Transfer Activities}

Product Developed - A SMES magnet system was developed under this agreement. The form, fit and function of the product has been described above. The unit is designed and built to provide $96 \mathrm{MW}$ of instant electrical power and can store $100 \mathrm{MJ}$ of electrical 
energy. It is modular in design which enables future size and capacity changes without the added costs of tooling changes and, it is portable to enable relocation to support needs at different sites. However the integration with a utility's transmission line has not been demonstrated. Therefore, this product should be labeled as developed, but not tested or verified.

Technology Transfer Activities - The technology and the manufacturing equipment has been transferred to the Center for Advanced Power Systems located at Florida State University. Specifications, design drawings and analyses, and plans have been shared with technical specialists at CAPS. CAPS technicians have been familiarized and trained in the operations of magnet fabrication and the operating procedures have been provided. The physical equipment and tooling, along with the product and inventory has been shipped and relocated to the CAPS facility.

Patent Activity - Much technical innovation was incorporated into the system design to provide the robust insulation system and the low cost, low loss, CICC superconducting cable. Most of those technical advancements were identified above. Additionally, several US patents were conceived and awarded from this work. The following is a list of patents obtained by BWXT:

\begin{tabular}{|c|l|l|}
\hline US Patent No. & \multicolumn{1}{|c|}{ Title } & \multicolumn{1}{|c|}{ Date Issued } \\
\hline $5,718,034$ & $\begin{array}{l}\text { Aluminum Stabilized Superconductor } \\
\text { Supported by Aluminum Alloy Sheath }\end{array}$ & February 17, 1998 \\
\hline $5,661,646$ & $\begin{array}{l}\text { Multi-Phase DC-DC Chopper with Different } \\
\text { Number of Phases }\end{array}$ & August 26, 1997 \\
\hline $6,583,351$ & $\begin{array}{l}\text { Superconducting Cable-In-Conduit Low } \\
\text { Resistance Splice }\end{array}$ & June 24, 2003 \\
\hline $6,671,953$ & $\begin{array}{l}\text { Folded Fabrication Line for the Production of } \\
\text { Cable-In-Conduit Conductors (CICC) }\end{array}$ & January 6, 2004 \\
\hline
\end{tabular}


Final Report - DOE Agreement No. DE-FC36-94G010011

Commercialization Demonstration of Mid-Sized Superconducting Magnetic Energy Storage Technology for Electric Utility Applications

APPENDIX A - Selected Drawings and Sketches

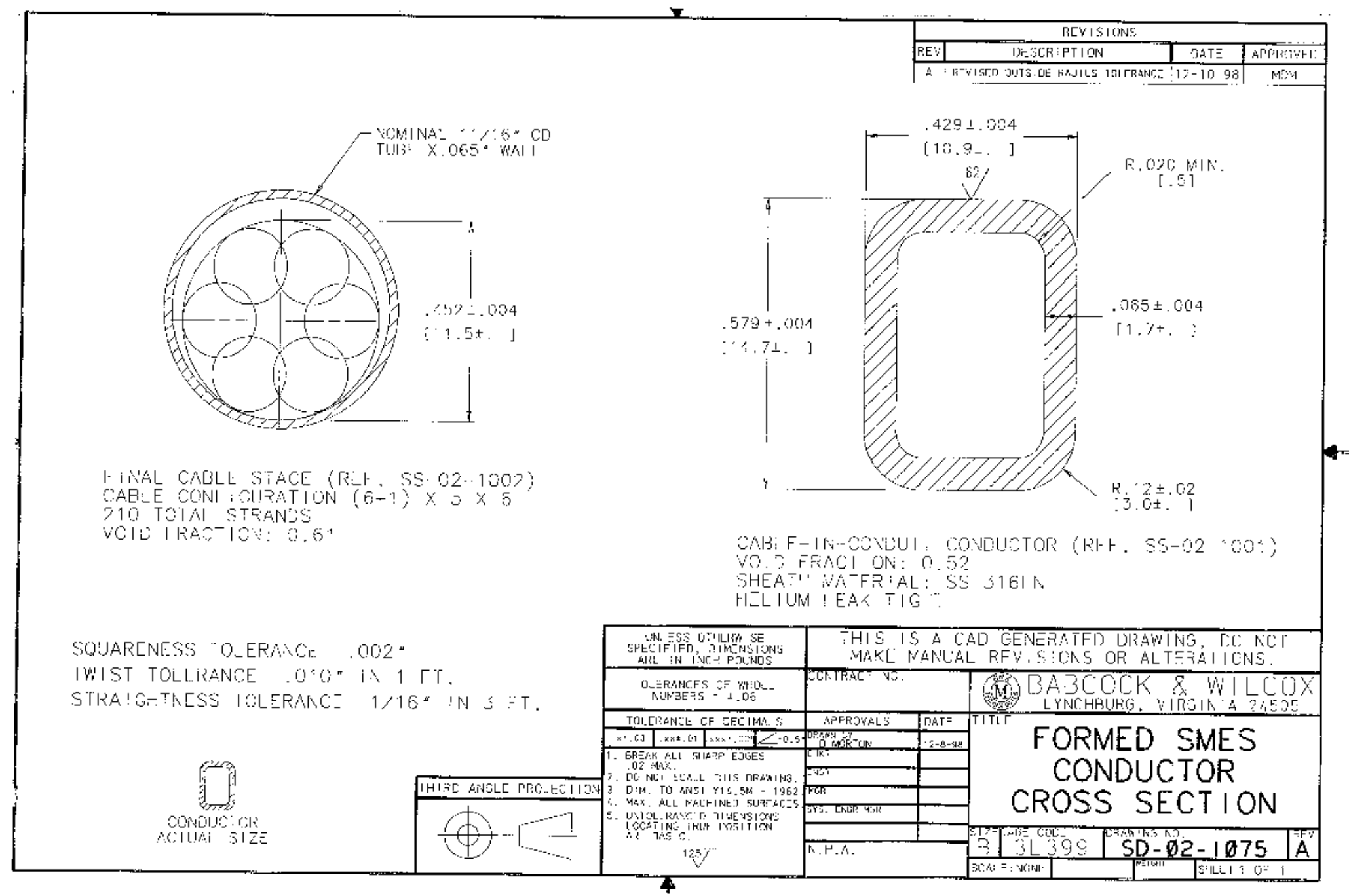

Figure A - 1 Drawing of SMES CICC Conduit 
Final Report - DOE Agreement No. DE-FC36-94G010011

Commercialization Demonstration of Mid-Sized Superconducting Magnetic Energy Storage Technology for Electric Utility Applications

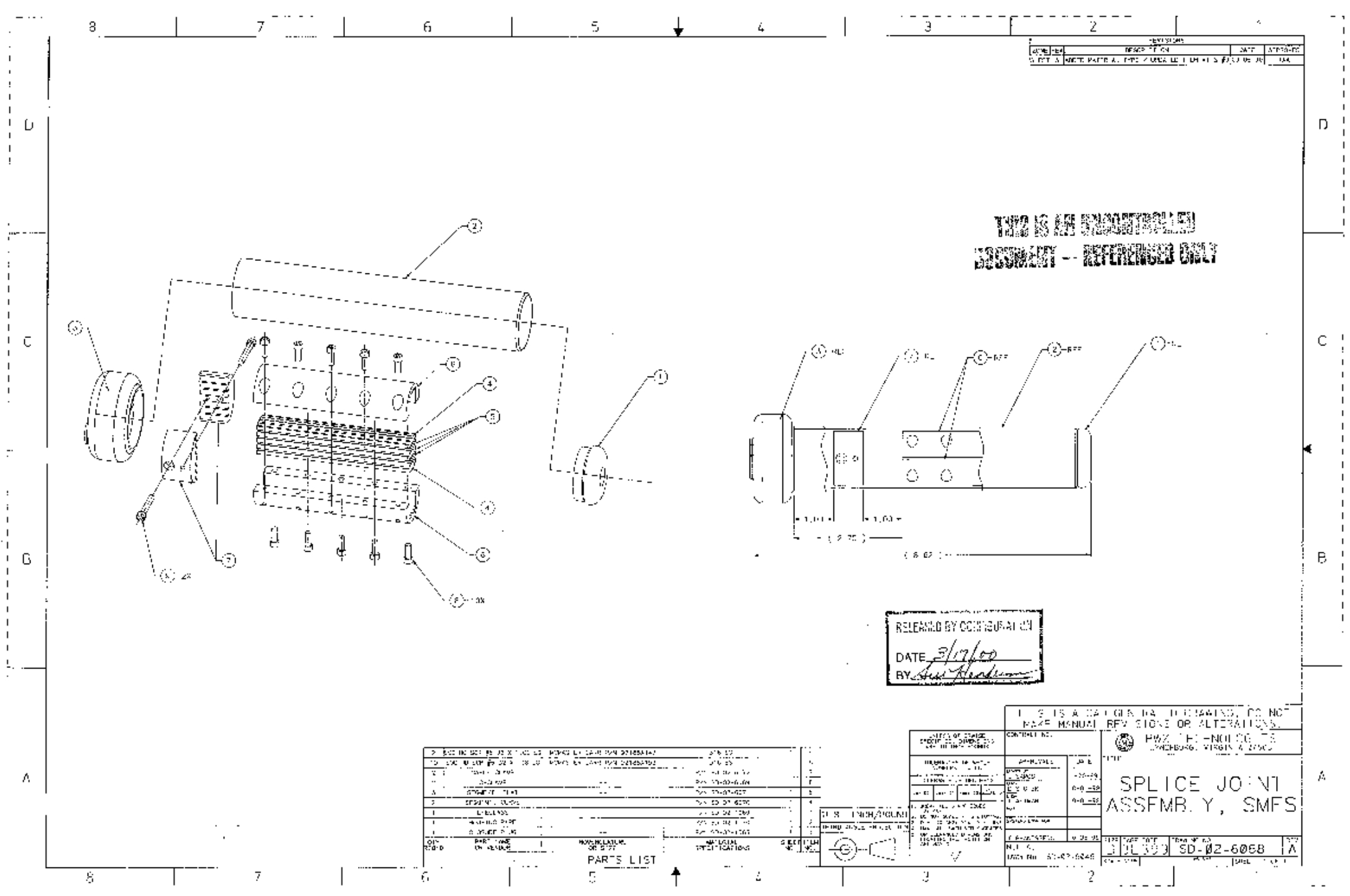

Figure A - 2 CICC Pancake Splice Joint Components 
Final Report - DOE Agreement No. DE-FC36-94G010011

Commercialization Demonstration of Mid-Sized Superconducting Magnetic Energy Storage Technology for Electric Utility Applications

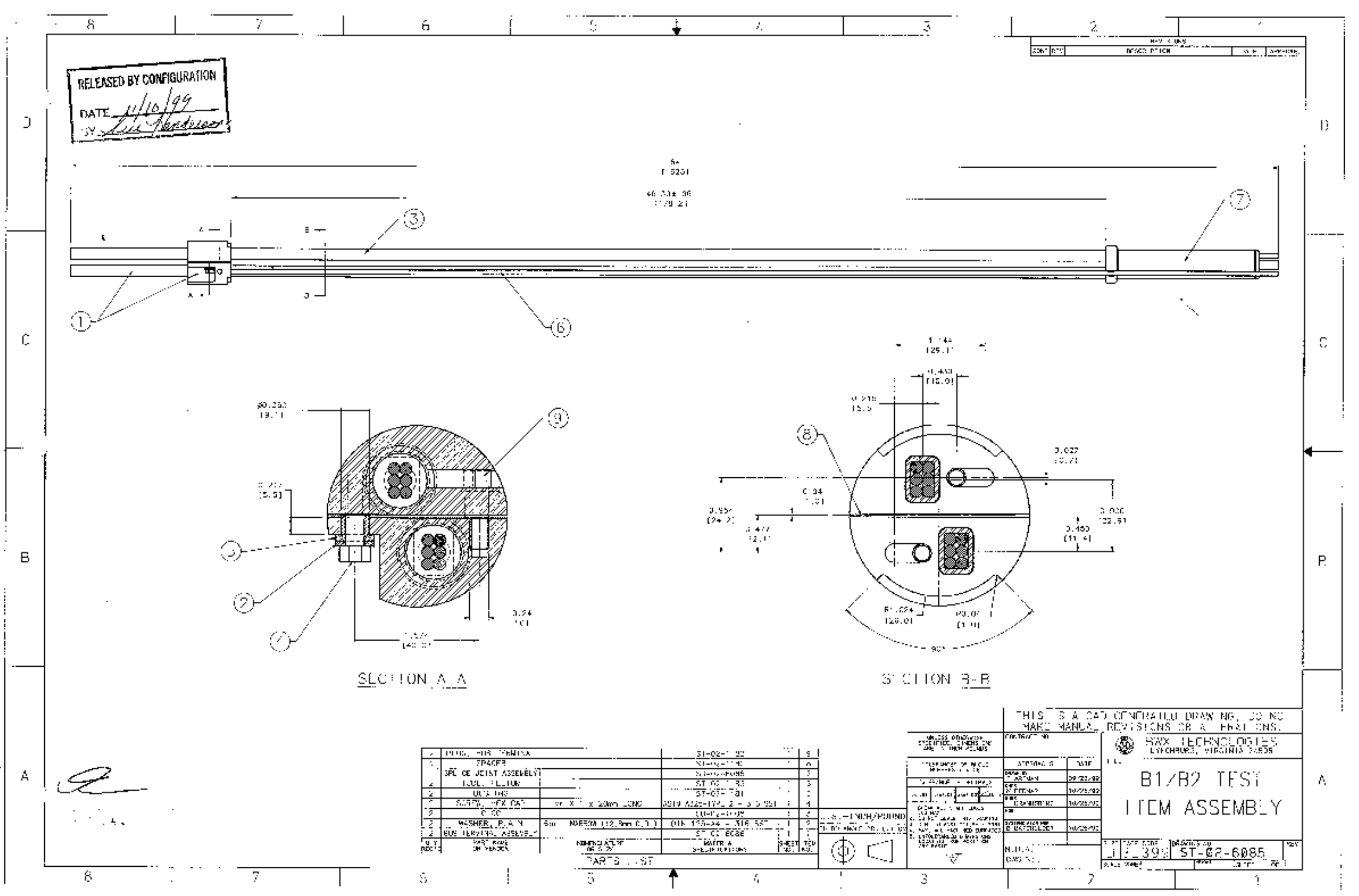

Figure A - 3 Conductor and Splices Test Assembly - Part 1 
Final Report - DOE Agreement No. DE-FC36-94G010011

Commercialization Demonstration of Mid-Sized Superconducting Magnetic Energy Storage Technology for Electric Utility Applications

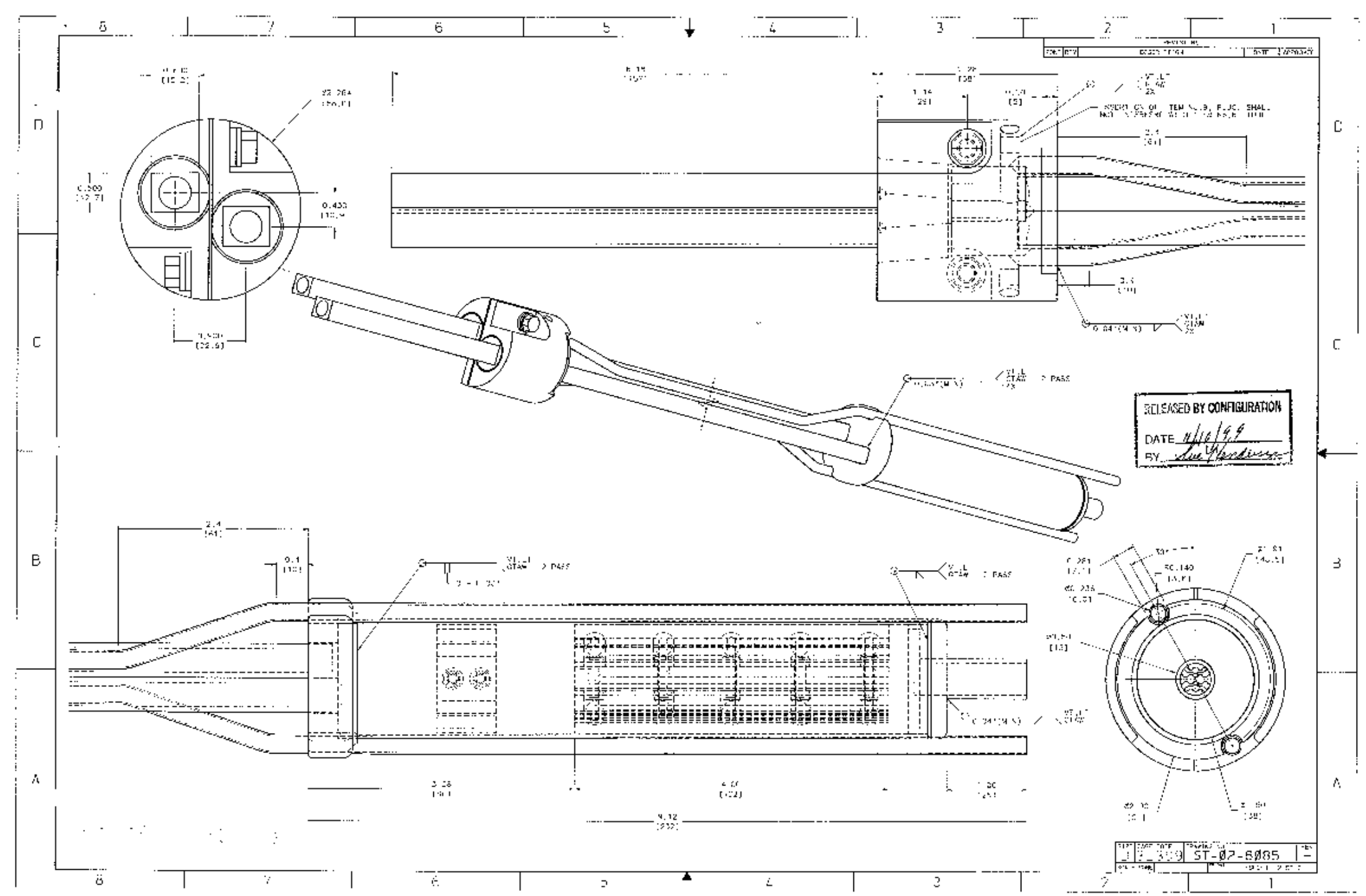

Figure A - 4 Conductor and Splices Test Assembly - Part 2, Illustrating Pancake Splice Joint Design 
Final Report - DOE Agreement No. DE-FC36-94G010011

Commercialization Demonstration of Mid-Sized Superconducting Magnetic Energy Storage Technology for Electric Utility Applications

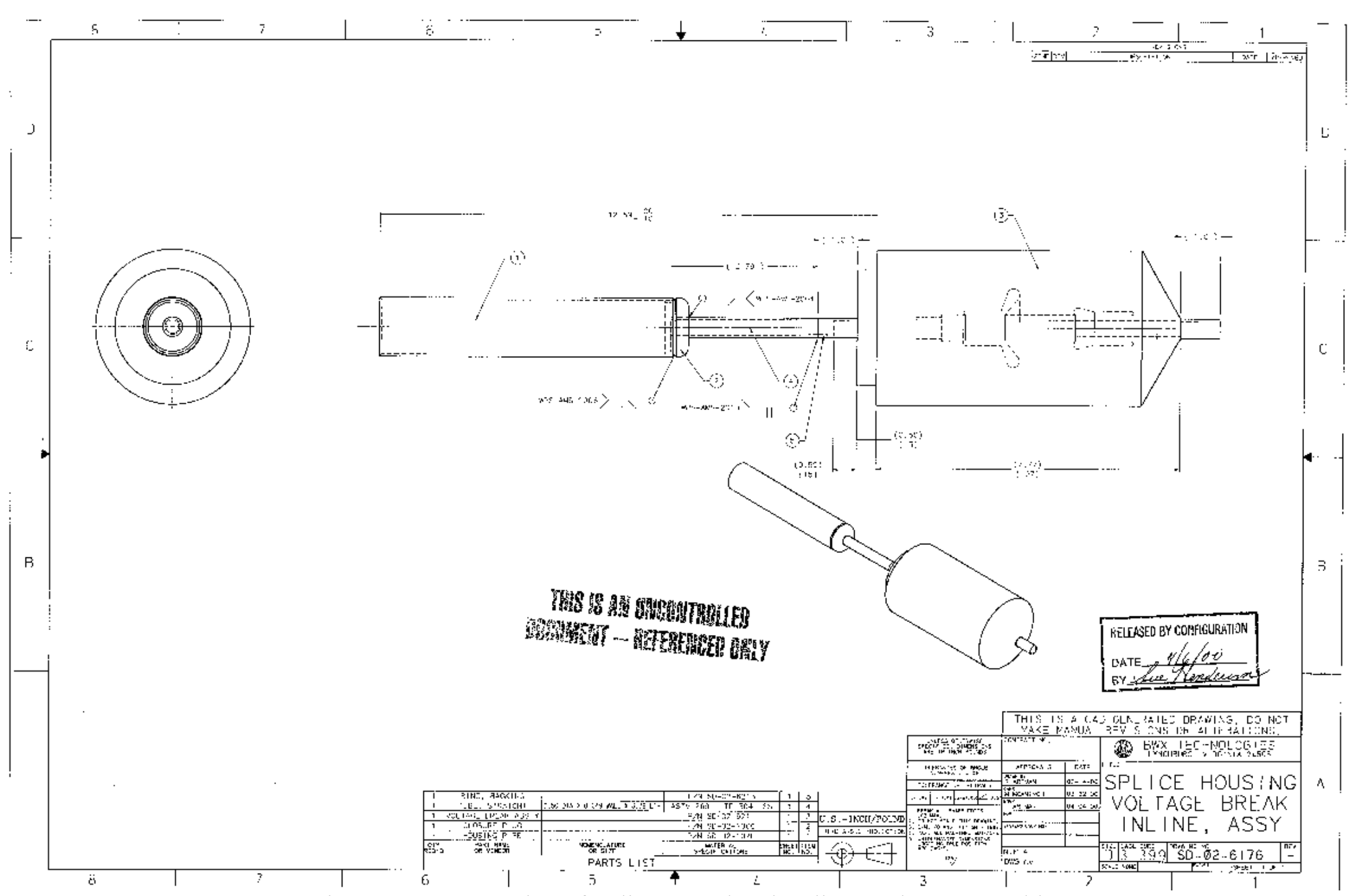

Figure A - 5 Drawing of Splice Vessel and Helium Isolator Assembly 
Final Report - DOE Agreement No. DE-FC36-94G010011

Commercialization Demonstration of Mid-Sized Superconducting Magnetic Energy Storage Technology for Electric Utility Applications

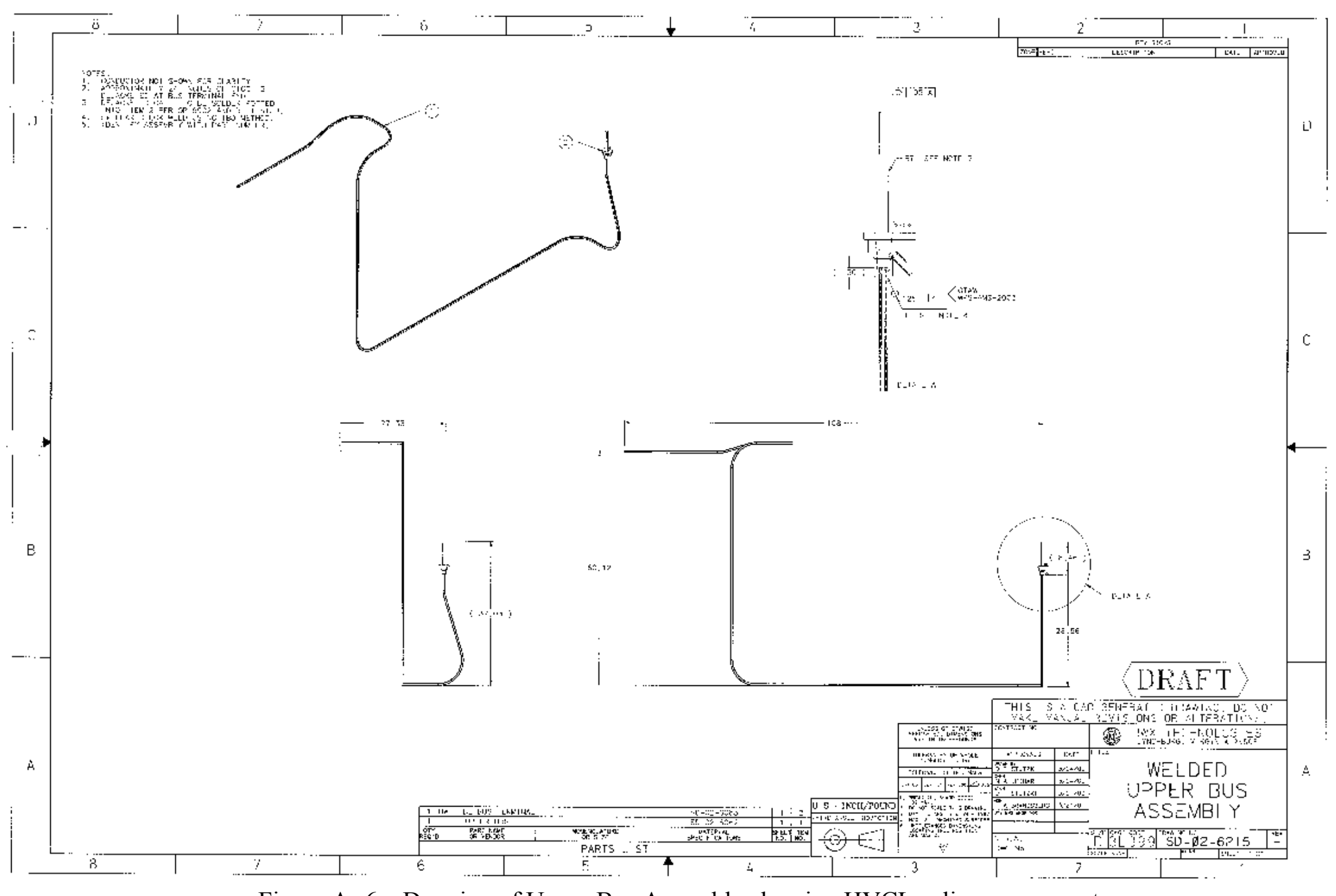

Figure A- 6 Drawing of Upper Bus Assembly showing HVCL splice component 


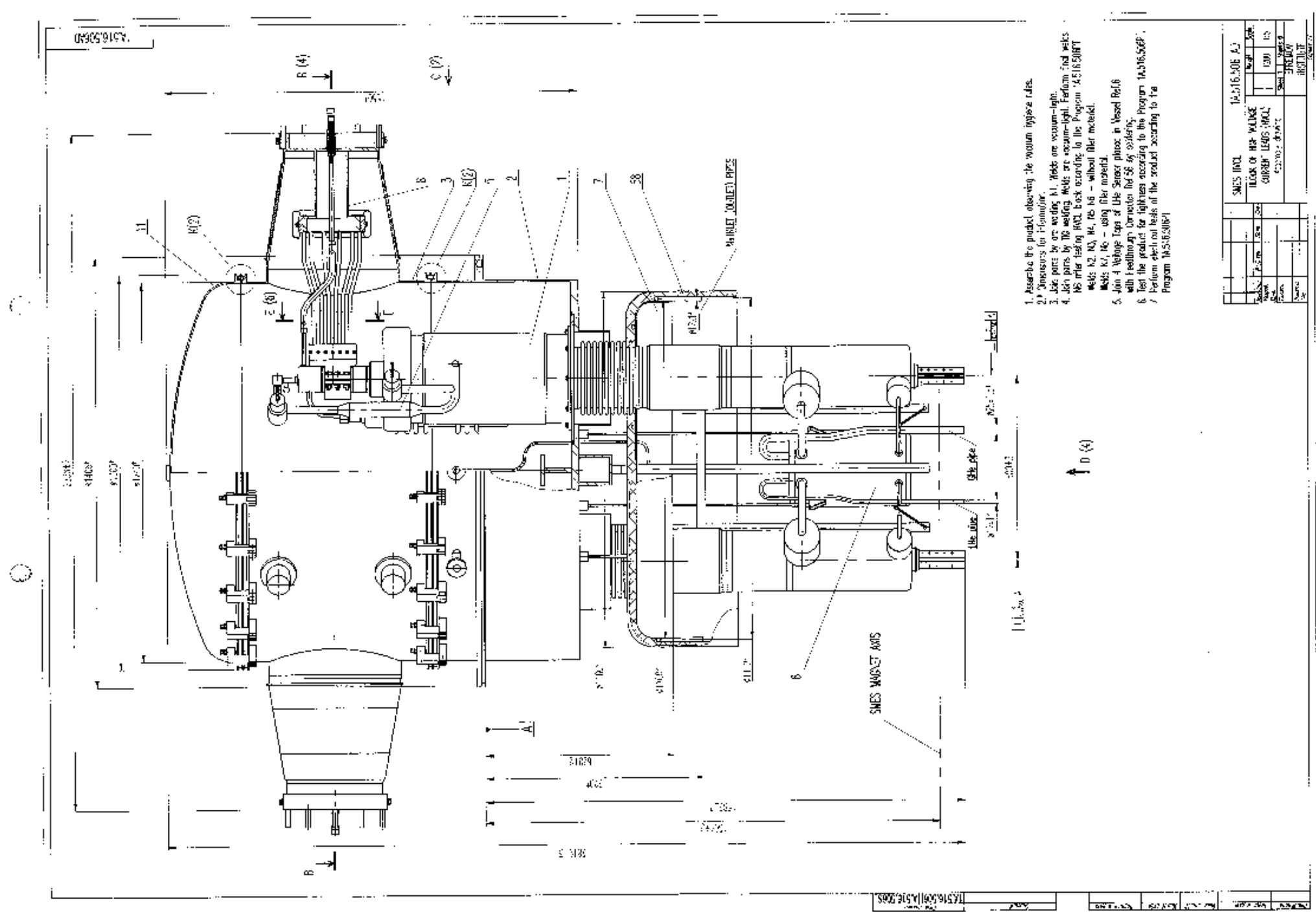

Figure A $-\overline{7}$ Drawing of High Voltage Current Leads 
Final Report - DOE Agreement No. DE-FC36-94G010011

Commercialization Demonstration of Mid-Sized Superconducting Magnetic Energy Storage Technology for Electric Utility Applications

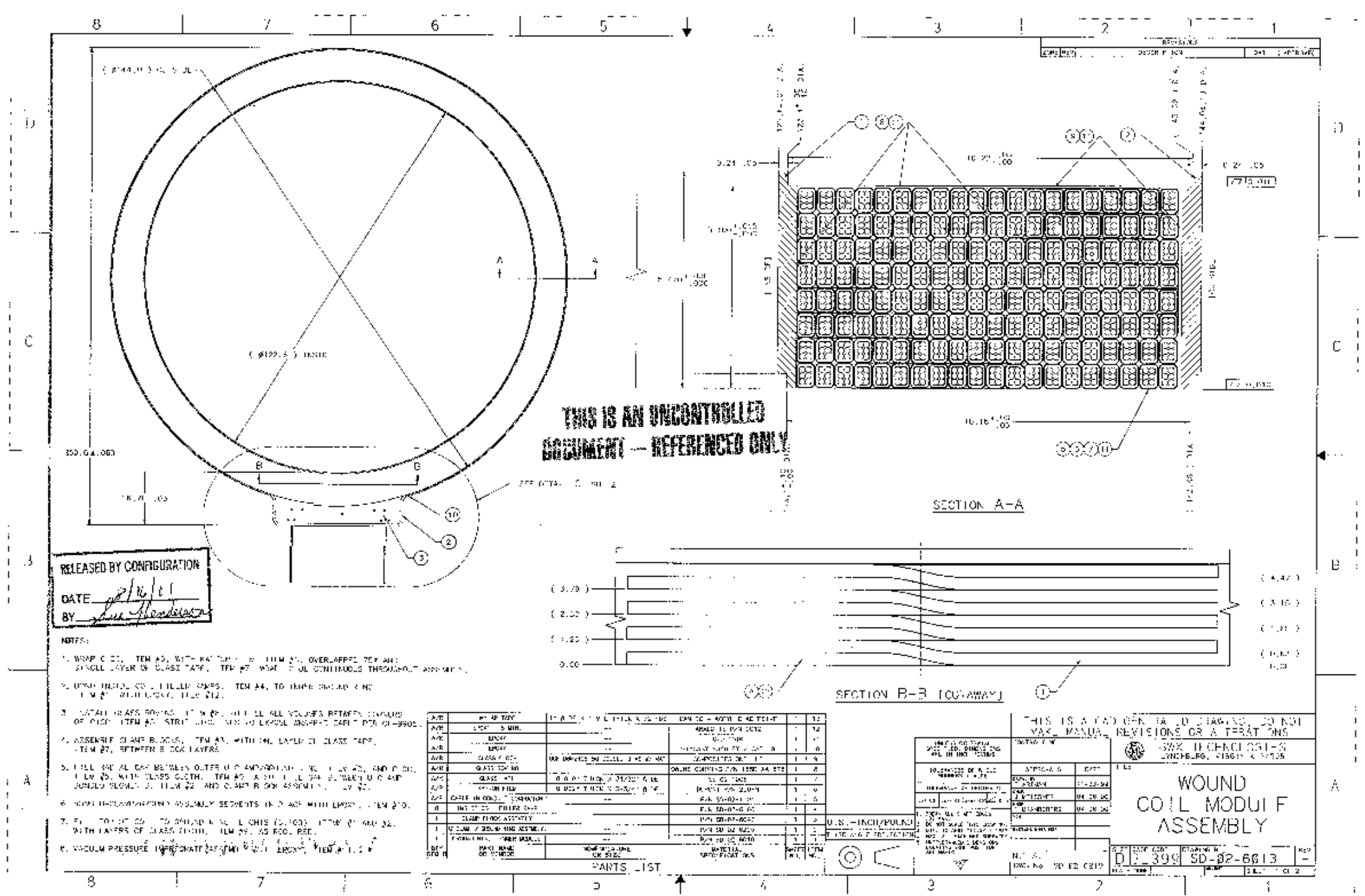

Figure A - 8 Drawing of Coil Module Assembly - Page 1 


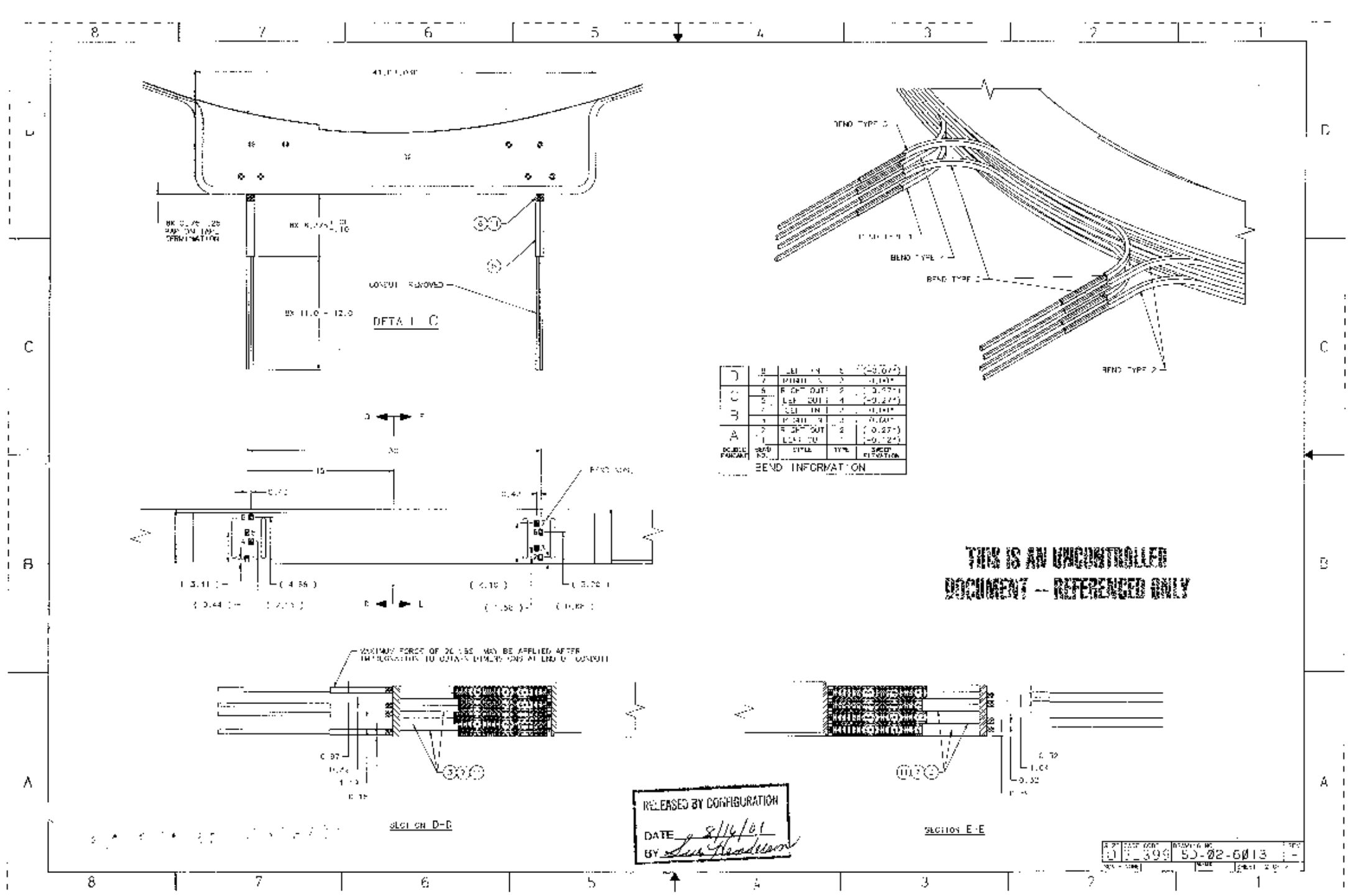

Figure A - 9 Drawing of Coil Module Assembly - Page 2 
Final Report - DOE Agreement No. DE-FC36-94G010011

Commercialization Demonstration of Mid-Sized Superconducting Magnetic Energy Storage Technology for Electric Utility Applications

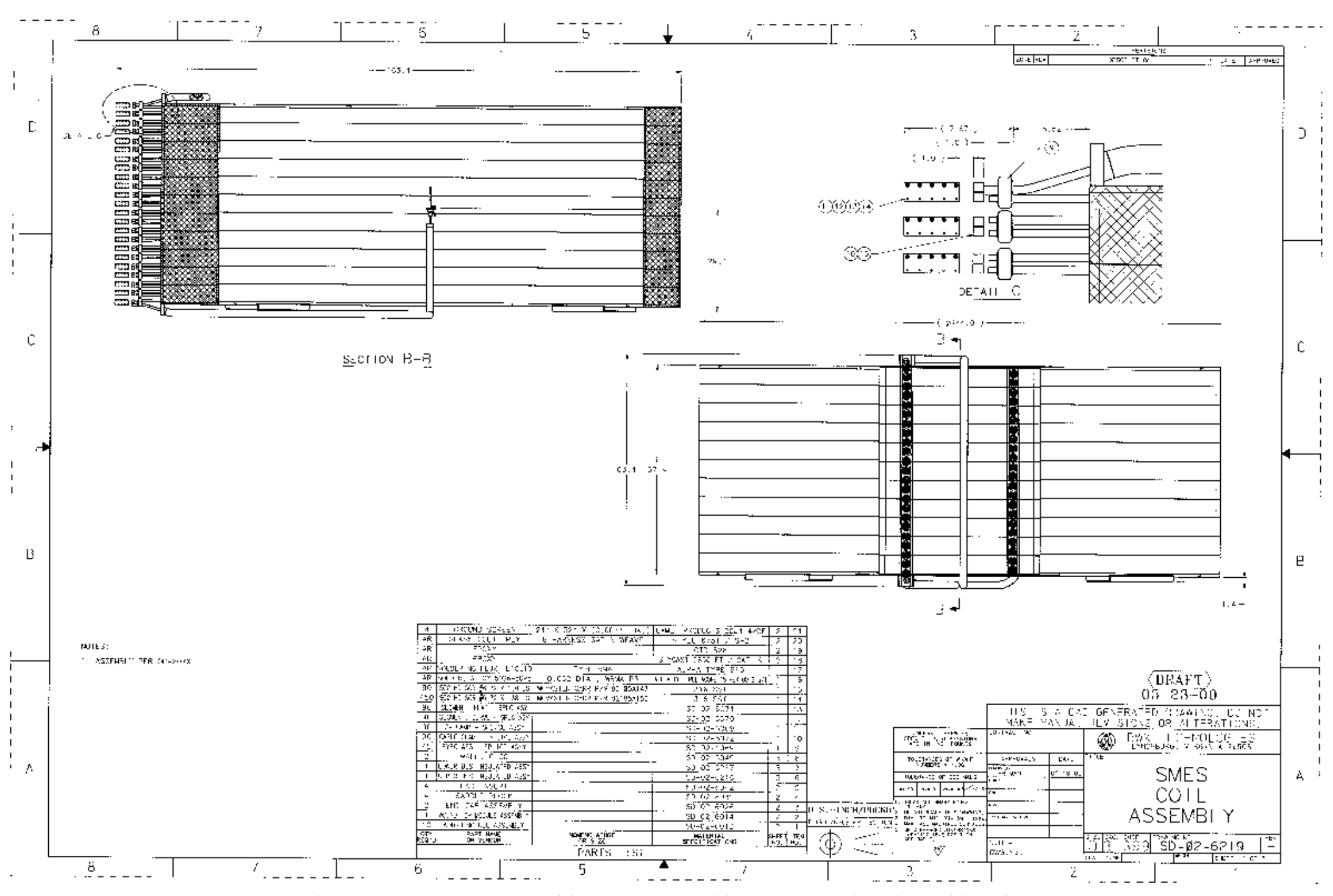

Figure A - 10 SMES Cold Mass Assembly, Page 1, Showing Side Views 
Final Report - DOE Agreement No. DE-FC36-94G010011

Commercialization Demonstration of Mid-Sized Superconducting Magnetic Energy Storage Technology for Electric Utility Applications

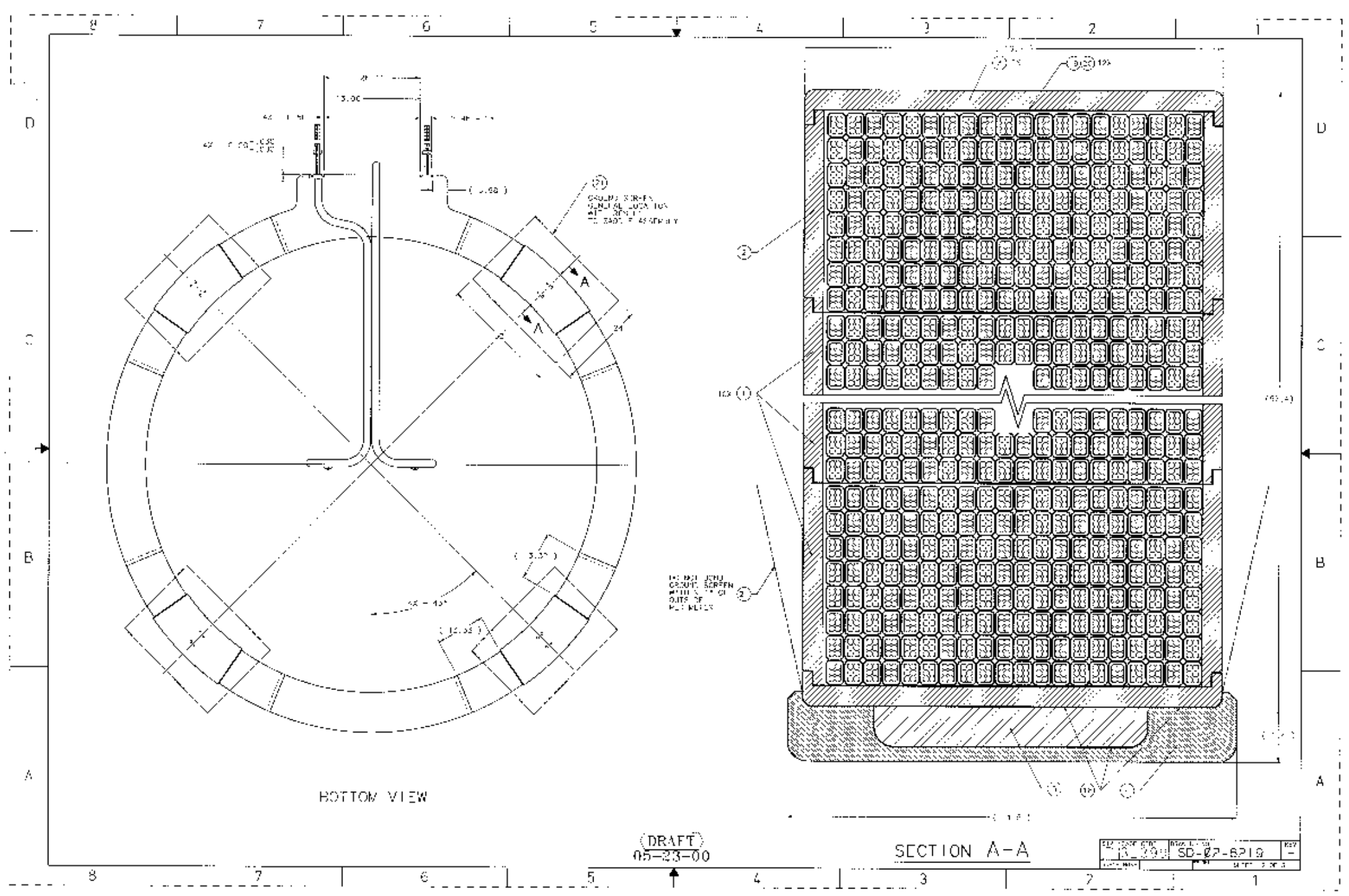

Figure A - 11 SMES Cold Mass Assembly, Page 2, Showing Bottom and Cross-Section Views 


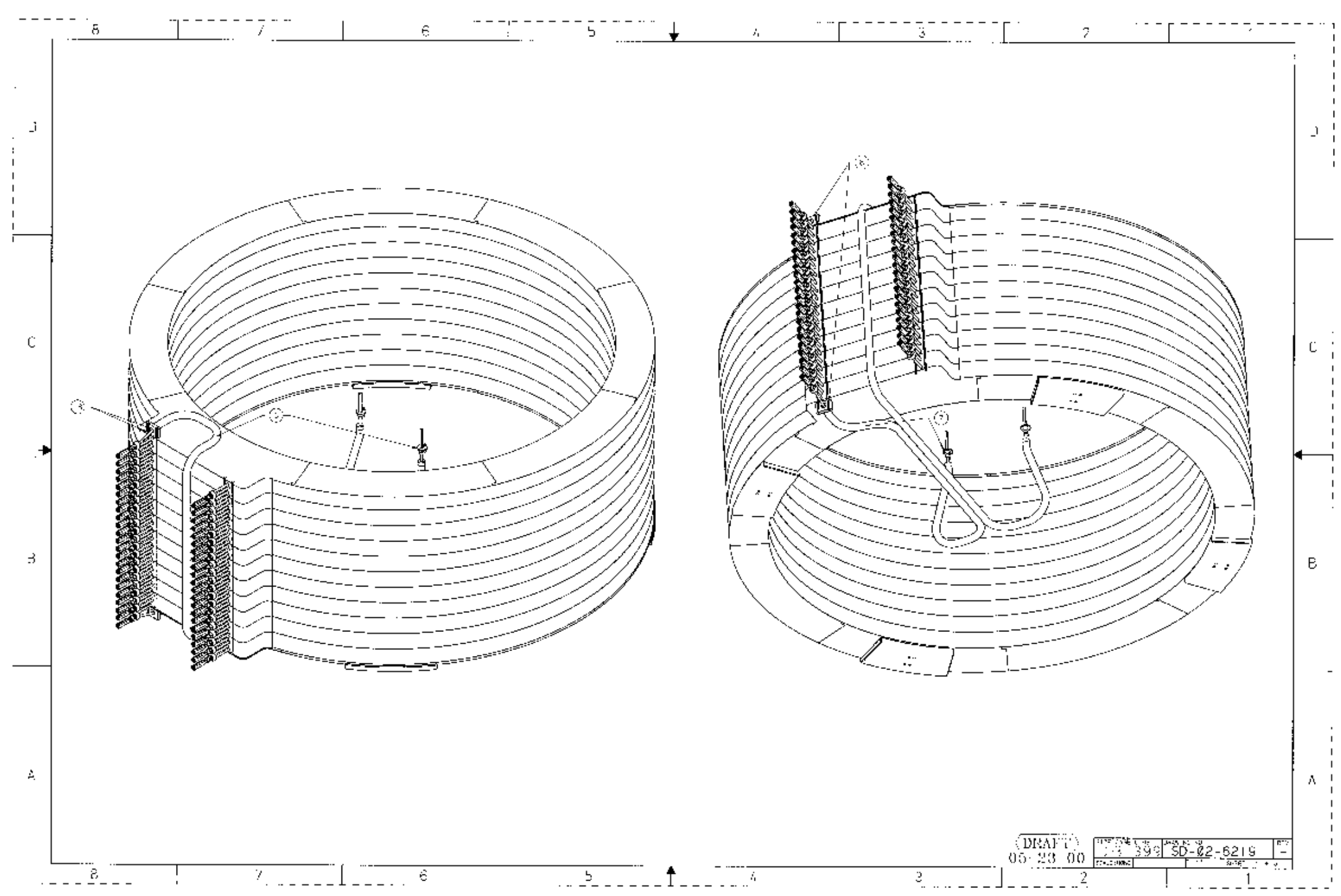

Figure A - 12 SMES Cold Mass Assembly, Page 3, Top and Bottom Isometric Views, with Leads and Splices 


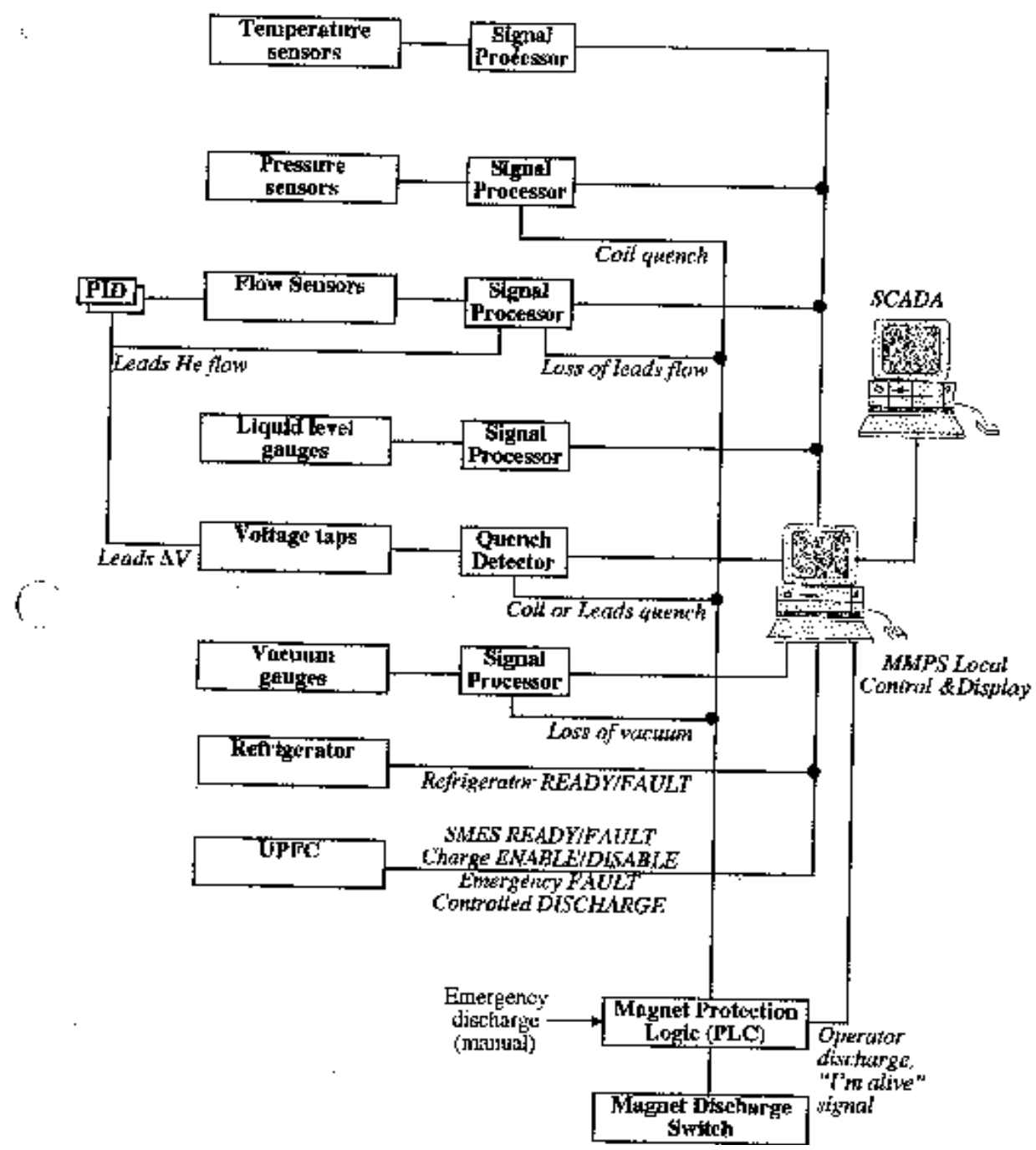

Figure A - 13 Block Diagram of the SMES Magnet Monitoring and Protection Subsystem 
Final Report - DOE Agreement No. DE-FC36-94G010011

Commercialization Demonstration of Mid-Sized Superconducting Magnetic Energy Storage Technology for Electric Utility Applications

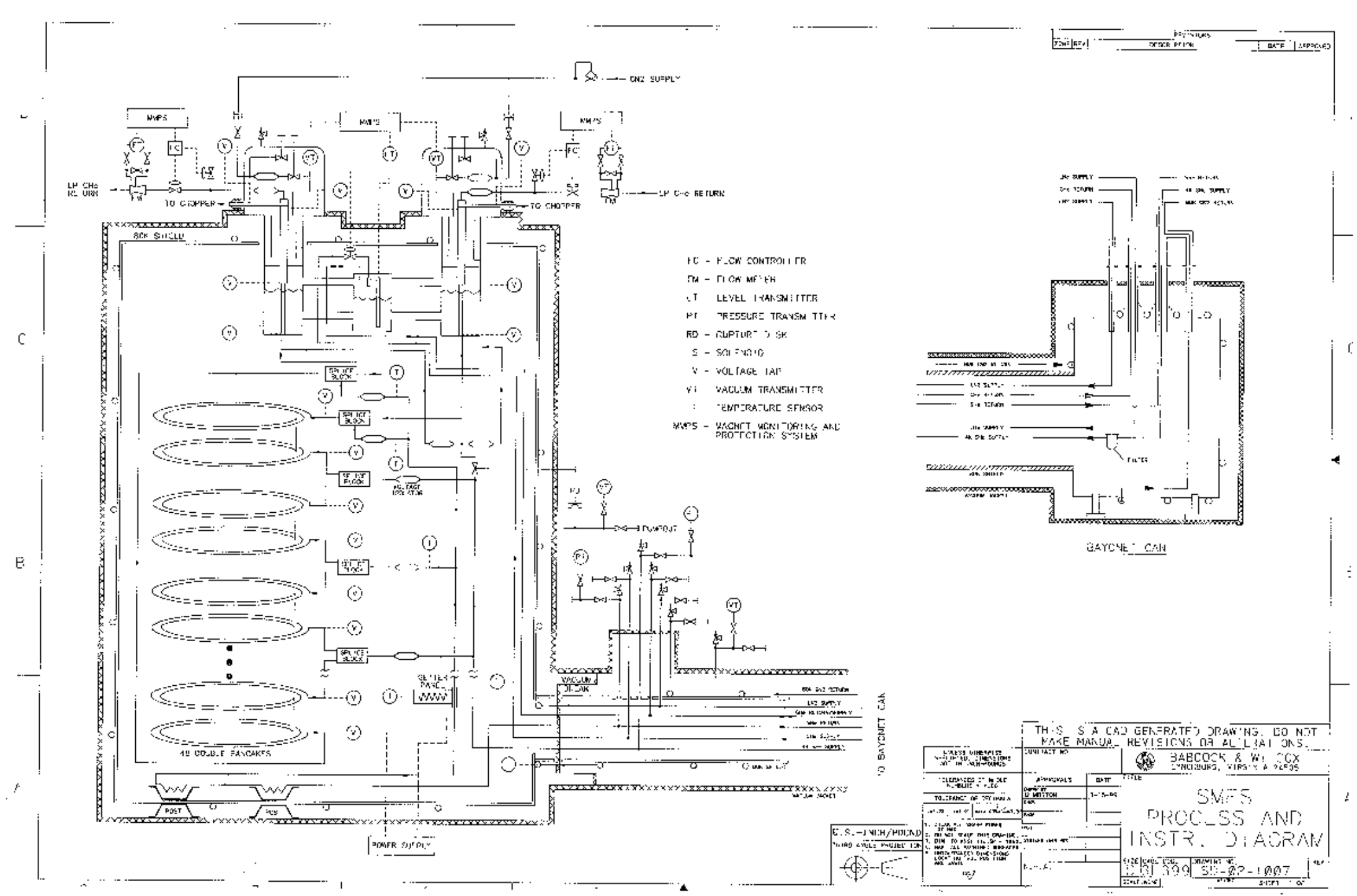

Figure A - 14 SMES Process and Instrumentation Diagram (P\&ID) 
Final Report - DOE Agreement No. DE-FC36-94G010011

Commercialization Demonstration of Mid-Sized Superconducting Magnetic Energy Storage Technology for Electric Utility Applications

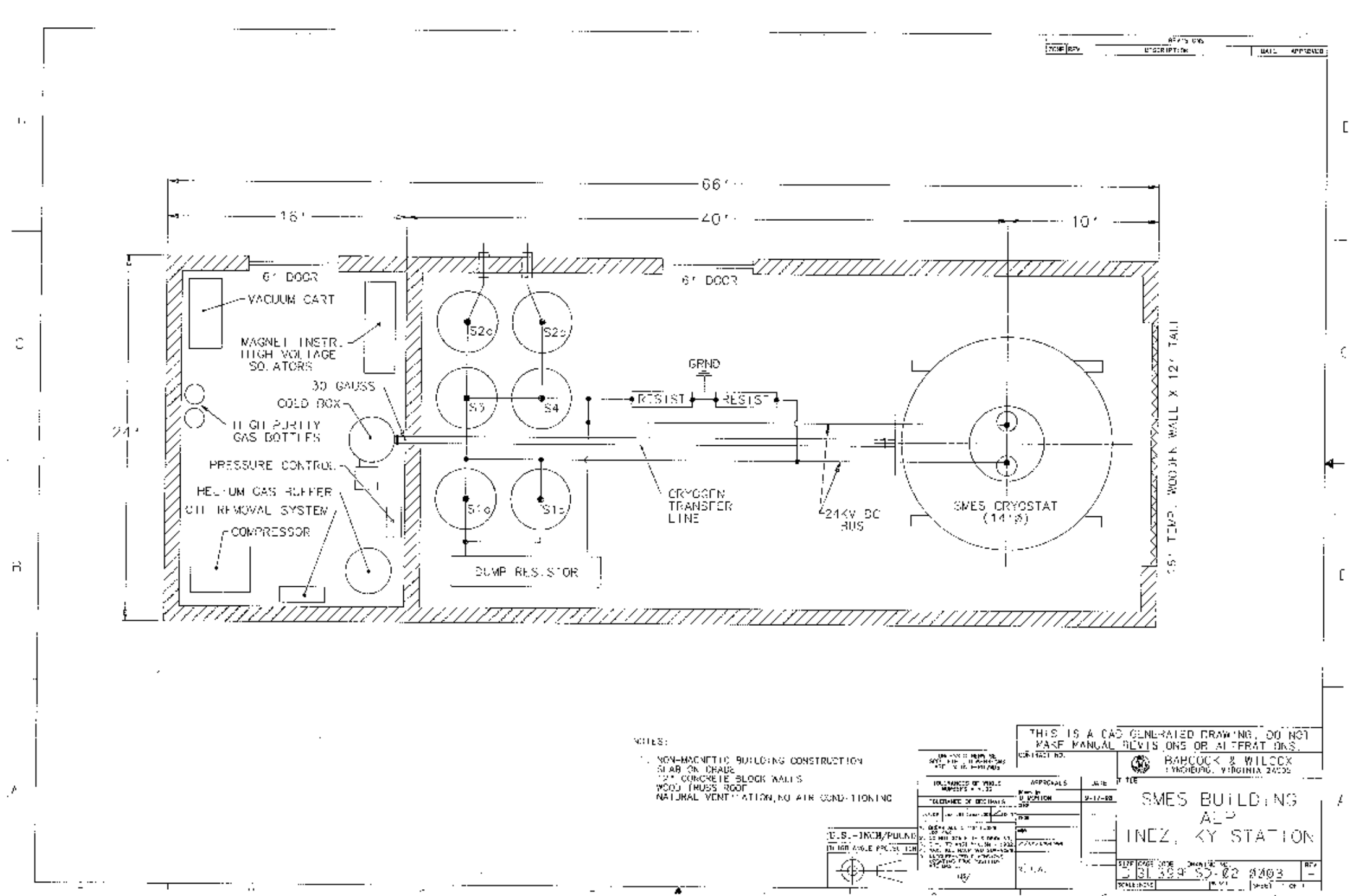

Figure A - 15 SMES Building and Layout of SMES Equipment at the Site 


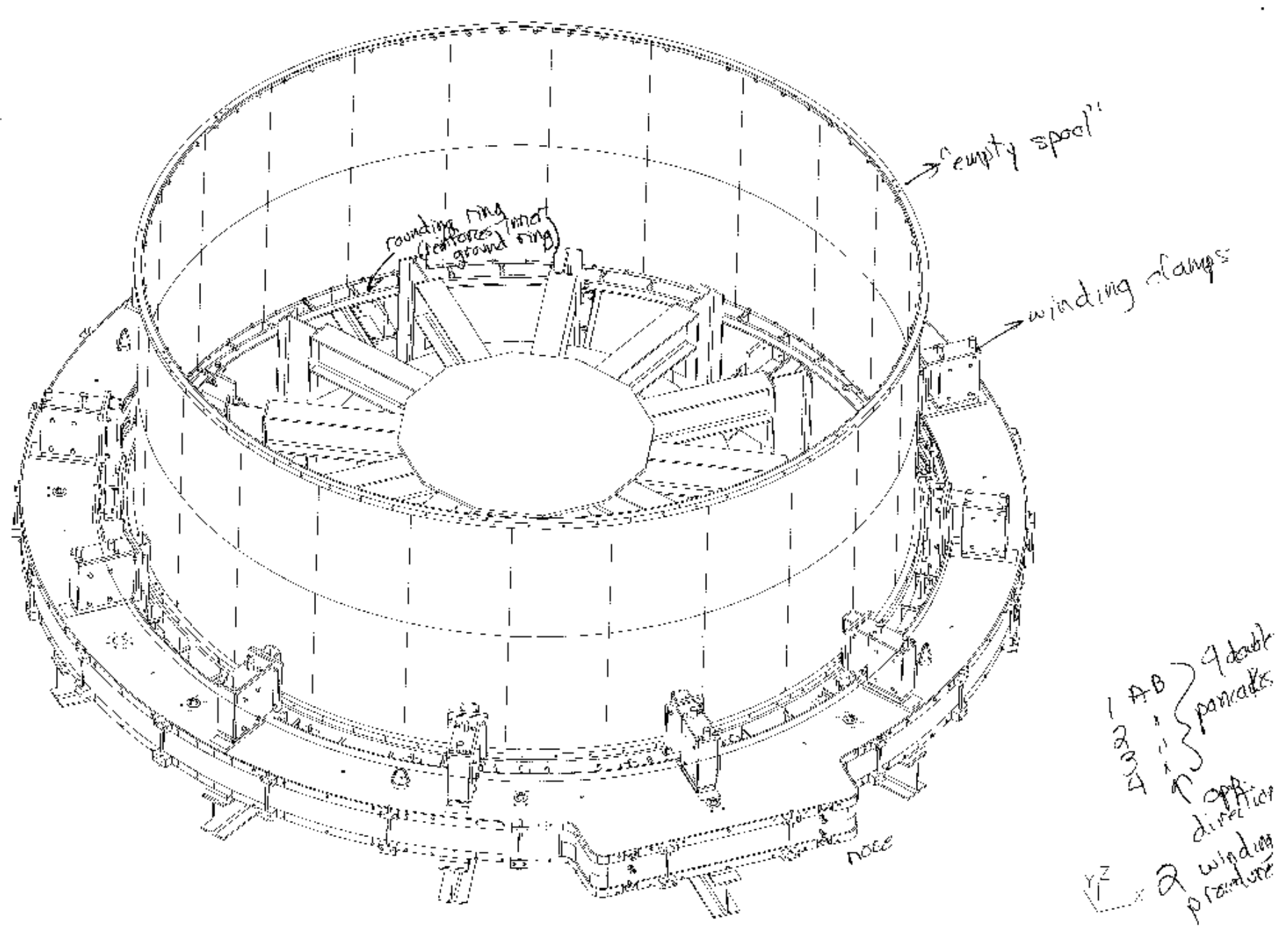

Figure A - 16 Sketch of Winding Fixture with take-up Spool and hold-down hydraulic clamps 
Final Report - DOE Agreement No. DE-FC36-94G010011

Commercialization Demonstration of Mid-Sized Superconducting Magnetic Energy Storage Technology for Electric Utility Applications

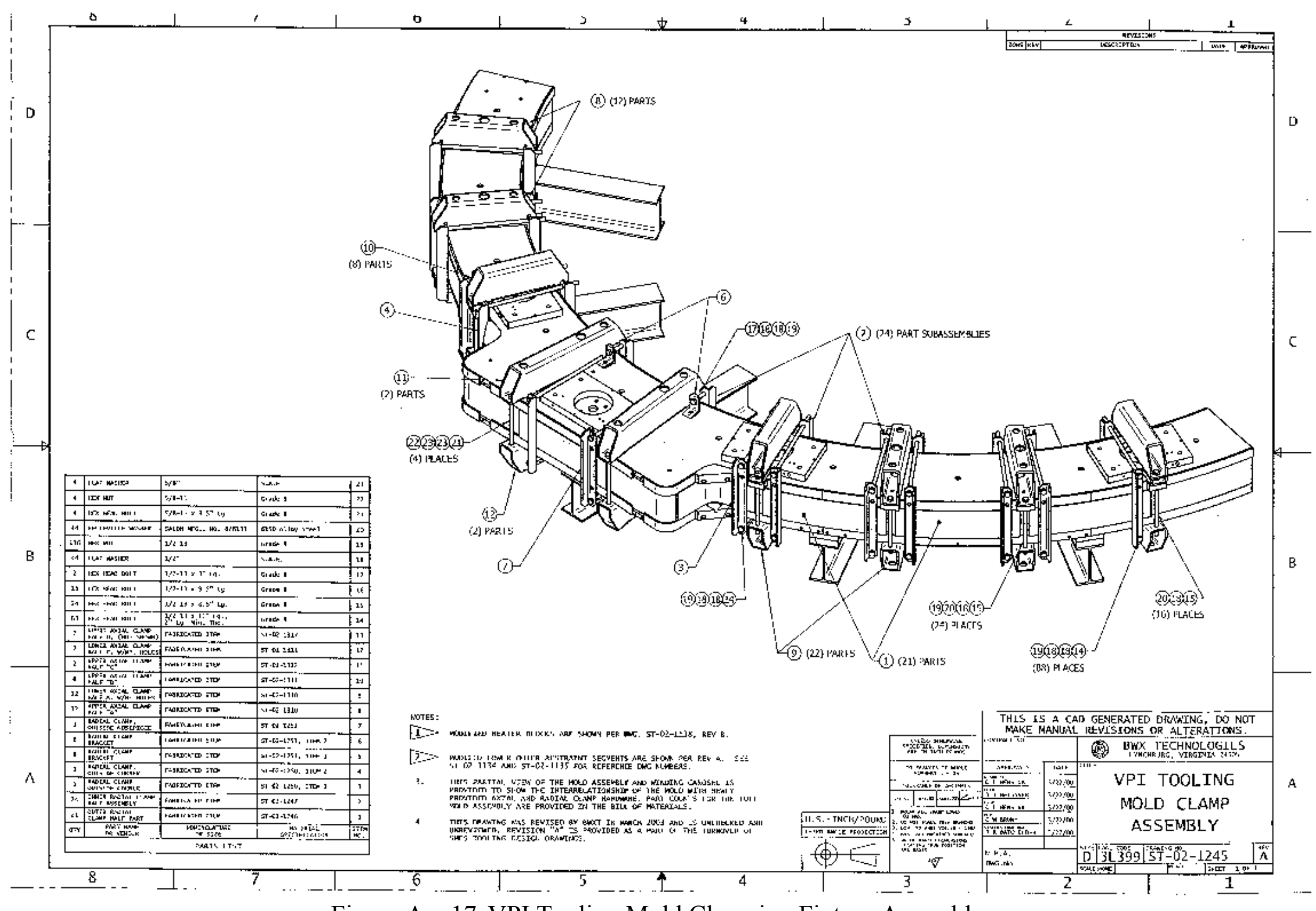

Figure A - 17 VPI Tooling Mold Clamping Fixture Assembly 
Final Report - DOE Agreement No. DE-FC36-94G010011

Commercialization Demonstration of Mid-Sized Superconducting Magnetic Energy Storage Technology for Electric Utility Applications

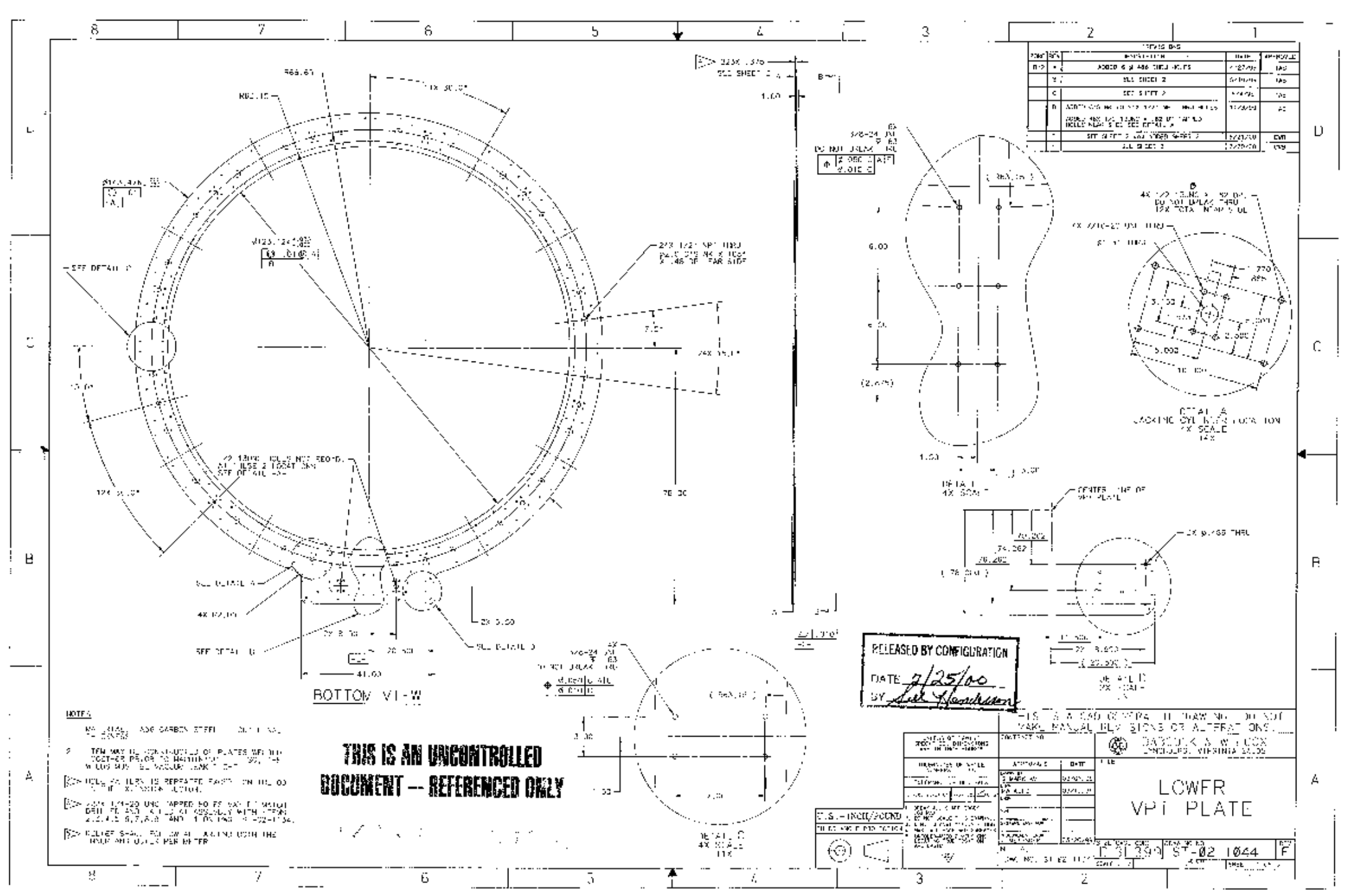

Figure A - 18 Lower VPI Tooling Plate 
Final Report - DOE Agreement No. DE-FC36-94G010011

Commercialization Demonstration of Mid-Sized Superconducting Magnetic Energy Storage Technology for Electric Utility Applications

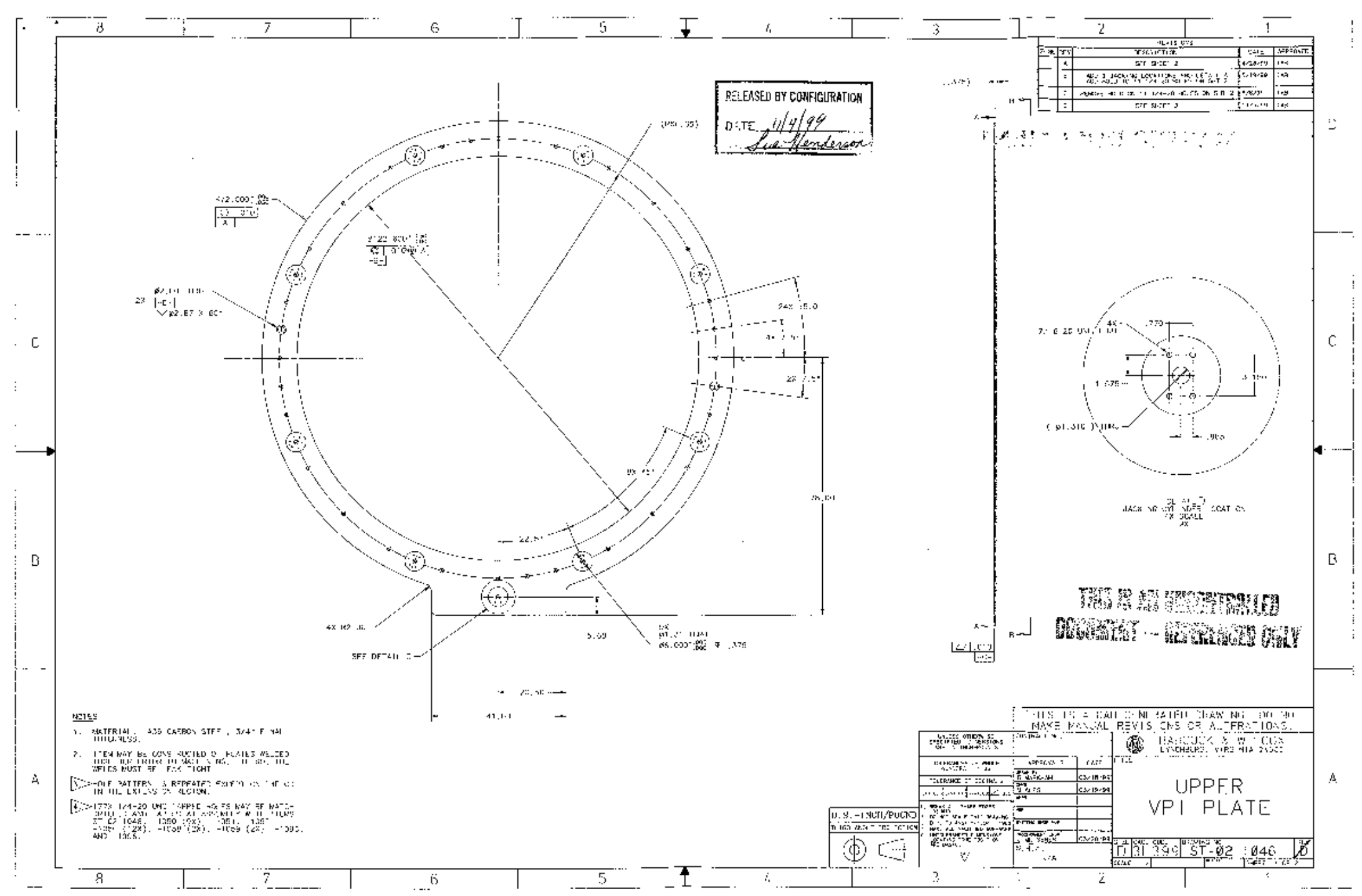

Figure A - 19 Upper VPI Mold Tooling Plate 
Final Report - DOE Agreement No. DE-FC36-94G010011

Commercialization Demonstration of Mid-Sized Superconducting Magnetic Energy Storage Technology for Electric Utility Applications

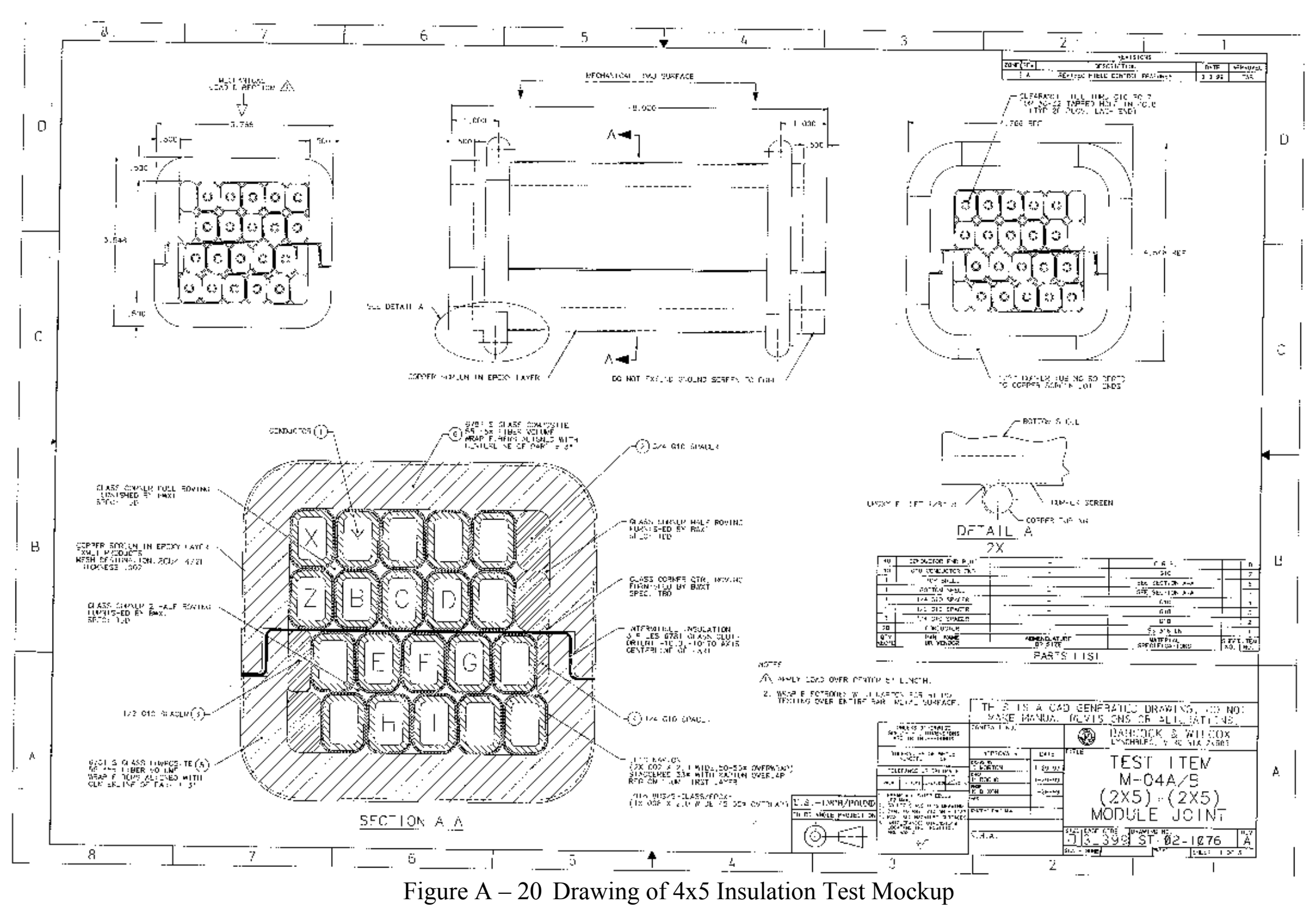

Page 61 of 83 


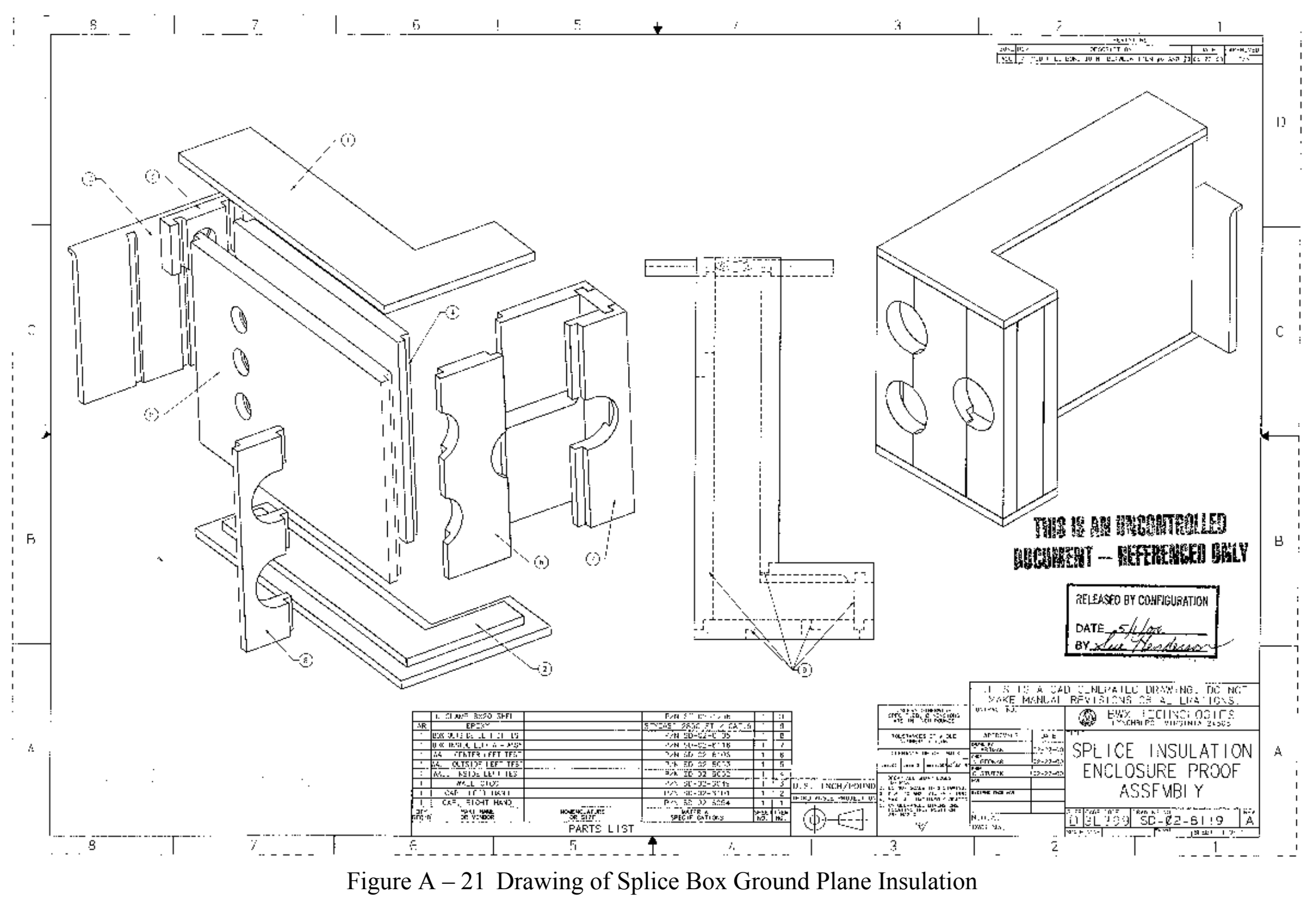


Final Report - DOE Agreement No. DE-FC36-94G010011

Commercialization Demonstration of Mid-Sized Superconducting Magnetic Energy Storage Technology for Electric Utility Applications

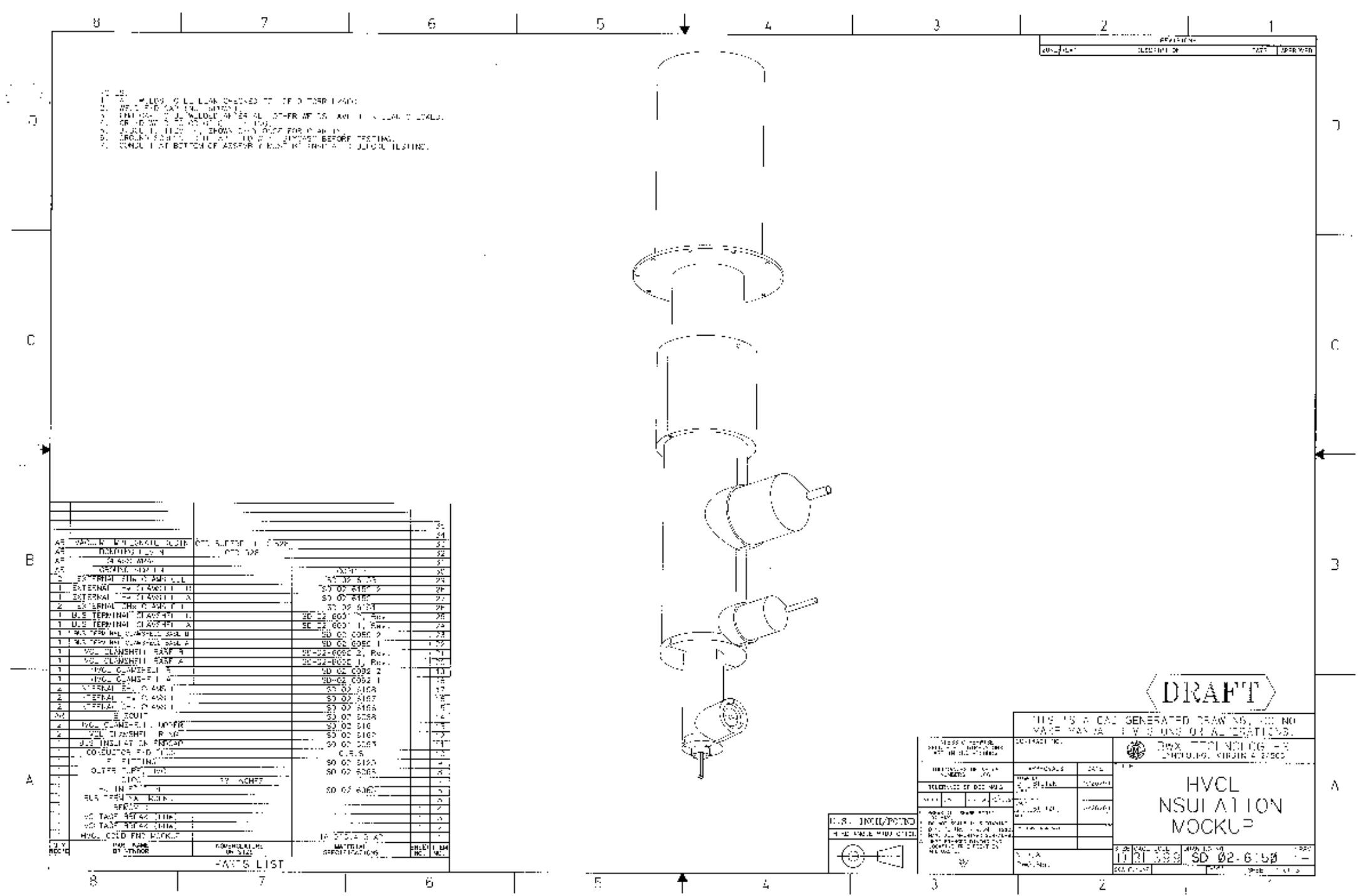

Figure A - 22 High Voltage Current Lead Ground Plane Insulation Mockup 


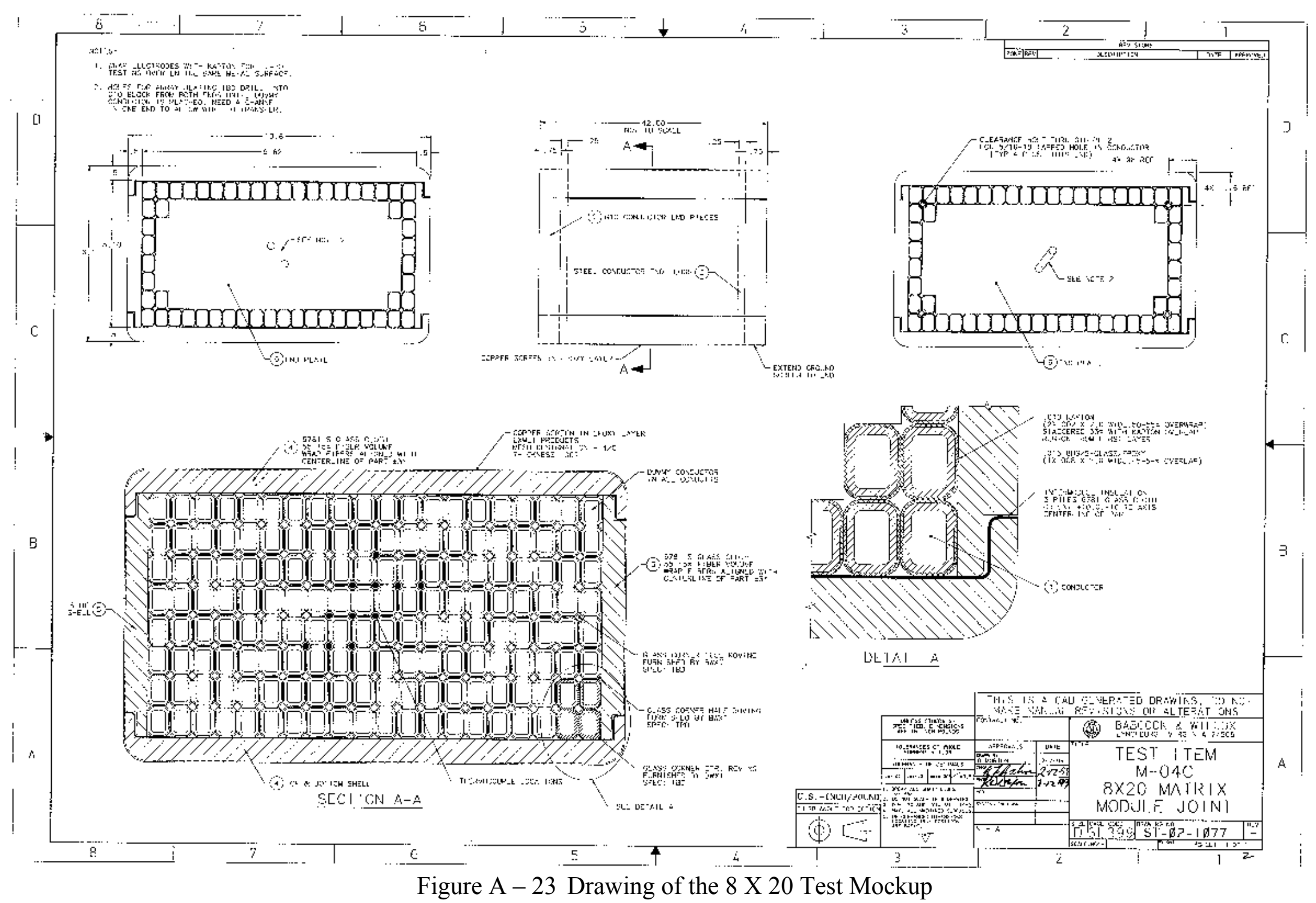




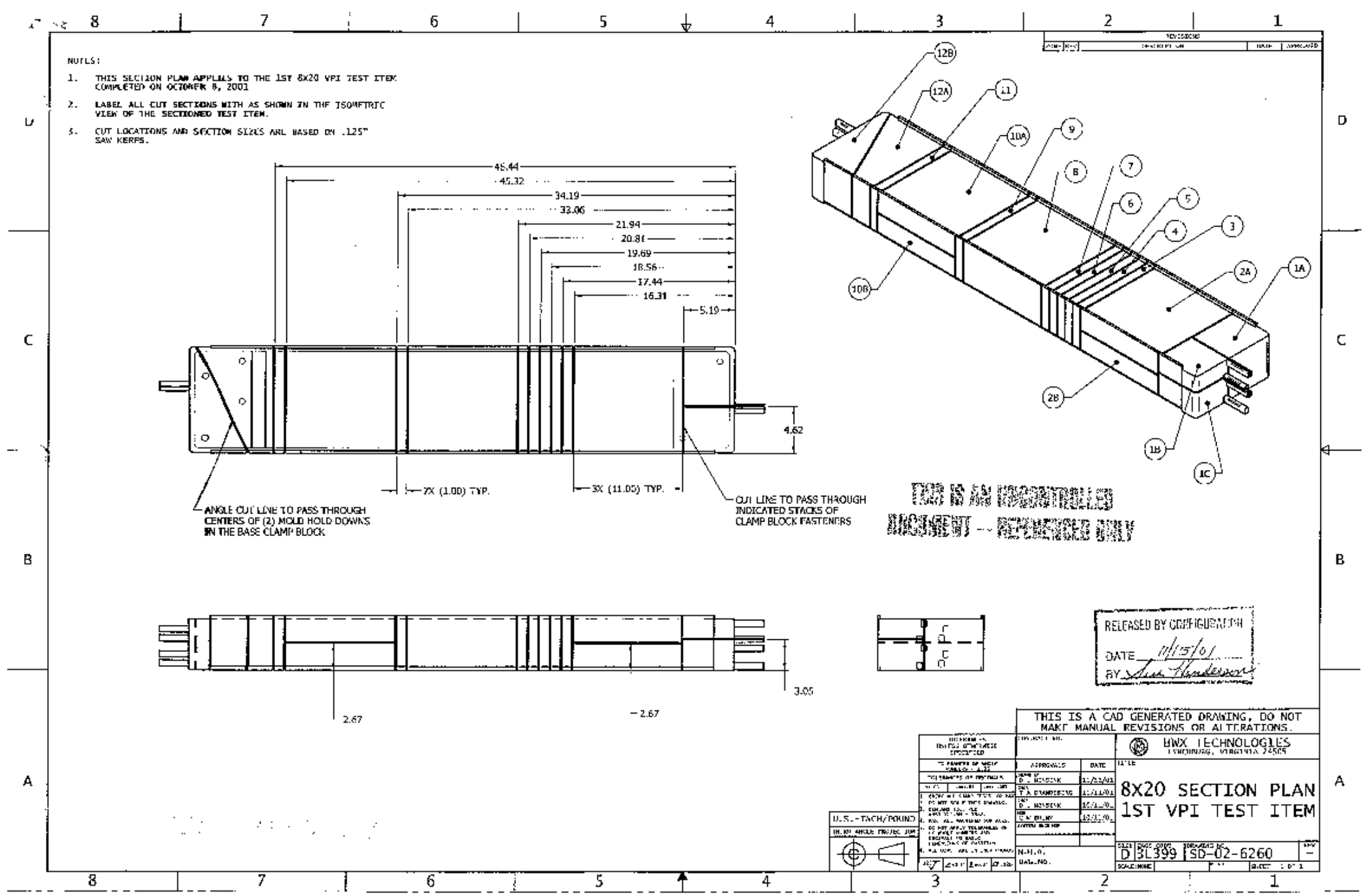

Figure A - 24 Sketch of 8 X 20 Mockup and Sectioning Plan 
Final Report - DOE Agreement No. DE-FC36-94G010011

Commercialization Demonstration of Mid-Sized Superconducting Magnetic Energy Storage Technology for Electric Utility Applications

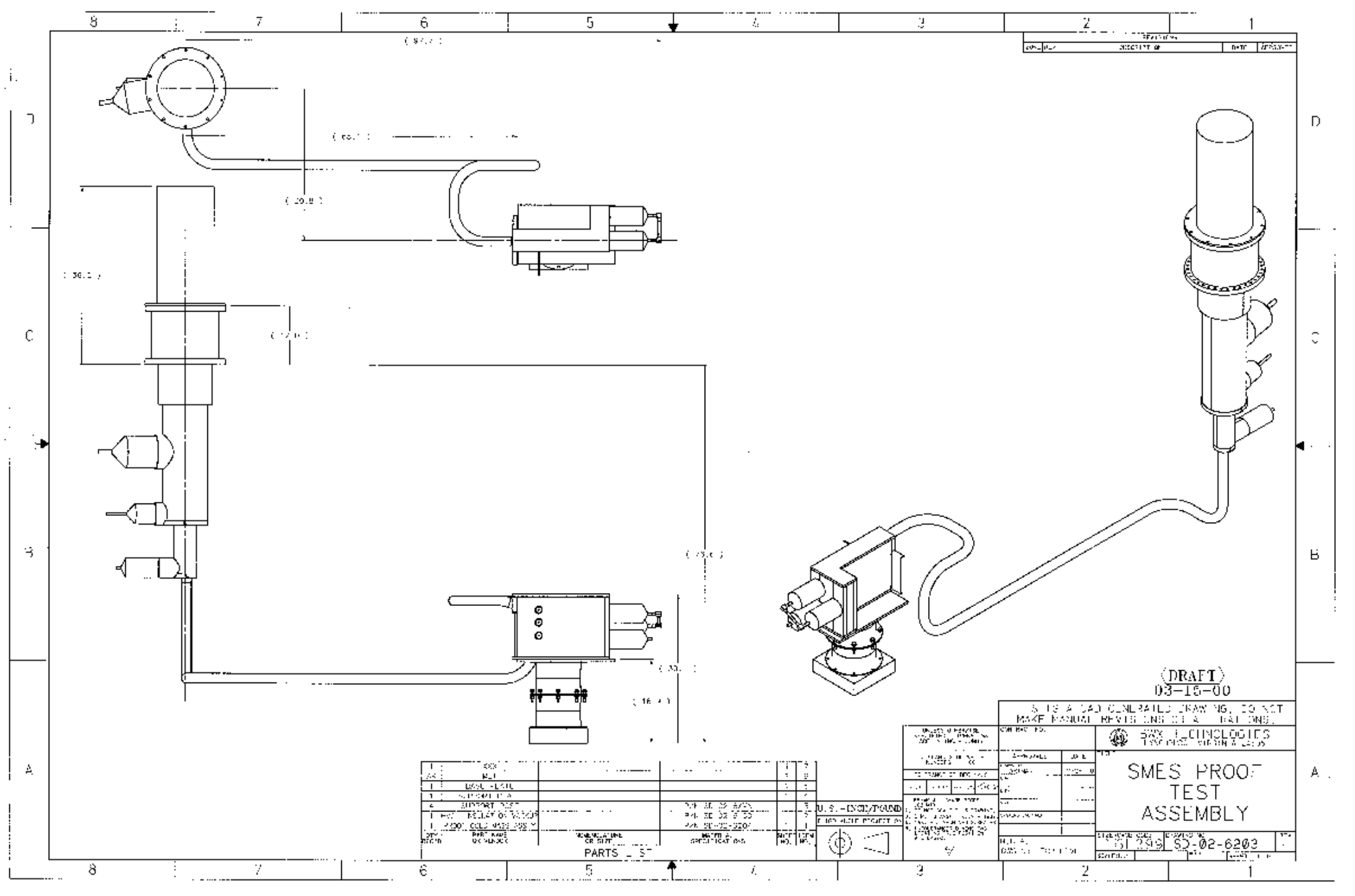

Figure A - 25 SMES Proof Test Assembly Mockup 
Final Report - DOE Agreement No. DE-FC36-94G010011

Commercialization Demonstration of Mid-Sized Superconducting Magnetic Energy Storage Technology for Electric Utility Applications

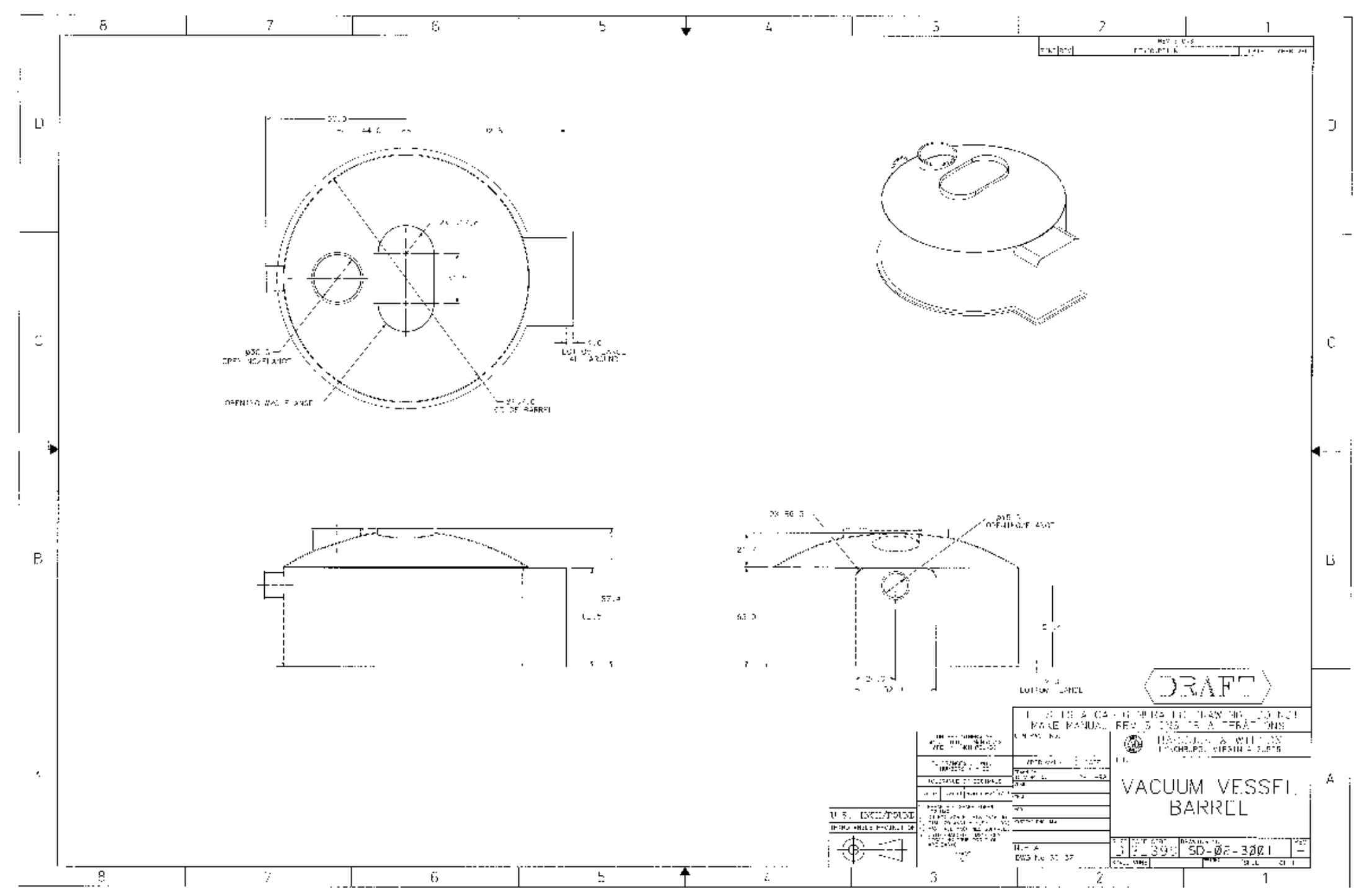

Figure A - 26 Sketch of Vacuum Vessel Barrel 
Final Report - DOE Agreement No. DE-FC36-94G010011

Commercialization Demonstration of Mid-Sized Superconducting Magnetic Energy Storage Technology for Electric Utility Applications

\section{APPENDIX B - PHOTOGRAPHS AND ILLUSTRATIONS}

Figure B - 1 SMES and CICC Manufacturing Facility Viewed Toward Mill End

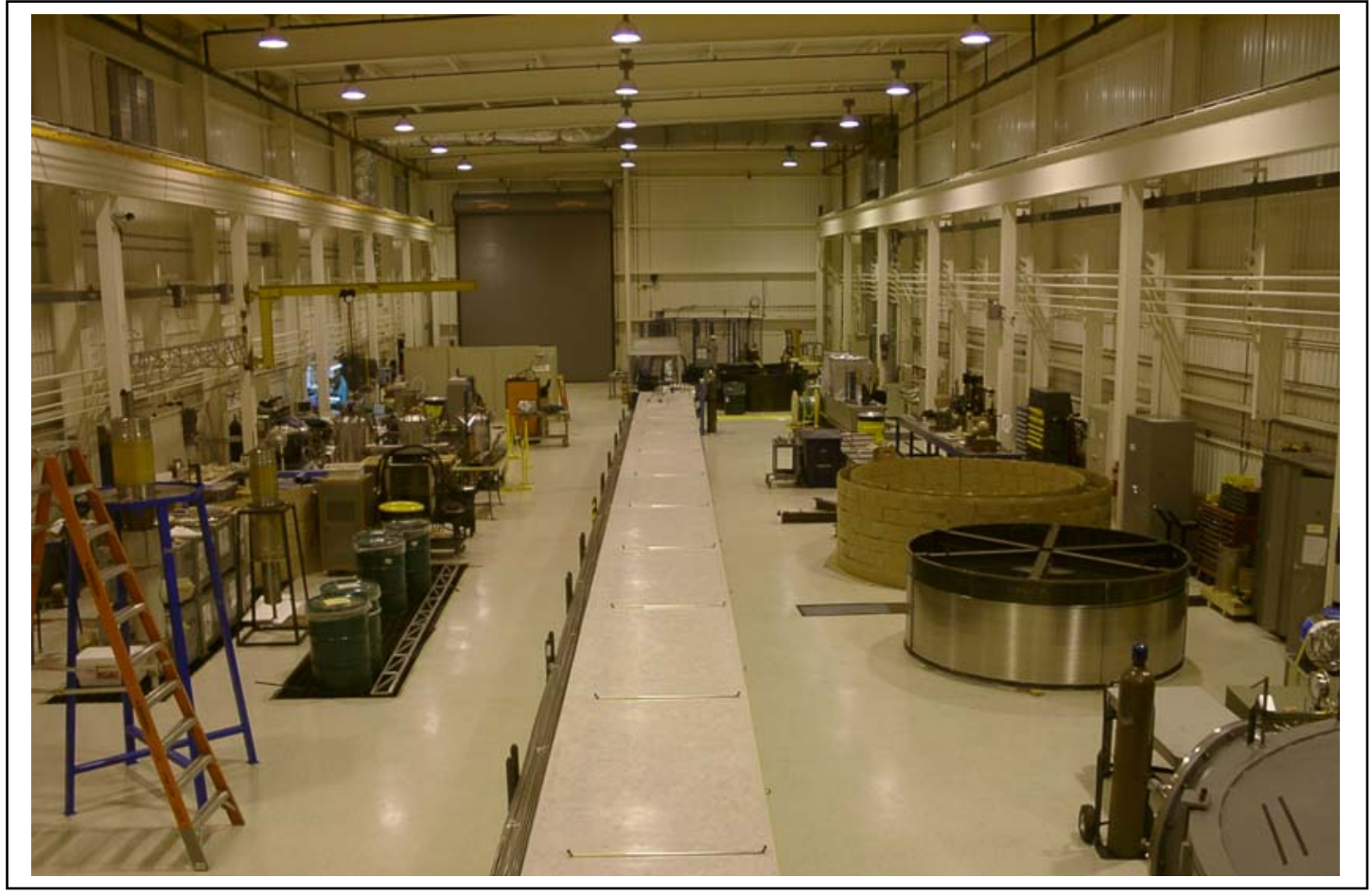

Figure B - 2 SMES and CICC Manufacturing Facility Viewed Toward Tensioning End

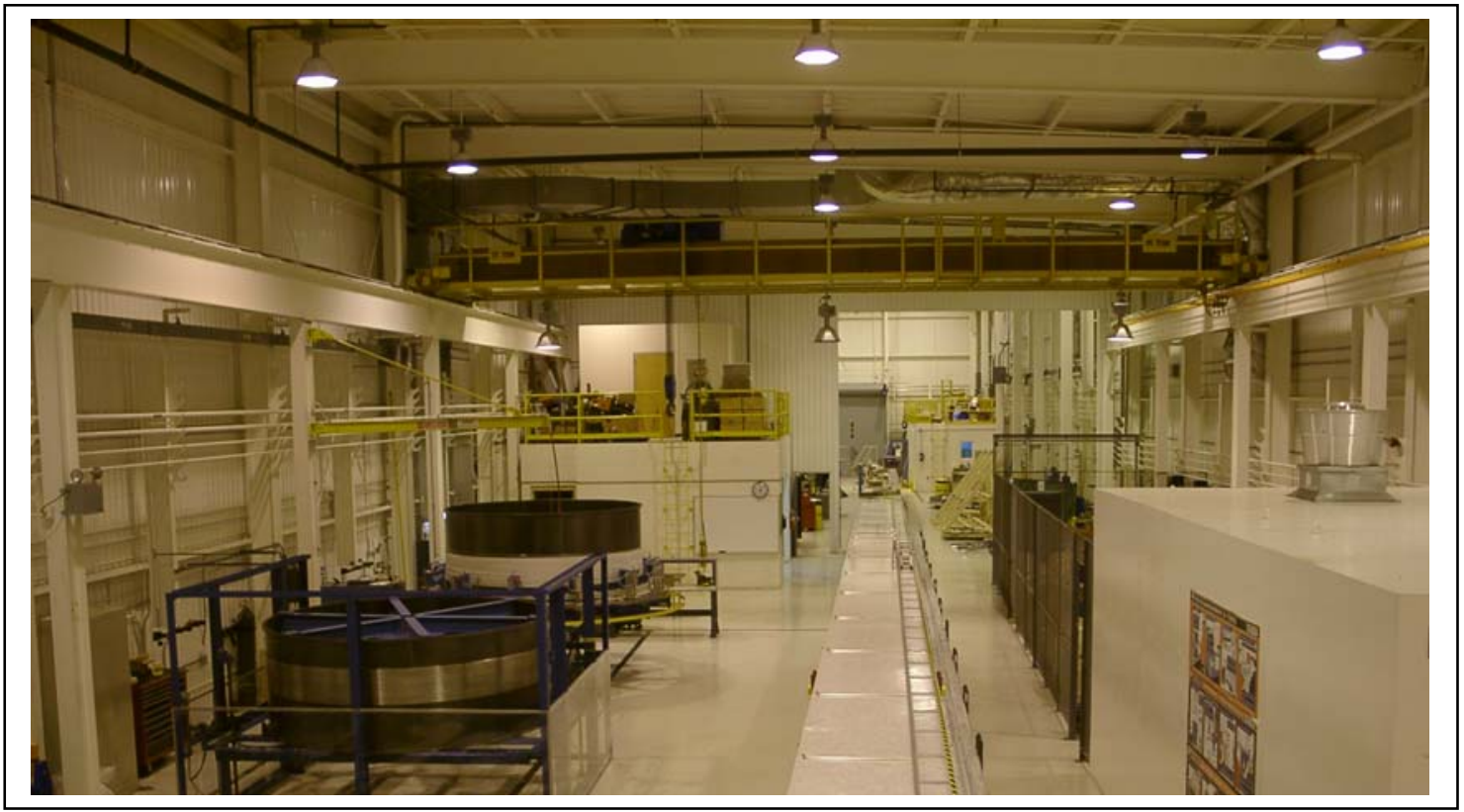


Final Report - DOE Agreement No. DE-FC36-94G010011

Commercialization Demonstration of Mid-Sized Superconducting Magnetic Energy Storage Technology for Electric Utility Applications

Figure B - 3 Photograph Showing Internal Splice Arrangement and Components

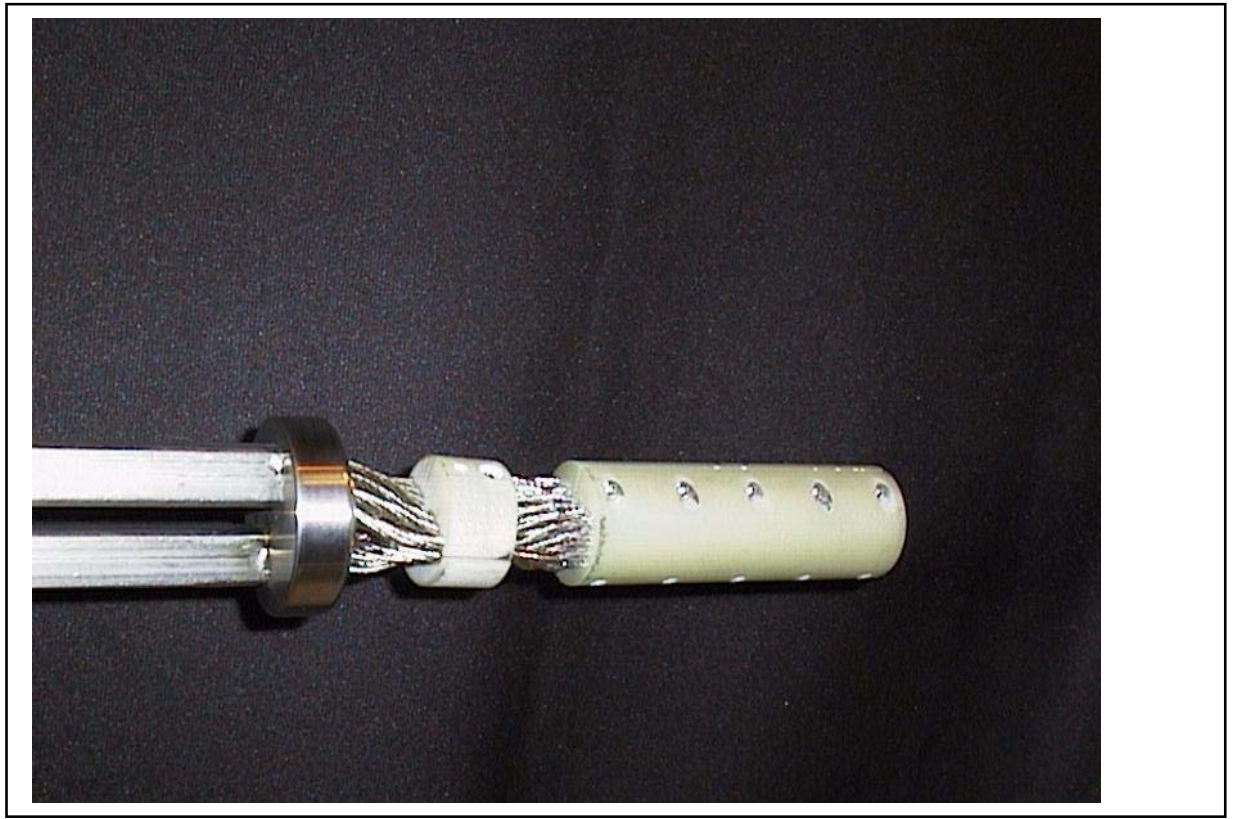

Figure B - 4 Sketch Showing Cross-Section View of a Coil Module with the VPI Tooling

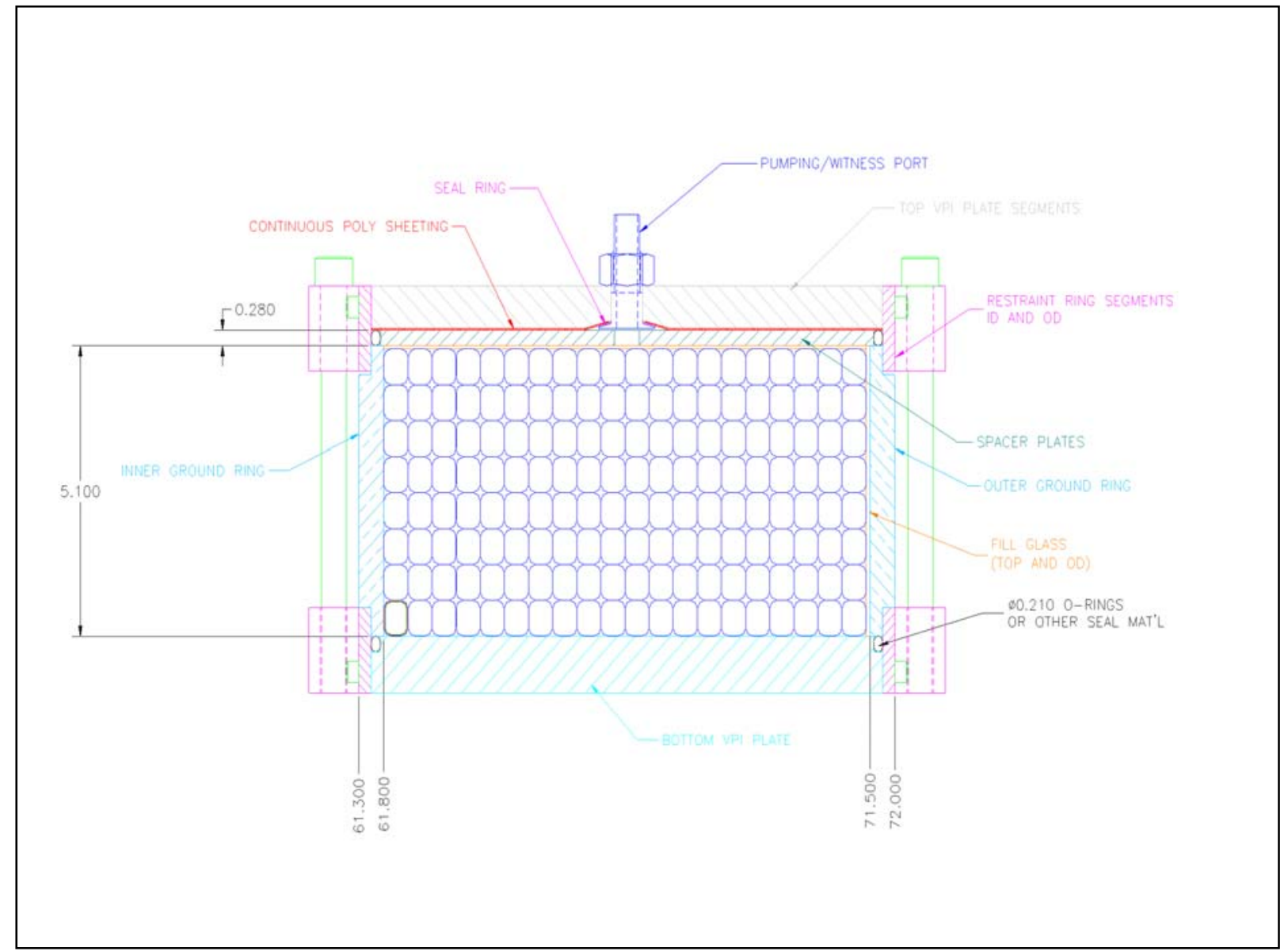


Figure B - 5 Illustration of Coil Module Showing Leads

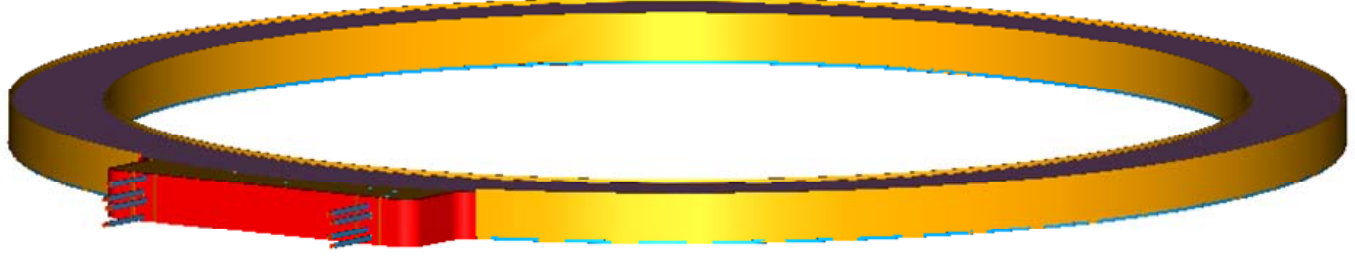

Figure B - 6 Isometric Illustration of Cold Mass Assembly from Below Showing Coil Modules, Lead Busses and Splices

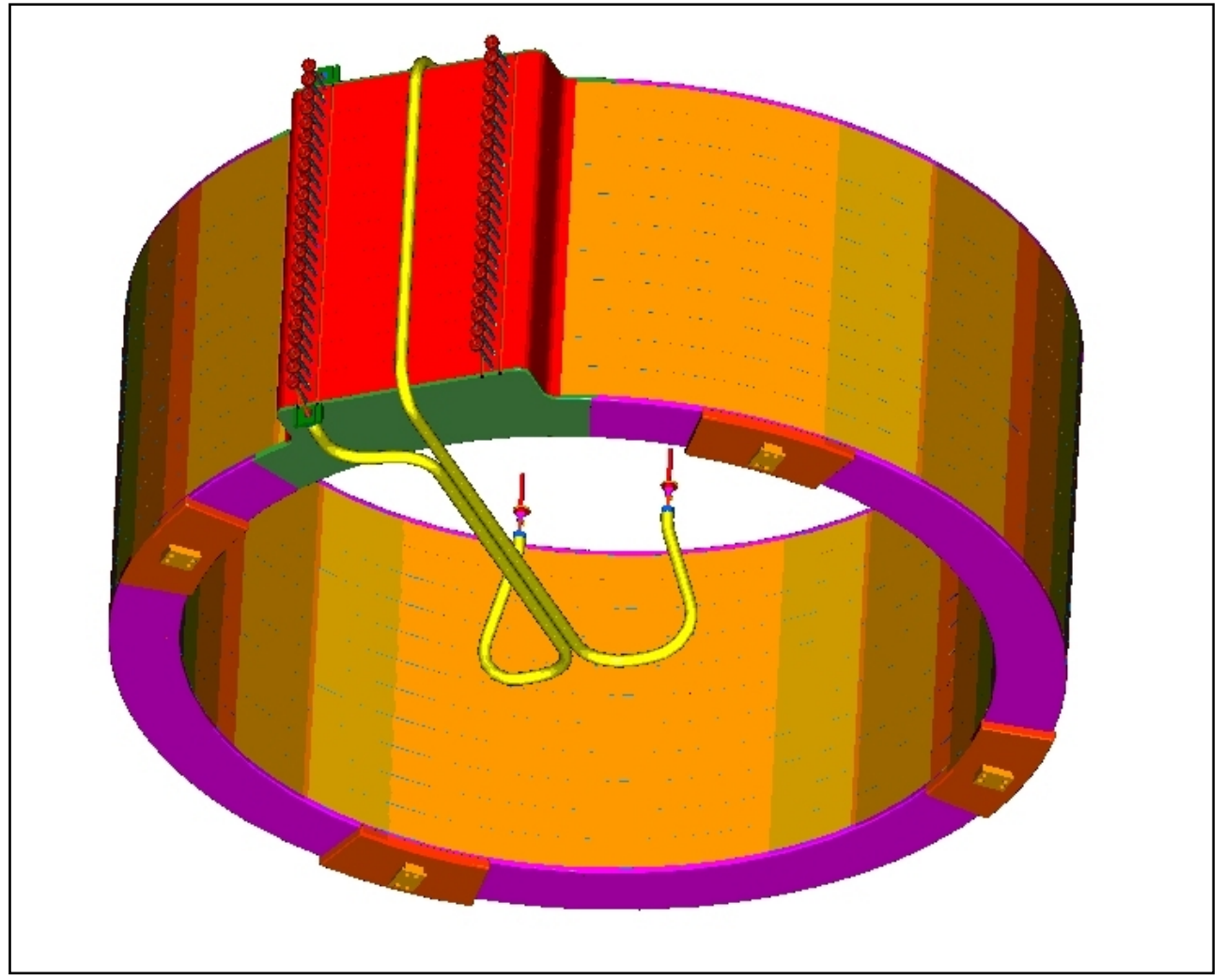


Figure B - 7 Expanded, Isometric View of SMES Magnet With Vacuum Vessel (Magnet Assembly was 10' Height, 14' Diameter and Weighed 35 Ton)

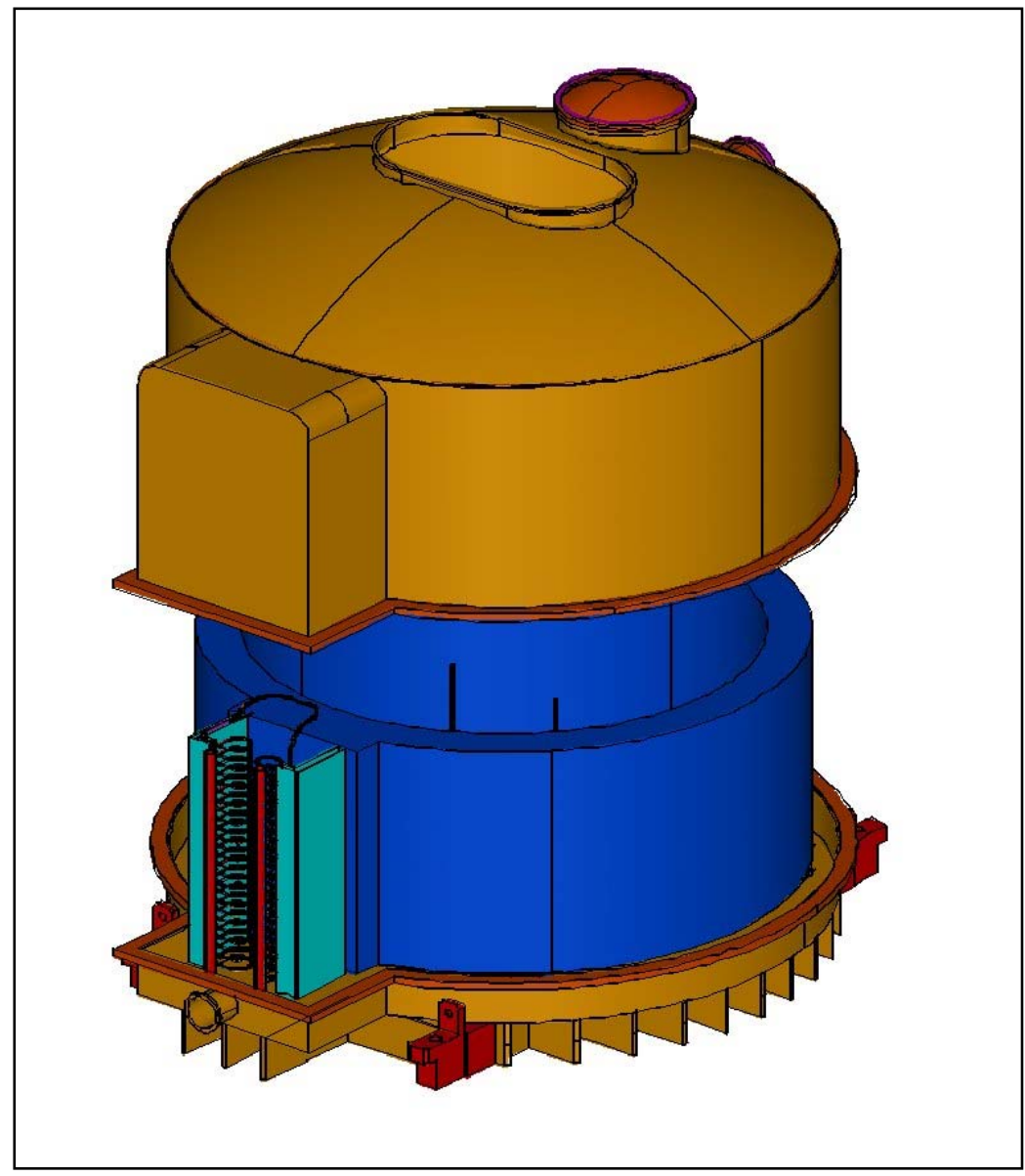


Final Report - DOE Agreement No. DE-FC36-94G010011

Commercialization Demonstration of Mid-Sized Superconducting Magnetic Energy Storage Technology for Electric Utility Applications

Figure B - 8 Illustration of Final Assembly with Coil in Cryostat on Support Base

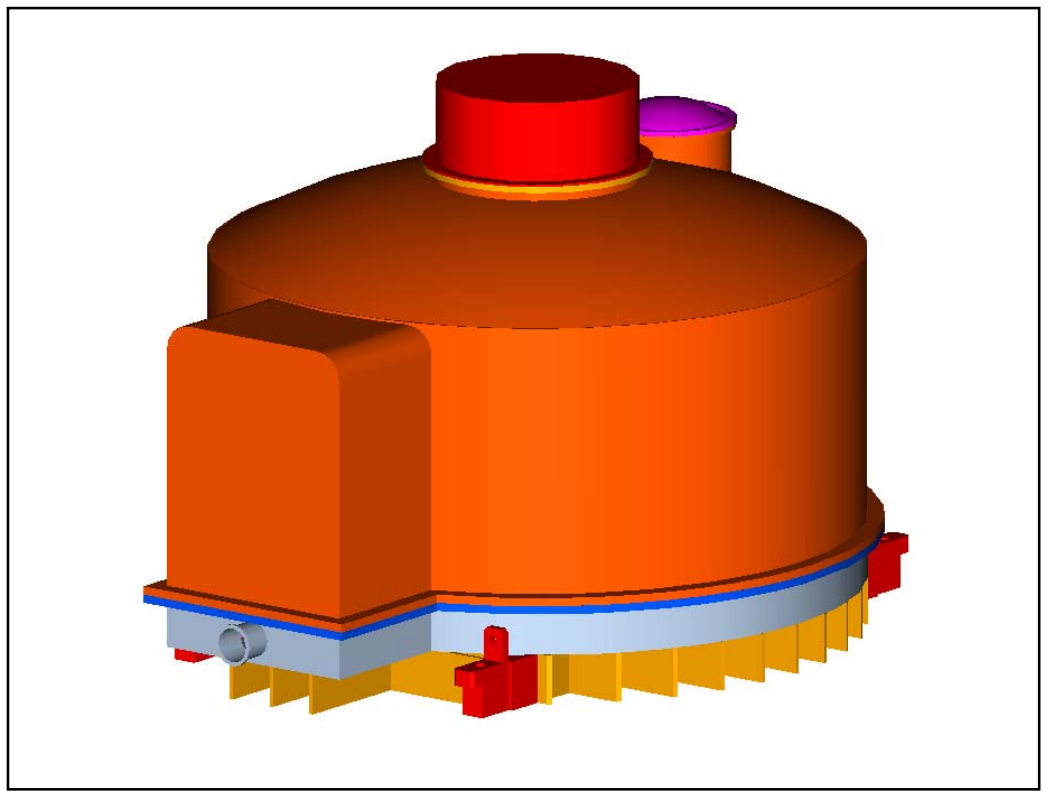

Figure B - 9 SMES fabrication bay showing CICC jacketing line with rolling mill

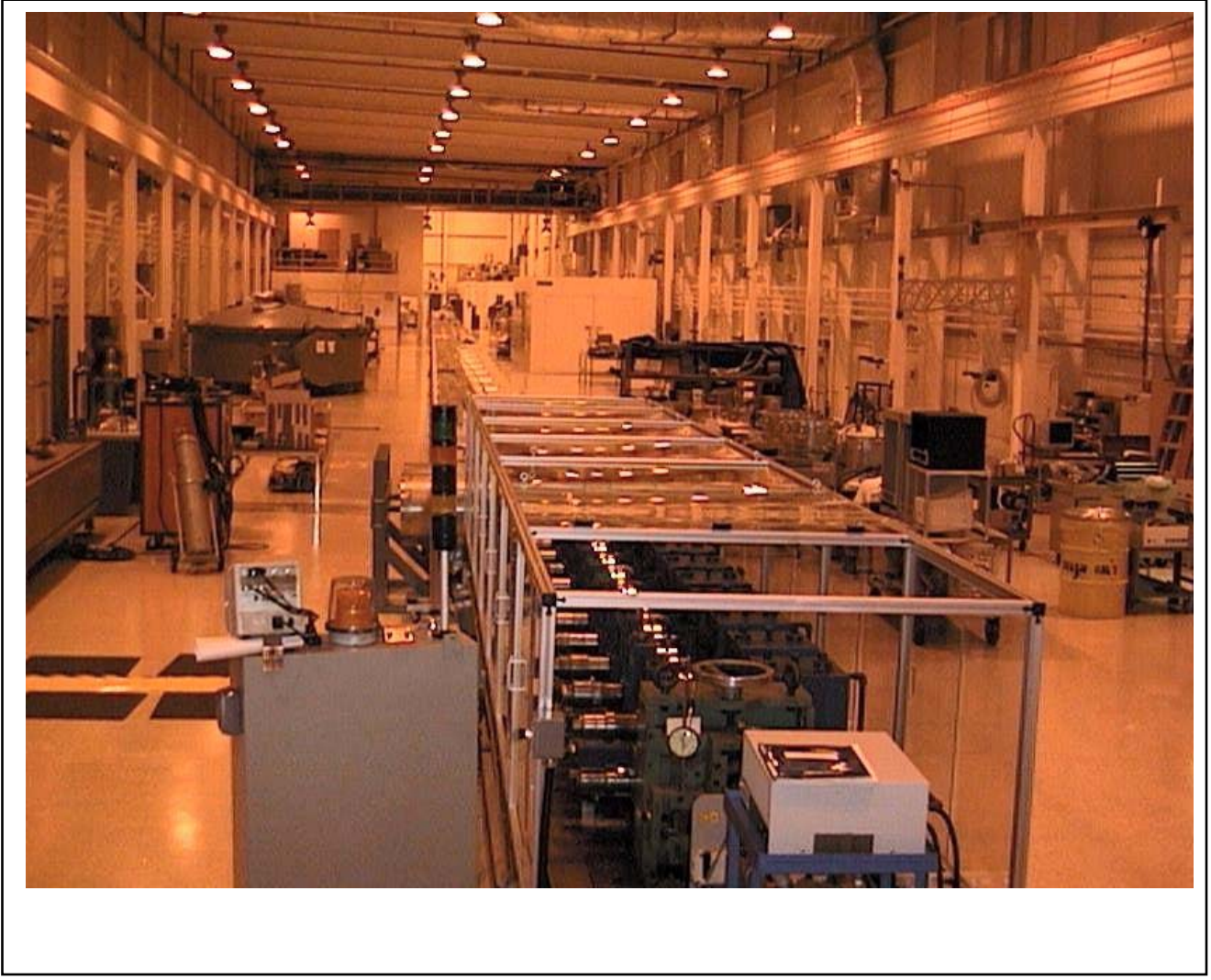


Final Report - DOE Agreement No. DE-FC36-94G010011

Commercialization Demonstration of Mid-Sized Superconducting Magnetic Energy Storage Technology for Electric Utility Applications

Figure B - 10 Photograph of winding machine containing a wound module

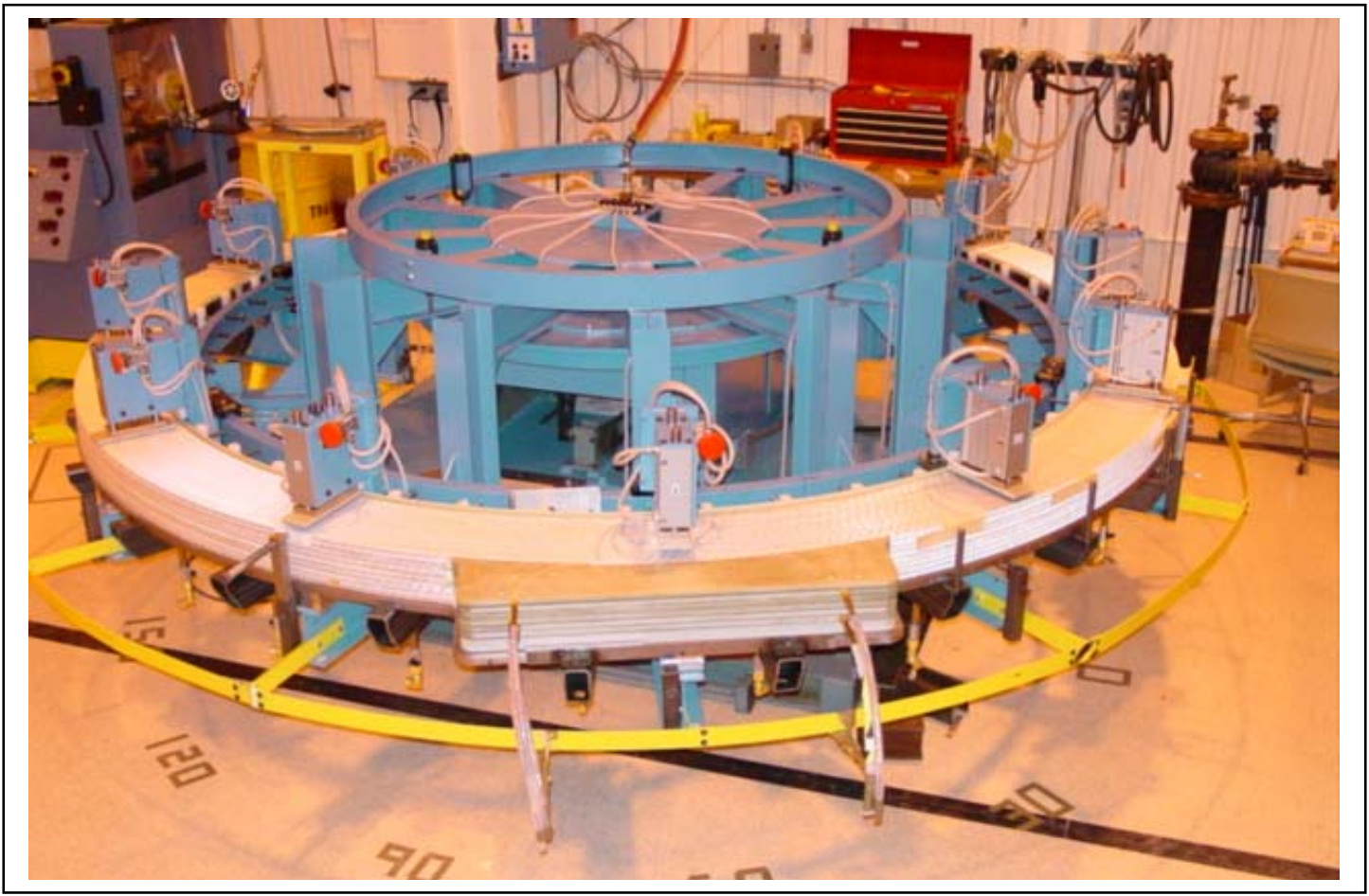

Figure B - 11 Photograph of winding machine showing insulated CICC spooled on center of winding table and un-insulated CICC on payout station spool

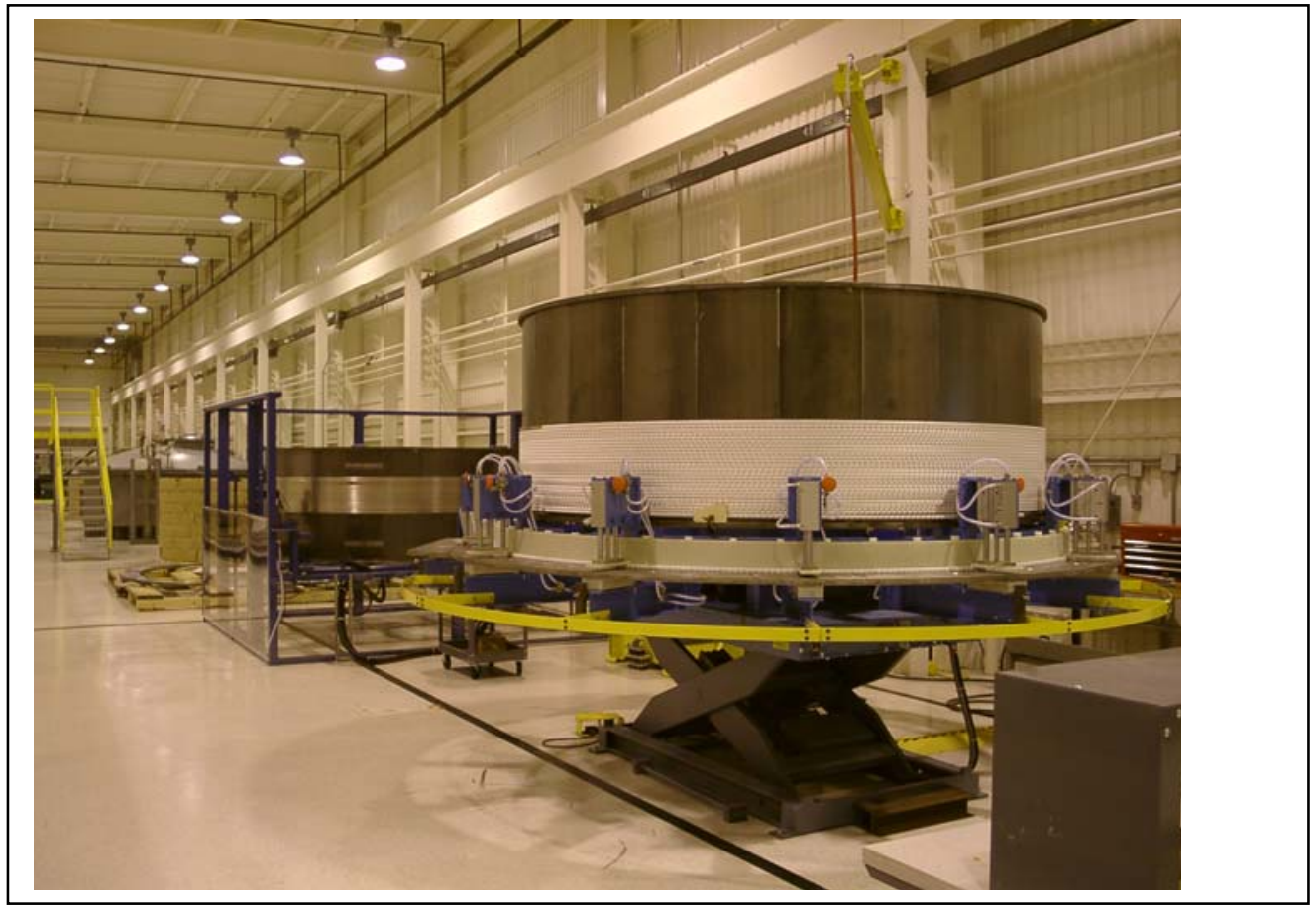


Final Report - DOE Agreement No. DE-FC36-94G010011

Commercialization Demonstration of Mid-Sized Superconducting Magnetic Energy Storage Technology for Electric Utility Applications

Figure B - 12 Photograph of $2^{\text {nd }}$ layer winding with insulated CICC transferred to payout station

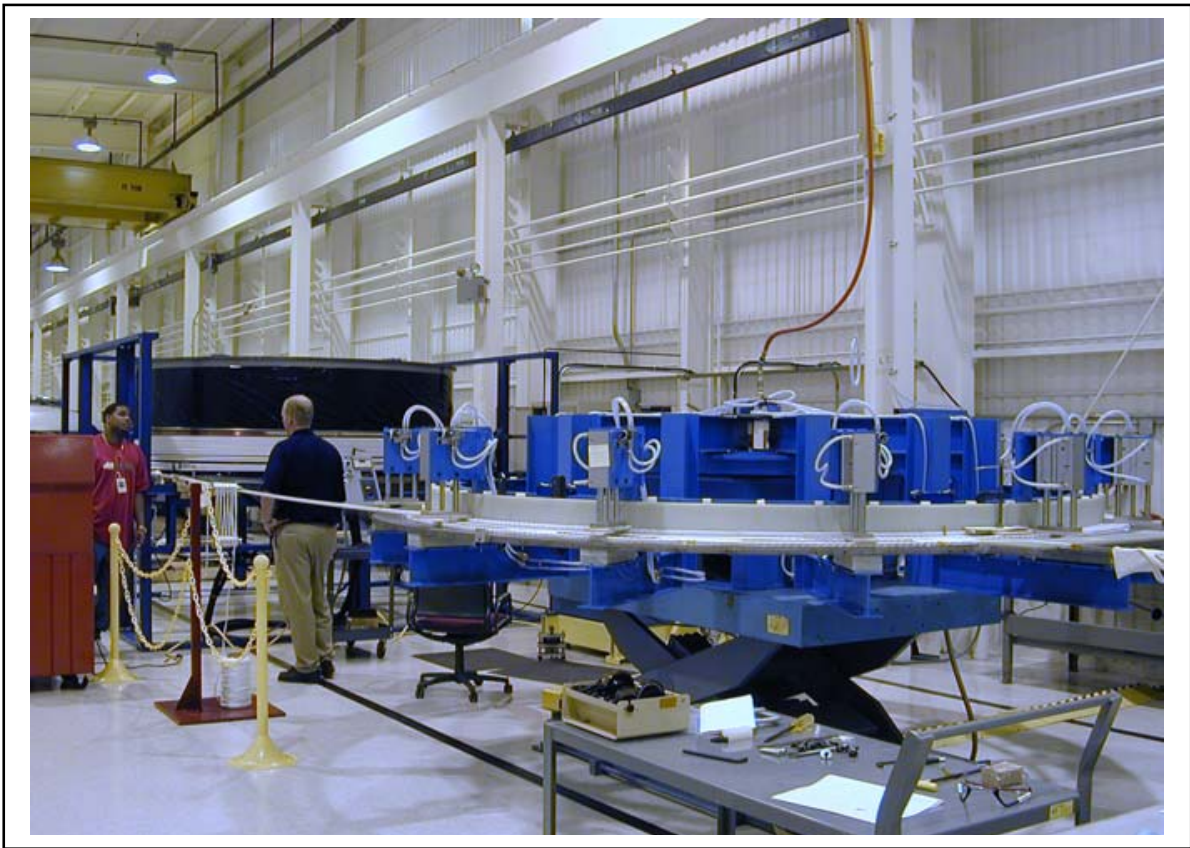

Figure B - 13 Photograph of winding showing CICC from orbital taping head and corner roving. $2^{\text {nd }}$ turn of first layer being applied to fixture's lower VPI mold plate.

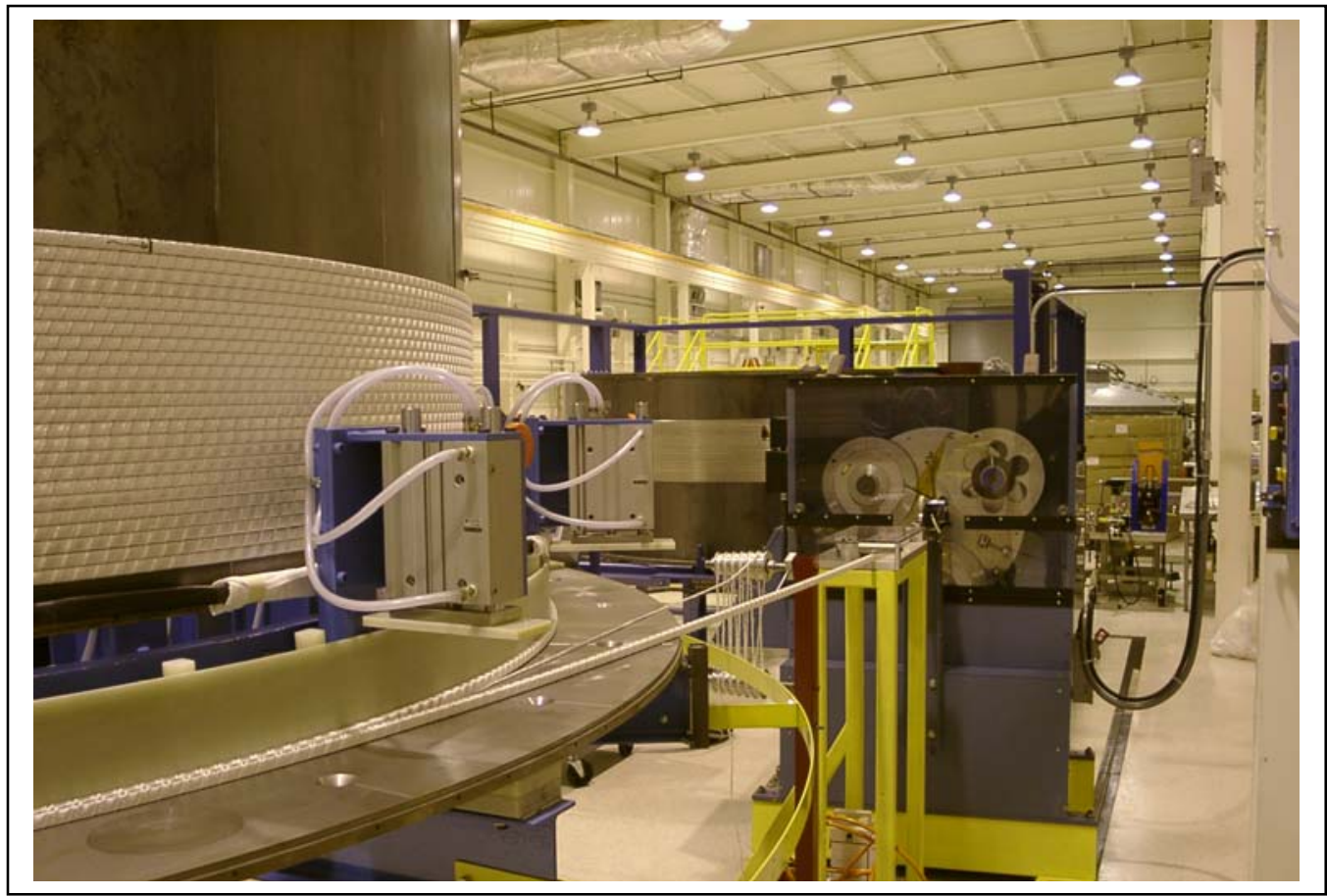


Figure B - 14 Photograph showing 3 wound double pancakes and the lead clamp plate area with stripped SC cable

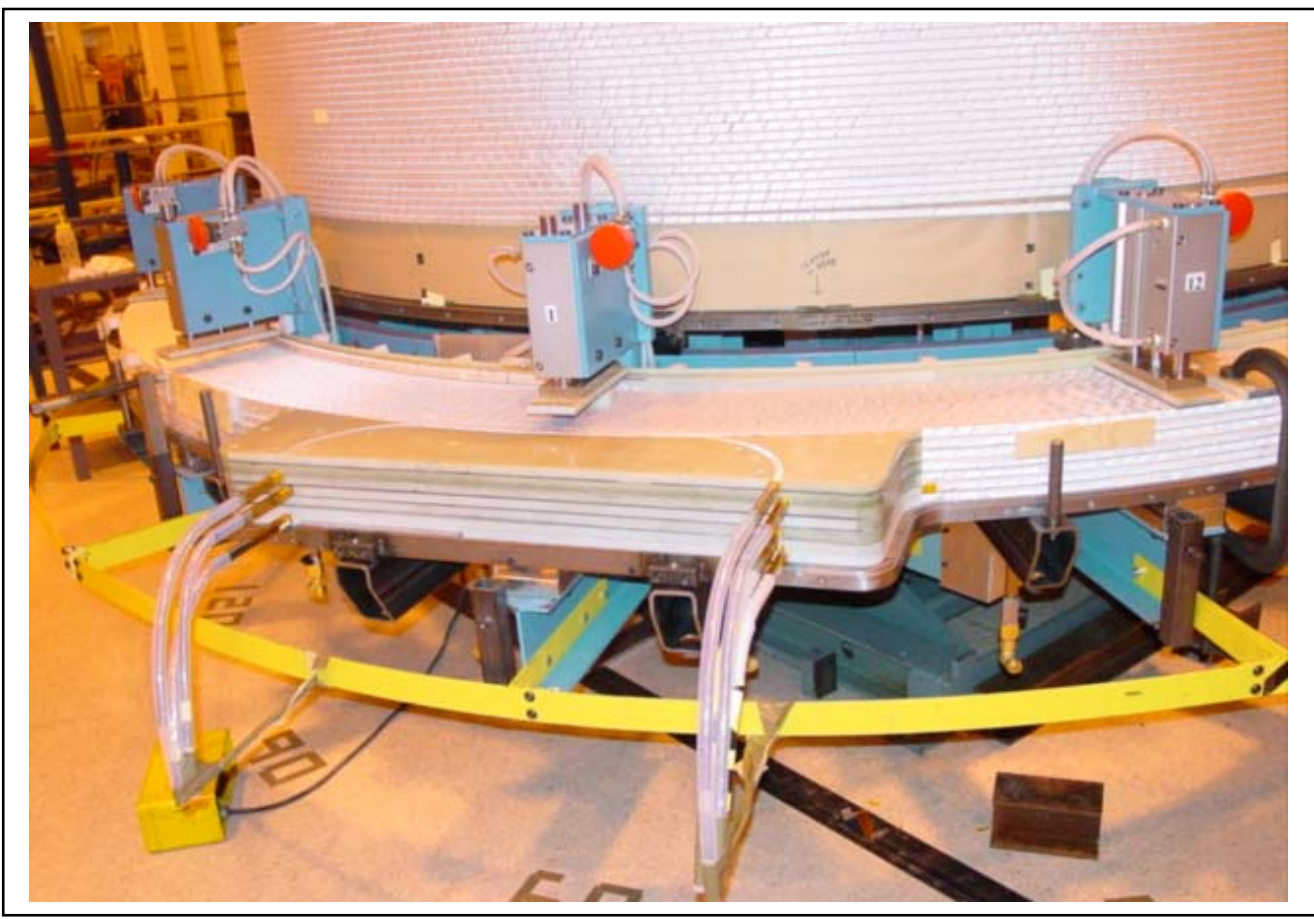

Figure B - 15 Photograph of wound coil module section showing glass taped insulated CICC and hydraulic coil hold down clamps

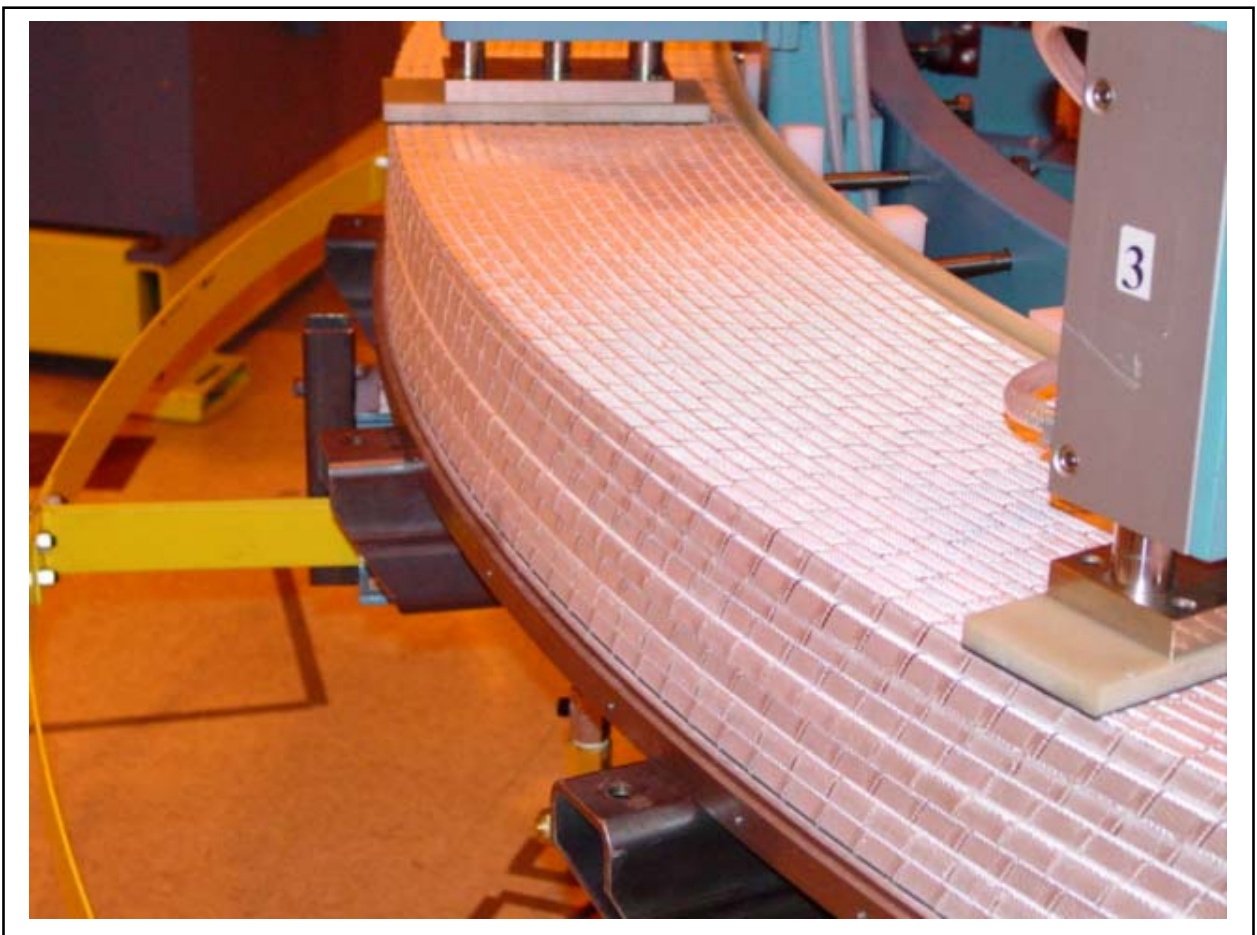


Final Report - DOE Agreement No. DE-FC36-94G010011

Commercialization Demonstration of Mid-Sized Superconducting Magnetic Energy Storage Technology for Electric Utility Applications

Figure B - 16 Drawing of coil module in VPI mold tooling

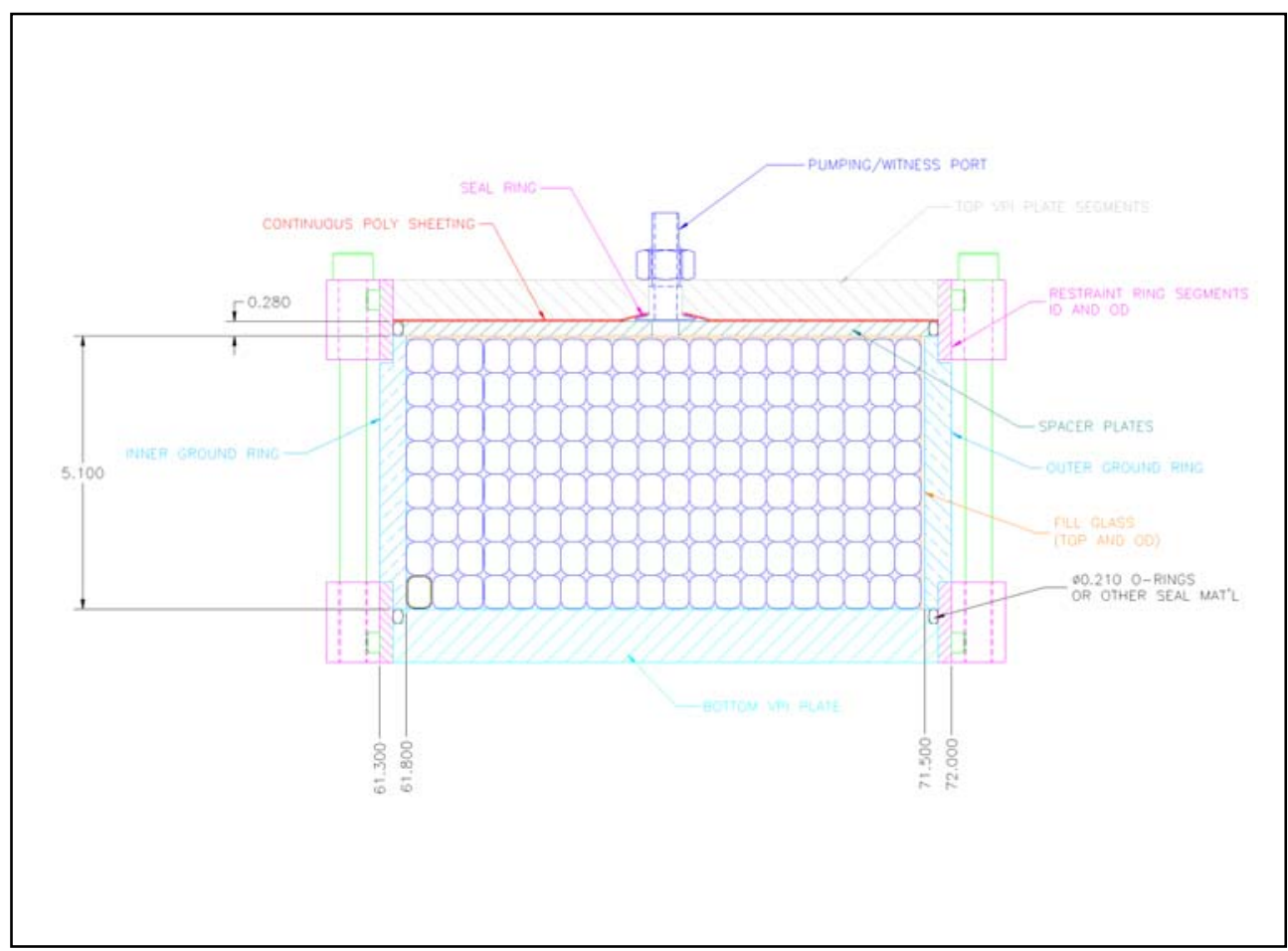

Figure B - 17 Photograph of coil module on VPI stand with insulation and curtains ready for epoxy injection

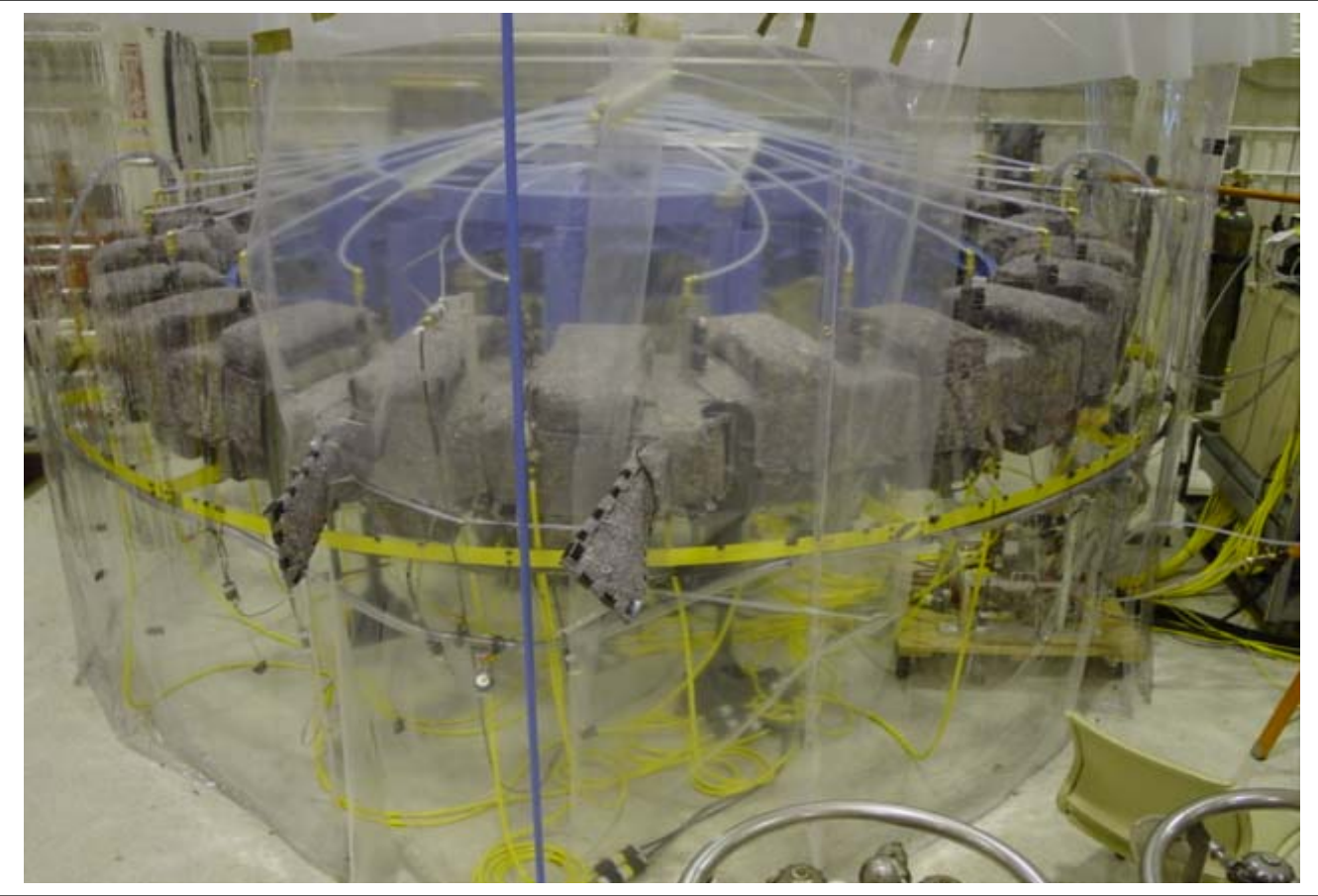


Figure B - 18 Photograph of coil module on VPI stand with insulation and mold tooling helium leak test cart

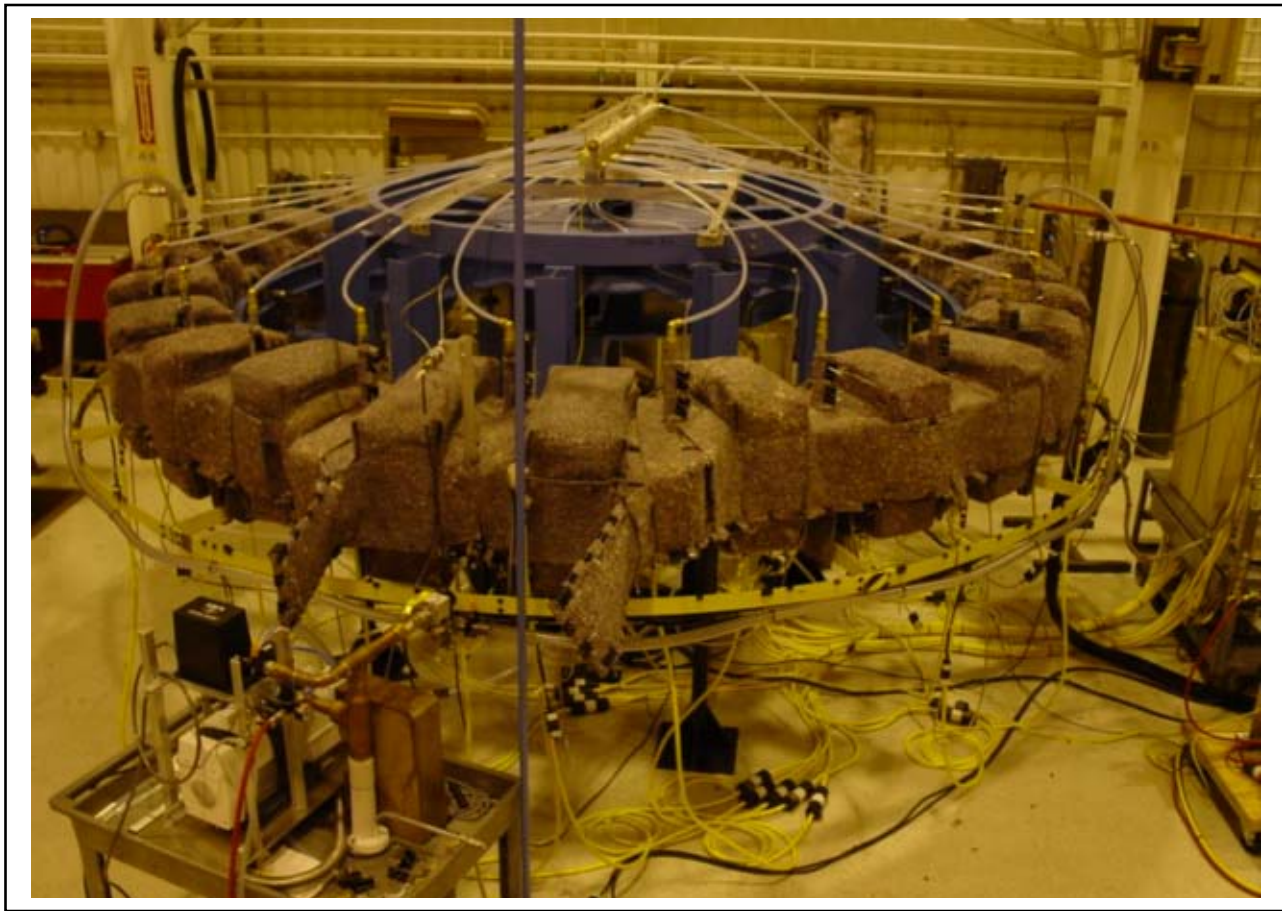


Final Report - DOE Agreement No. DE-FC36-94G010011

Commercialization Demonstration of Mid-Sized Superconducting Magnetic Energy Storage Technology for Electric Utility Applications

Figure B - 19 Photograph of completed 2-ton coil module being lower into position

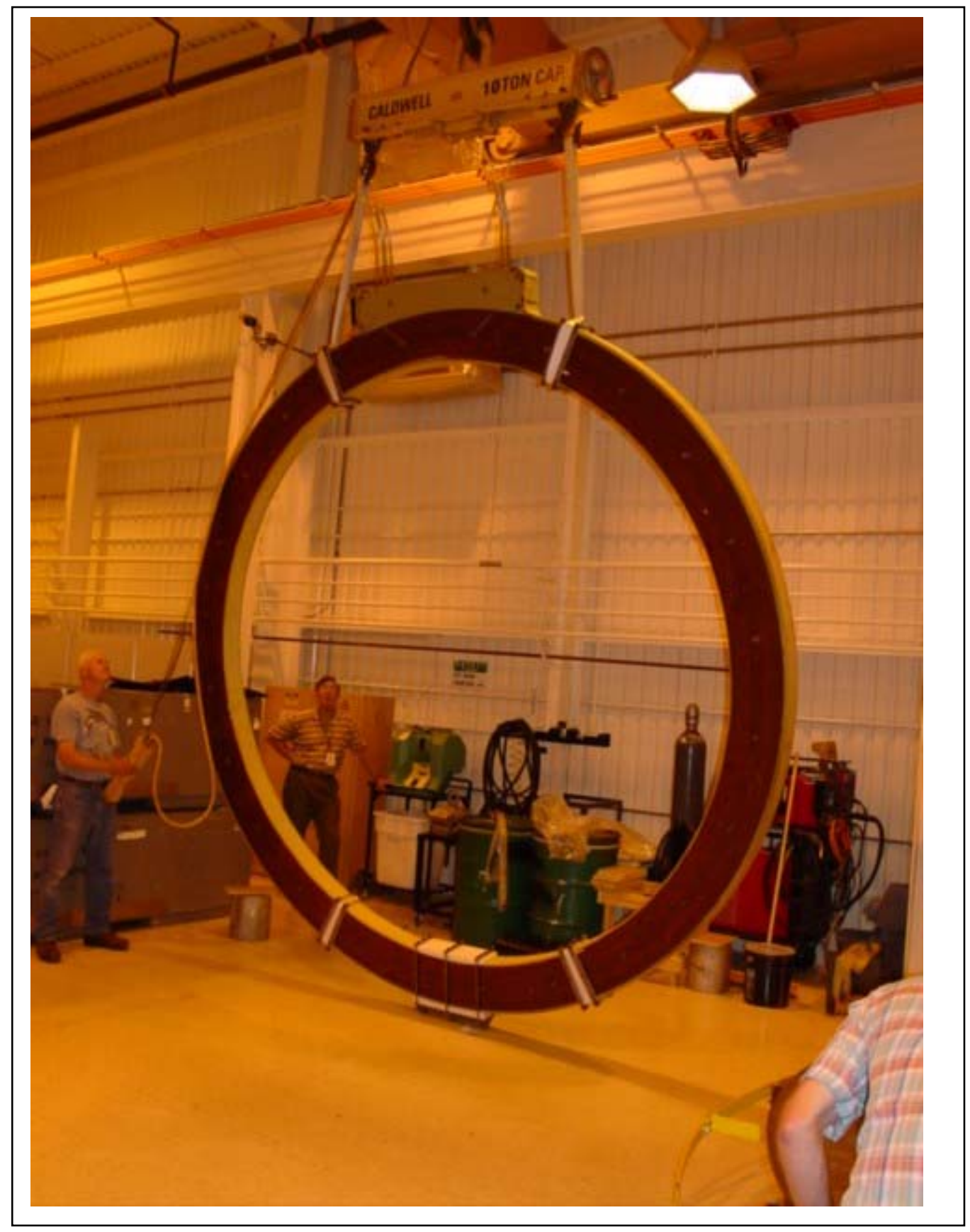


Figure B - 20 Photograph of a cross-Section of the $4 \times 5$ insulation test mockup showing the ground plane insulation, lap joint and insulated conduit

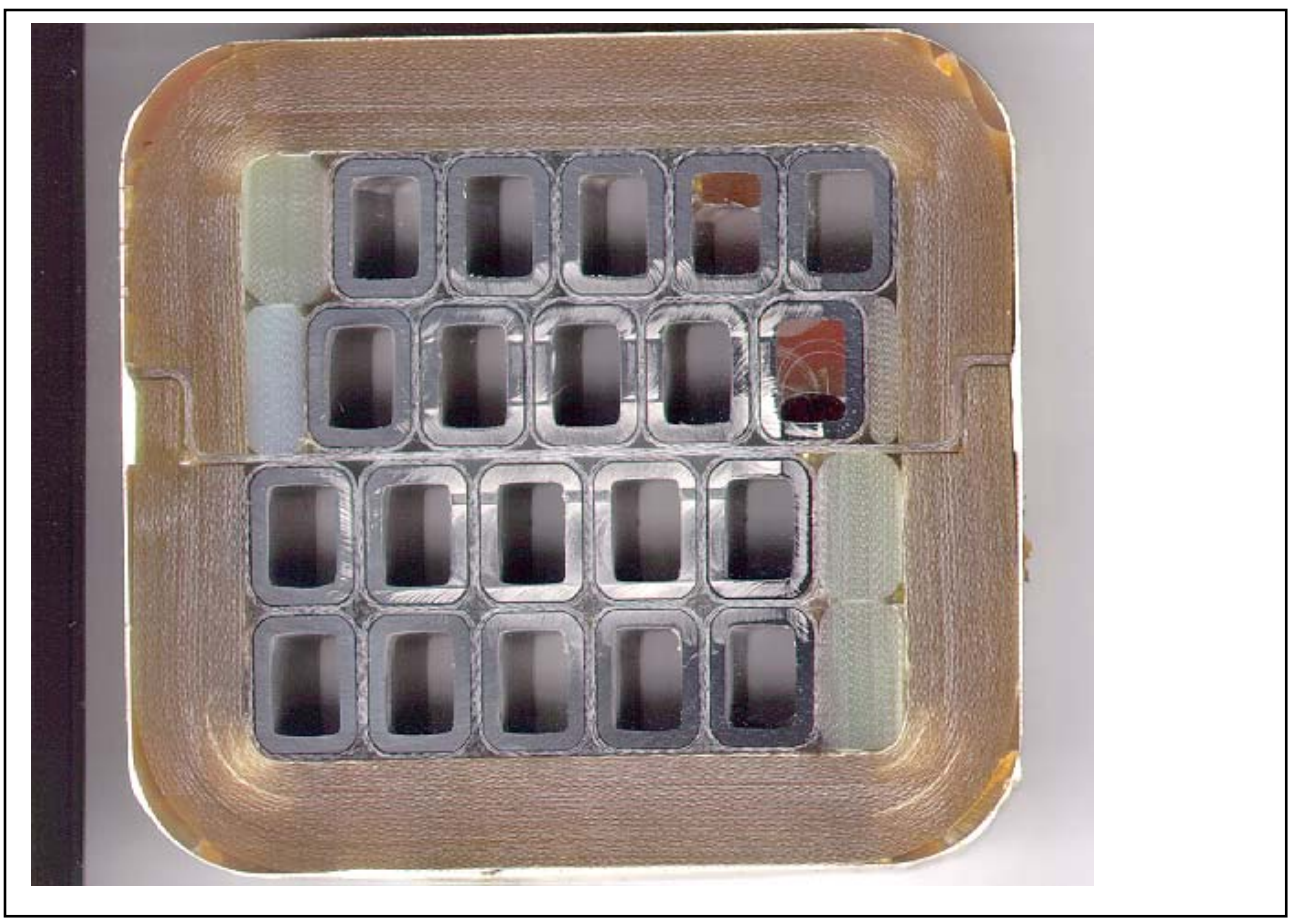

Figure B - 21 Photograph of the HVCL insulation mockup suspended in the test stand

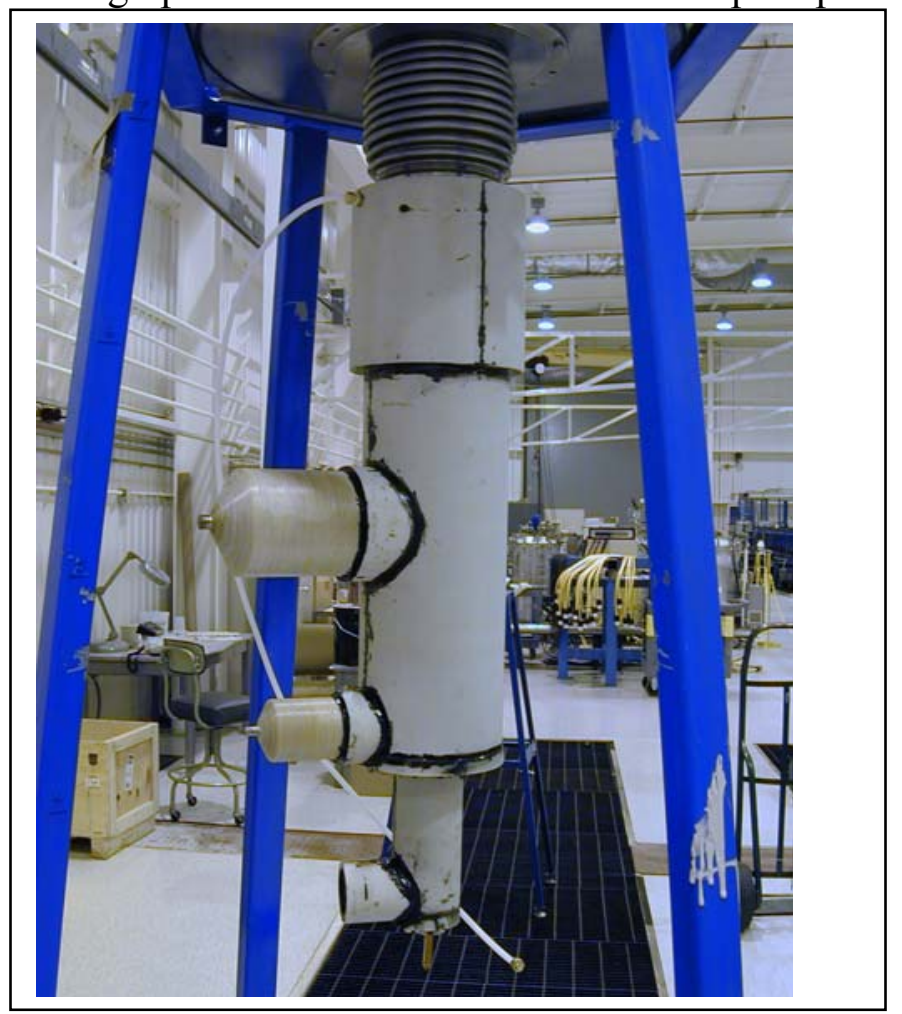


Figure B - 22 Photograph of superconducting conductor and splices test article

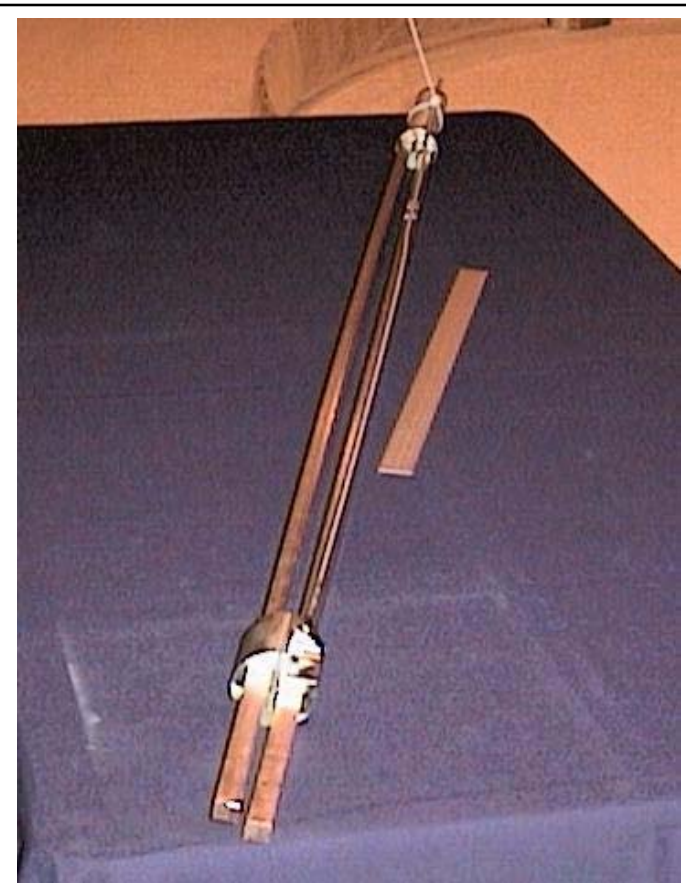

Figure B - 23 Miscellaneous Test Results

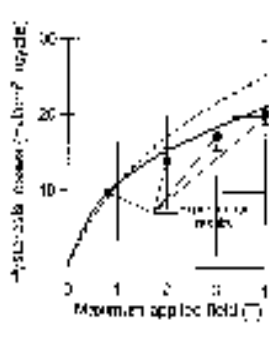

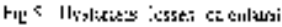

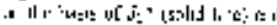

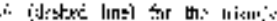

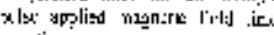
×xilitum.

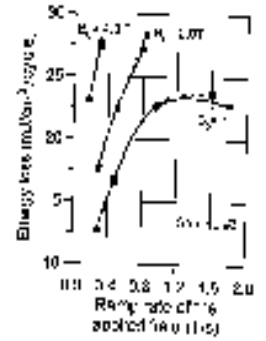

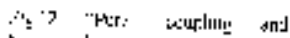

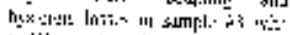

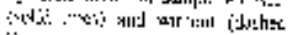

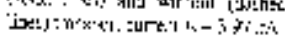


Figure B - 24 Miscellaneous Test Results
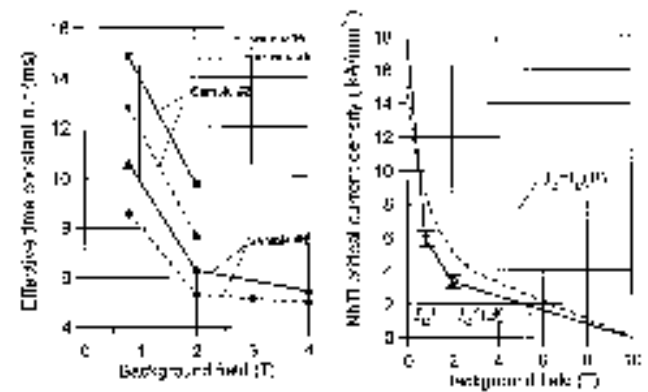

F. A Rili i: I Lul cu ralt densicy

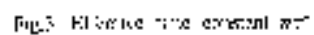

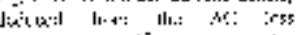

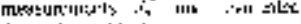

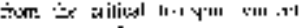

riesuremtar s

Figure B - 25 Photograph of $8 \times 20$ mockup with sectioned piece demonstrating the VPI quality, tooling and methods

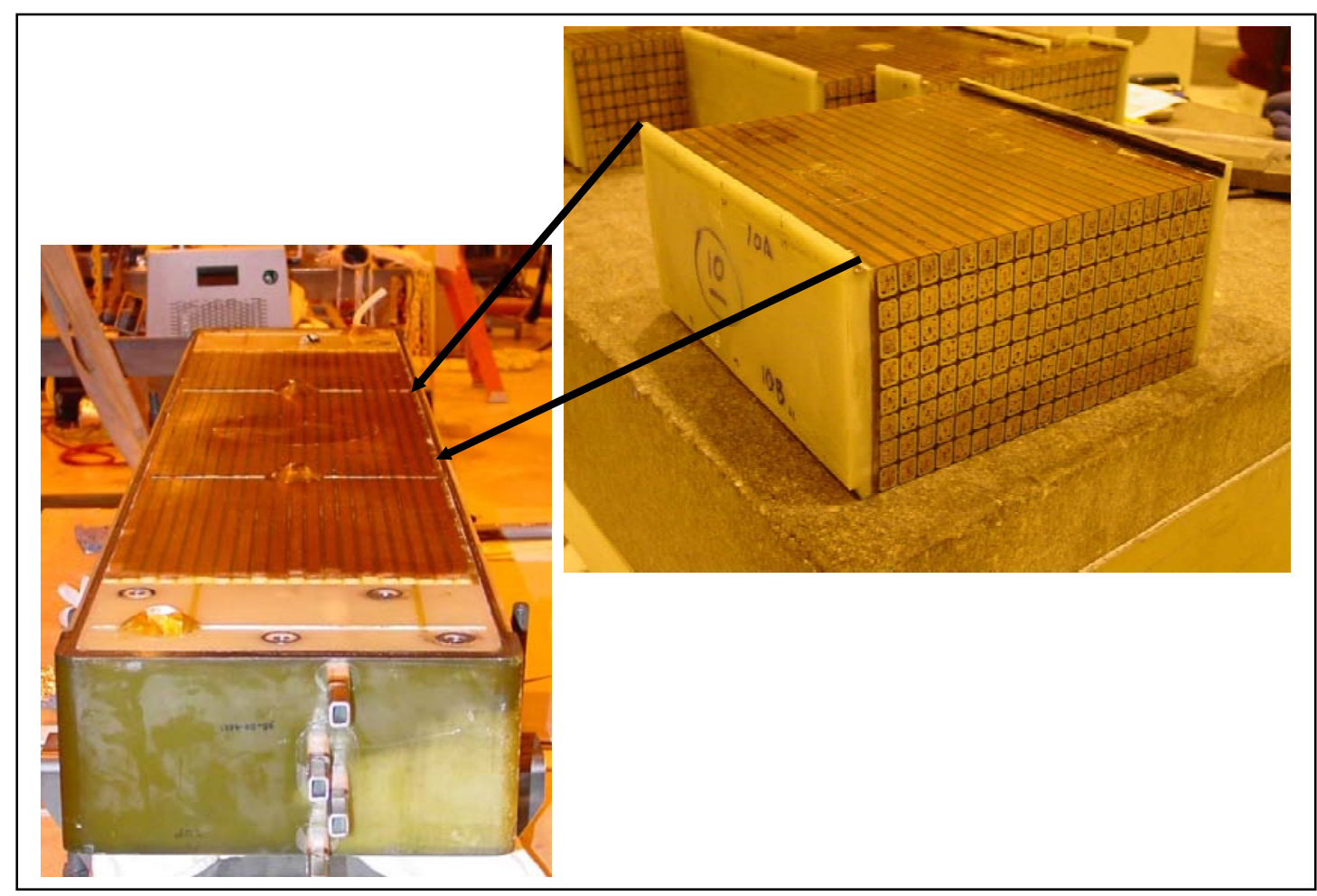


Figure B - 26 Photograph of Vacuum Test Vessel containing Proof Test. Shows voltage tap feed-throughs in flange door.

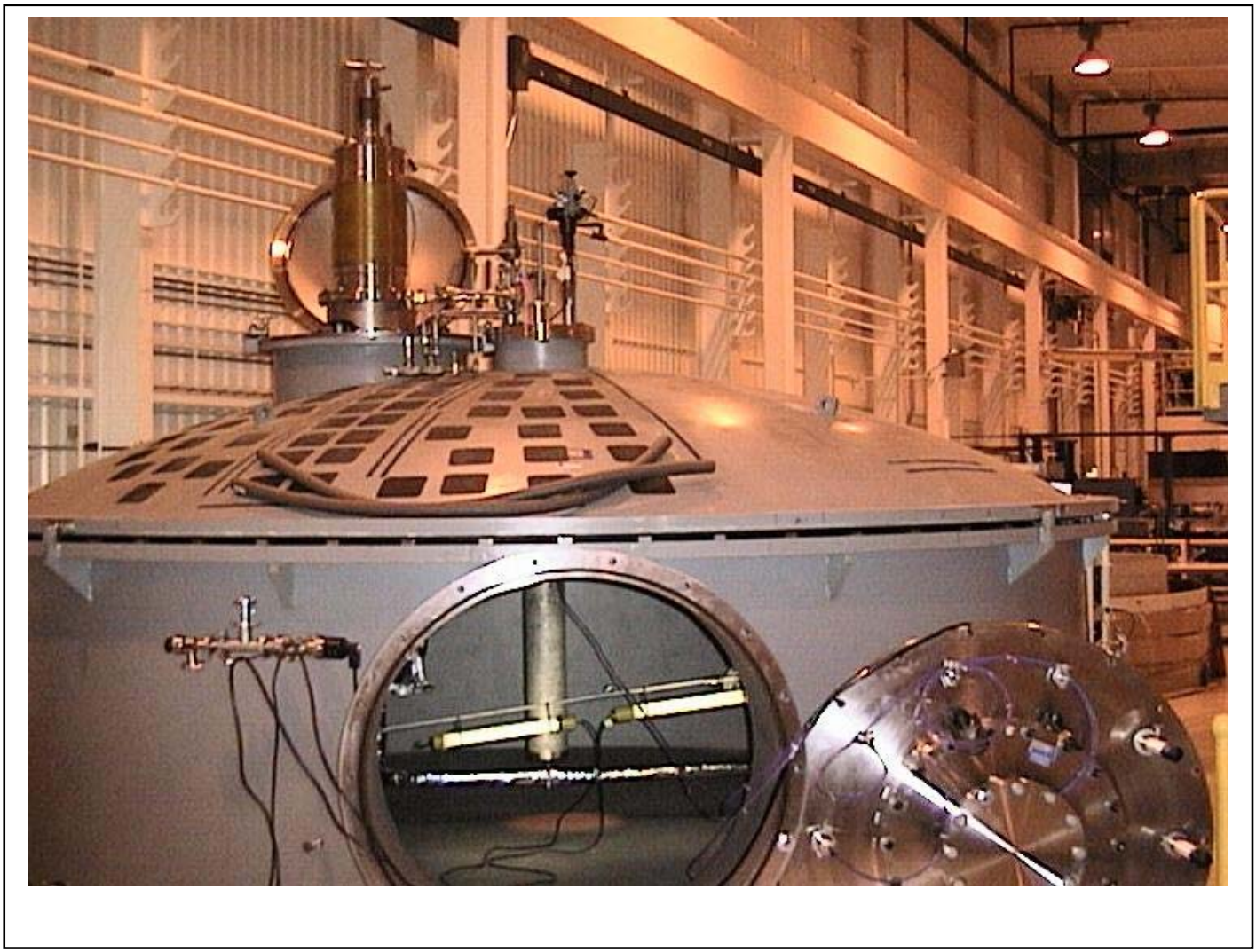


Final Report - DOE Agreement No. DE-FC36-94G010011

Commercialization Demonstration of Mid-Sized Superconducting Magnetic Energy Storage Technology for Electric Utility Applications

Figure B - 27 CAPS Power Arrangement for SMES Equipment Testing

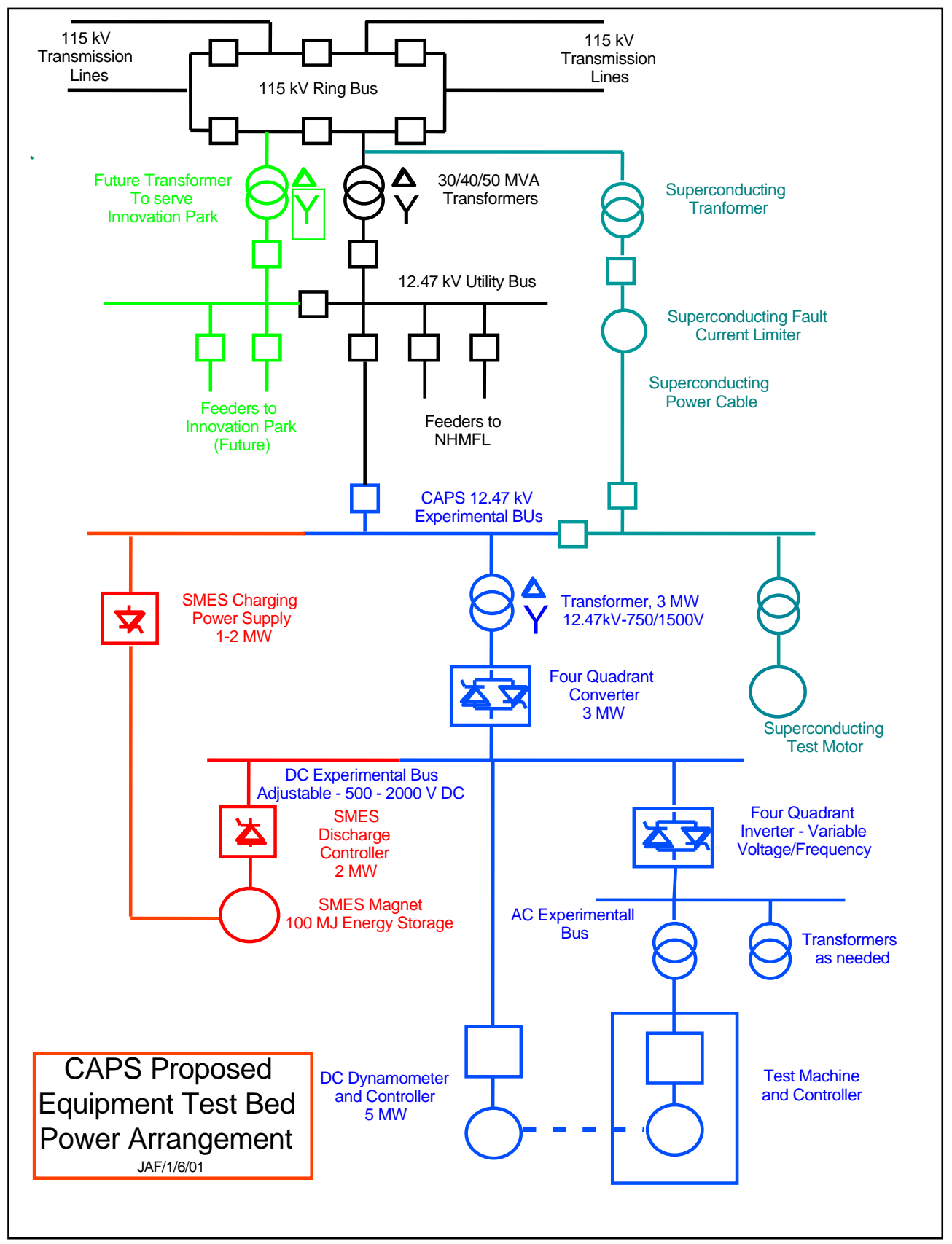

